\title{
A Metallographic Review of 3D Printing/Additive Manufacturing of Metal and Alloy Products and Components
}

\author{
L. E. Murr ${ }^{1}$
}

Received: 15 February 2018/ Accepted: 20 February 2018/ Published online: 12 March 2018

(C) Springer Science+Business Media, LLC, part of Springer Nature and ASM International 2018

\begin{abstract}
Applications and examples of light and electron micrographs illustrating microstructures, which describe metallurgical phenomena in 3D printing/additive manufacturing of metal and alloy products and components, are presented along with extensive process and processing parameter descriptions and review. Examples include microstructures that have defined turbine blade fabrication and optimization over the past half century, including contemporary electron beam melting fabrication of turbine blade alloys and other novel microstructures and architectures, which result from layer by layer, nonequilibrium melt solidification and epitaxial growth involving powder bed laser and electron beam fabrication. Phase transformations and second-phase formation by rapid cooling in metal and alloy components fabricated by laser and electron beam melting technologies are illustrated for a range of high-temperature materials. Using a range of examples, the advantages of fabricating complex (especially porous) biomedical and related commercial products are described. Prospects for future developments of direct 3D metal and alloy droplet printing, as a key component of the digital factory of the future, are described. This technology is compared with more conventional solidification and powder bed layer building thermo-kinetics, especially in the context of large structure and component fabrication.
\end{abstract}

Keywords Metal additive manufacturing (AM) - Laser and electron beam melting · Metal droplet deposition · $3 \mathrm{D}$ printing $\cdot$ Microstructures and mechanical properties

\section{Introduction}

Over the past several years, there have been a plethora of reviews that analyze and summarize the state of the art of metal and alloy processing by means of 3D printing and additive manufacturing (AM). As exemplified in the related literature, these two terms are now used interchangeably [1-19]. The whole spectrum of additive manufacturing, including the wide range of stereo-lithography processes, which include polymers, ceramics, and metallic materials, is estimated to encompass an economic valuation exceeding \$10B (in 2017) worldwide. This number is increasing rapidly in all sectors, including machine sales of various kinds, especially in the USA [20]. In addition, over the past

\section{E. Murr}

lemurr@utep.edu

1 Department of Metallurgical, Materials and Biomedical Engineering; W. M. Keck Center for 3D Innovation, The University of Texas at El Paso, El Paso, TX 79968, USA
2 years major aerospace and other manufacturers such as General Electric (GE) have opened advanced manufacturing and additive manufacturing centers in various parts of the world (2016-2017). In addition, facilities for producing precursor products, especially metal and pre-alloyed powders have been constructed [20].

While most available metal 3D printing/additive manufacturing commercial systems, especially powder bed machines, have limited build volumes of around $0.3-0.5 \mathrm{~m}^{3}$, GE Additive, announced in mid-2017 the development of the world's largest laser powder bed AM machine especially tailored for the aerospace industry. This laser melting system will be able to "print" in a build volume of $1 \mathrm{~m}^{3}$, suitable for jet engine structural parts and other aircraft components, as well as similar components for automotive and related industries. 3D printing of oneof-a-kind parts and reverse engineering for obsolete parts is also a valuable application for large build formats.

Although many of the recent reviews of metal and alloy AM fabrication of parts and components using commercial, 
small volume $\left(\sim 0.3 \mathrm{~m}^{3}\right)$ build machines have addressed aspects of precursor materials optimization, process parameter optimization, and residual product structure, properties, processing, and performance connections in some instances [21, 22], a full realization of the AM potential will require a continuing and more extensive understanding of the structure-property-processing linkage for a broader range of advanced materials. This is especially true for component scale-up from dimensions of $\sim 0.3$ to $>1 \mathrm{~m}$, including thermo-kinetic control and optimization during the build process, as this affords residual microstructure and property control and optimization for fabricated parts.

There have been numerous publications, including reviews, which have illustrated and/or compared various AM microstructures for a wide range of metals and alloys as well as more conventional wrought or cast products $[4,13,14,21,22]$. In the case of wrought and cast products, thermo-mechanical (TM) processing to create specific microstructure-property-performance linkages has been crucial for steels, aluminum alloys, and superalloy product development and optimization. However, for geometrically complex and other close tolerance (net shape) AM product or component fabrication not amenable to TM, process parameter manipulation and post-process thermal treatments including HIP (hot isostatic processing) are the viable avenues for microstructure control and manipulation. Moreover, conventional metallurgical heat treatments may not lead to results typical of wrought metal behavior, especially microstructure development. Metallographic observations, using both light and electron microscopy, are essential for observing microstructure and microstructure evolution [23].

This review reverses the chronology of the abstract because it begins with an overview of the current AM technologies involving wire and powder precursor metals and alloys variously melted by laser or electron beams. Some attention is paid to the details of processing parameters and their optimization and tailoring for a range of metal and alloy melting points: From aluminum at $\sim 660{ }^{\circ} \mathrm{C}$ to niobium at $\sim 2495{ }^{\circ} \mathrm{C}$. This approach will set the stage for a discussion of prospects for the evolution of direct metal droplet deposition (3D metal printing) which has been proposed in published research and patent filings for more than 3 decades [24-26]. Consequently, this aspect of the present review will attempt to illustrate both current and future technical and economic realities of metal additive manufacturing.

Following this comprehensive overview, metallographic examples of variously fabricated AM metal and alloy products and components will be presented with the intent not only to illustrate some of the unique and novel AM microstructures and microstructural issues, but also to compare variances and similarities with more conventional metallurgically fabricated components. Finally, on the basis of the overview of metal AM fabrication techniques and their related product microstructures, this review will summarize how current understanding and successful applications can inspire new approaches and fabrication strategies for the manufacture of advanced materials products and components.

\section{Overview of Contemporary Metal Additive Technologies}

Additive manufacturing technologies involving controlled metal buildup has evolved over the past half century from fusion welding to repair or rebuilding worn and damaged components [27]. There was also the development of cladding and hardfacing of surfaces by powder injection (especially with hard ceramic powders) into the melt pool, including electron and laser beam melting [28] for cladding and hard surfacing by continuous wire or powder feed (or injection) into a melt pool generated by an electron or laser beam [29, 30]. These processes evolved into so-called rapid prototyping or freeform fabrication technologies [31-33], for solid metal or alloy object generation, including laser-engineered net shaping (LENS) (or direct metal deposition (DMD)), involving CAD (computer-aided design)-controlled powder injection and laser melting, surrounded by an inert gas shroud for oxidation reduction [34, 35]. Related wire feed technologies, using laser and electron beam melting, evolved alongside LENS and DMD development [36].

Figure $1 \mathrm{a}$ and $\mathrm{b}$ illustrates these processes schematically. In Fig. 1a and b, the additively fabricating component builds by $\mathrm{x}-\mathrm{y}-\mathrm{z}$ movement of the build table (indicated by part motion in Fig. 1a) although a build head designed by shrouding a laser (or electron) beam with a powder injector (Fig. 1b) can be CAD driven as well. In this build strategy, the beam head moves $x-y$, while the build table or processing surface moves down (z-direction) for layer fabrication. While these additive technologies are embedded in commercial systems in use today [33, 35, 36], they have somewhat limited ability to fabricate precision components, although they are often adaptable to largescale product manufacturing, which compensates for precision.

Interesting variances of AM technologies for specialized surface repair and rebuilding have involved applications of Fig. 1b in repairing single-crystal turbine blades (airfoils) and other components grown by precision casting of Coand Ni-base superalloys. Basak et al. [37, 38] developed a scanning laser epitaxy process for turbine blade (air foil) surface rebuilding. In addition, this technique also has 


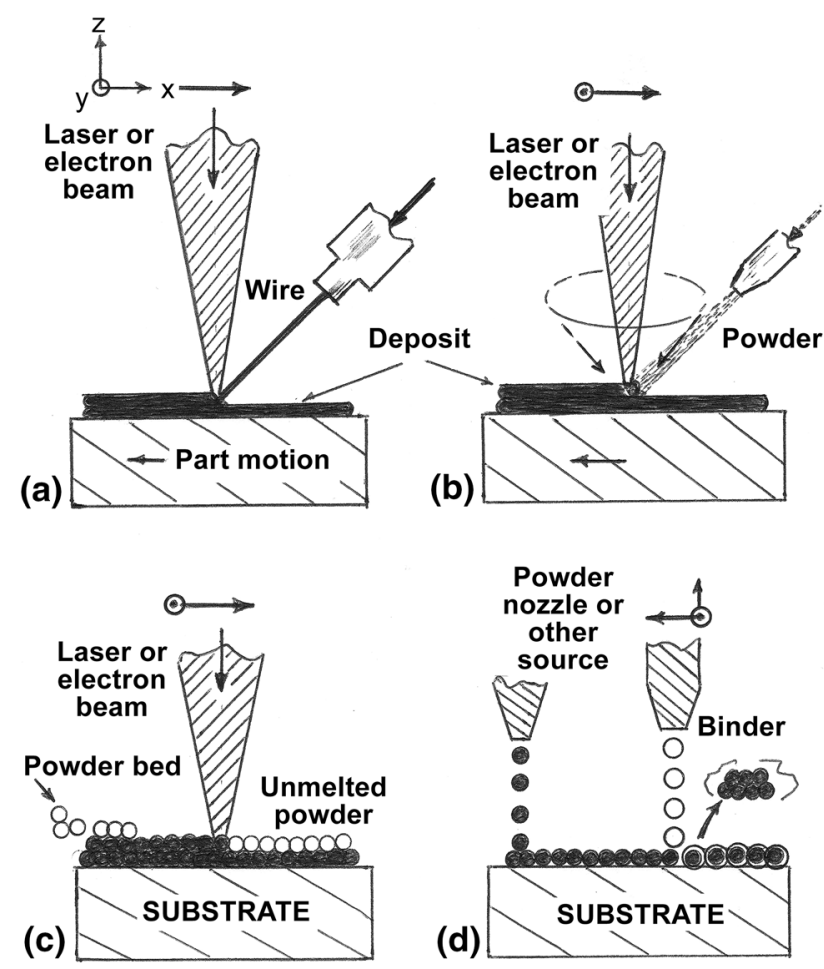

Fig. 1 Comparison of metal AM fabrication process schematics. (a) Laser or electron beam cladding using wire feed. (b) Laser or electron beam sinter/melt processes using powder feed. The powder is often fed through a shroud nozzle surrounding the beam; including an inert cover gas. (c) Powder bed fusion processes. Powder is rolled or raked onto the powder bed and melted using CAD-driven laser or electron beams. (d) Binder jet powder processes. After Murr and Johnson [19]

prospects for the AM fabrication of entire single-crystal blades. Figure 2 illustrates this blade rebuilding AM process, which preserves the single-crystal, directional, microdendritic microstructures, and in addition refines this microstructure by reducing the interdendritic spacing by a factor of $\sim 5$, thereby increasing the hardness of this AM product extension by nearly the same factor. This Ni-base superalloy (CMSX-4: see "Glossary of Alloy Compositions") is also creep strengthened by forming cuboidal, $\gamma^{\prime}$ $\left(\mathrm{Ni}_{3} \mathrm{Al}, \mathrm{Ta}\right)$ precipitates within the microdendrites [37]. Epitaxy is an important and often controllable growth process associated with AM fabrication and will be reviewed in more detail in the narratives that follow.

Over the past two decades, powder bed technologies employing CAD-directed electron or laser beam layer sintering and melting have become the most prominent metal AM process, as illustrated schematically in Fig. 1c. Figure 1d illustrates an alternative, but less popular metal powder process where powder is selectively spread in layers from a movable nozzle or a roller system. This is followed by selective dropping or jetting of a suitable binder from an ink-jet printer head directed by a CAD (a)

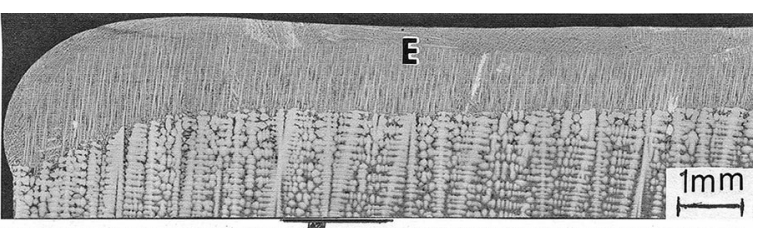

(b)

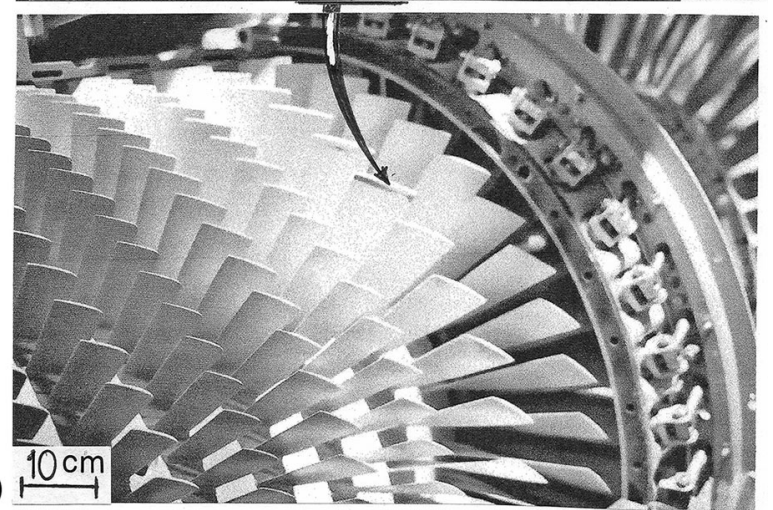

Fig. 2 Examples of superalloy turbine blade extension/repair using scanning laser epitaxy. (a) SEM image showing directional (singlecrystal) superalloy (CMSX-4), epitaxial (E) AM structure on singlecrystal substrate surface. Courtesy of S. Das, Georgia Tech. The arrow purports to illustrate how this process can repair single-crystal blade (air foil) surfaces. (b) Example of turbine blade system

program to create a metal powder/binder product. The binder is removed (vaporized) during a sintering operation at a high temperature to create a contiguous product. This is especially useful for fabricating parts of high-temperature powders such as stainless steels and superalloys. Additionally, this product (powder plus binder) can also be infused with a lower temperature molten metal. A common system is stainless steel infused with bronze. Such binder jetting or drop-on-powder printing processes [39] can also be utilized in a configuration similar to Fig. 1c) where a laser beam sinters or melts the powder while simultaneously evaporating the binder, although this approach is only viable for select metal powder fabrication.

Variances of the powder bed fusion processes illustrated in Fig. 1c: direct metal laser sintering (DMLS), selective laser sintering (SLS), selective laser melting (SLM) for laser beam processing, and selective electron beam melting (SEBM) or electron beam melting (EBM) for electron beam processing, have been available in commercial systems since the 1990s. Wohlers and Garnet have written an extensive historical account of AM processes, including past and present economic impact [40].

\section{Powder Bed Technologies: Electron and Laser Beam Melting}

From a more pragmatic, schematic view, Fig. 1c, as it applies to electron and laser beam selective melting of metal powder bed layers, can be visualized as shown in 

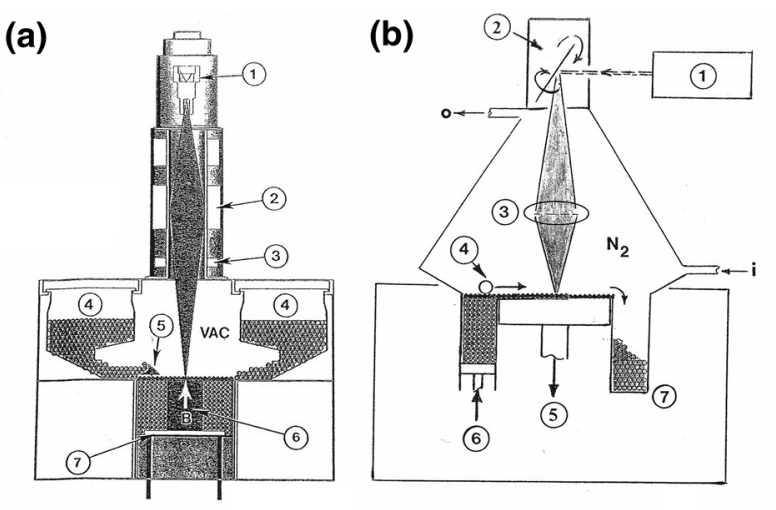

(c)

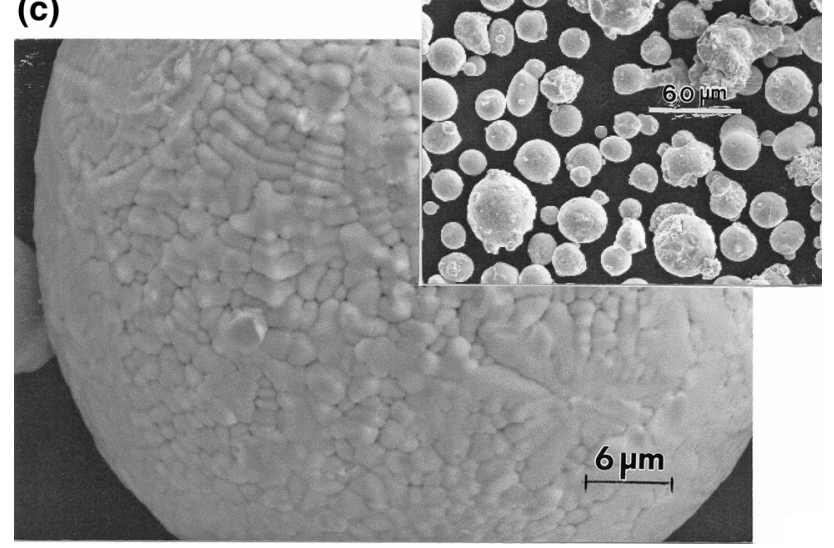

Fig. 3 Comparative schematics for EBM (a) and SLM (b) systems. In (a), (1) represents the electron beam source (gun); (2) magnetic lens focusing of the electron beam; (3) beam scan coils (CAD driven); (4) powder cassettes; (5) layer rake; (b) building product; (7) build table/ starter plate which is lowered to the layer thickness after each layer scanning/melting. In (b), the schematic features are as follows: (1) laser source; (2) beam deflection (scanning) mirror (CAD driven); (3) beam focus; (4) powder layer roller; (5) table (build) lowering; (6) powder supply cassette; (7) unmelted (excess) powder. (c) Illustrates a $\mathrm{Co}-\mathrm{Cr}$ alloy

Fig. 3a and $\mathrm{b}$ for electron beam melting (EBM) and selective laser melting (SLM), respectively. From a fundamental perspective, it can be appreciated that electrons of negative charge $(\bar{e})$ and finite mass $\left(m_{\mathrm{e}}\right)$ will interact with a metal powder bed quite differently to photons in a laser beam, which have no charge or "measurable" mass. Their corresponding beam energies are given by:

$E=m_{\mathrm{e}} v^{2} / 2$ for electrons, and

$E=h c / \lambda$ for a laser beam,

where $v$ is the electron velocity, $h$ is Planck's constant, $c$ is the velocity of light, and $\lambda$ is the corresponding wavelength. Cline and Anthony [41] have described electron and laser beam interactions, which are very complex as a consequence of beam energy absorption by electron-atom and electron-electron interaction for an electron beam, and photon-electron-phonon interactions in the case of a laser beam. Simplification for electron and laser beam melting

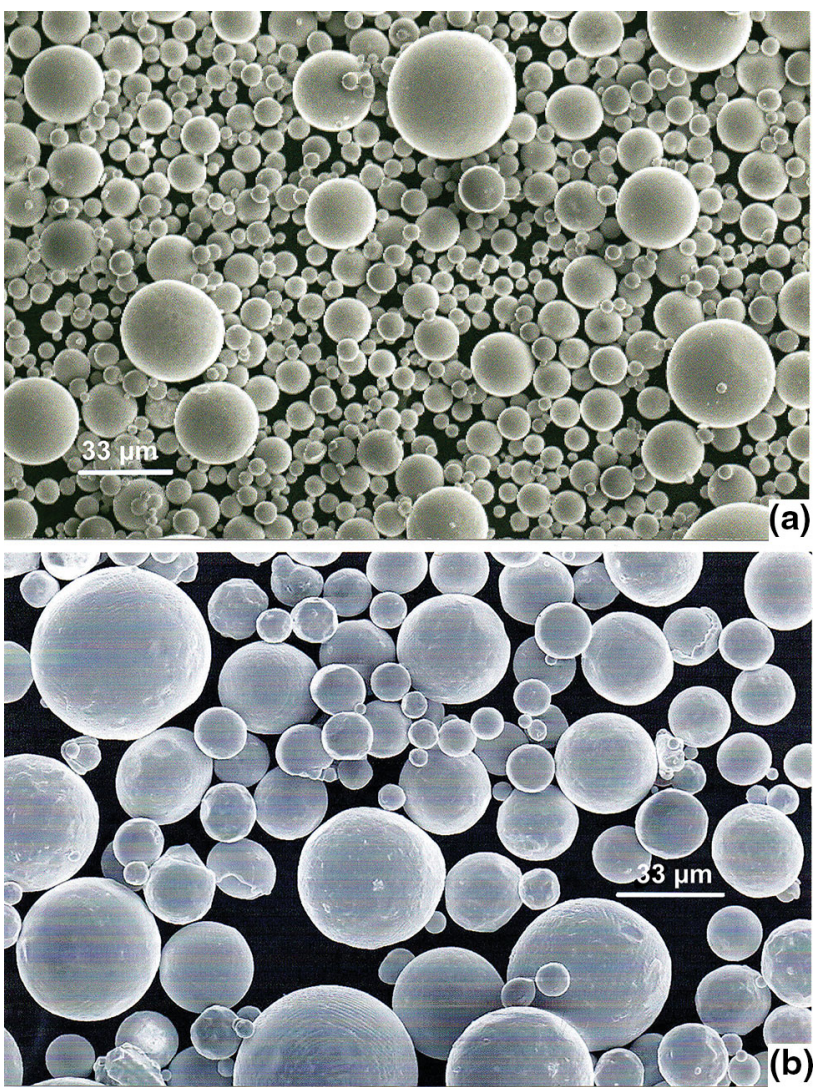

Fig. 4 Examples of spherical powders and powder size distributions. (a) Copper powder. (b) Inconel 625 powder

can involve consideration of energy or beam power absorption, where generally surface layer power absorption, $P(s)$, is given by

$P(s) \cong 2 \mathrm{Q} \Pi r^{2} \ell$,

where $Q$ is the power density, $r$ is the beam spot size, and $\ell$ is the absorption length which is related to the layer thickness as well as the layer integrity or continuity. This in turn is related to the powder size, size distribution, and morphology, including surface structure as implicit in Fig. 3c which shows a Co-Cr superalloy powder exhibiting a microdendritic structure and attached satellite particles, which alter the morphology in contrast to spherical, single particles illustrated in the examples of metal powders shown in Fig. 4. In this sense, powder properties are related to both layer density (packing density) and the ability of the particles to flow (often measured by a volumetric flow rate [42]), although there is not necessarily a relationship between particle properties and flow, or "flowability." Particle flow may be more important in the EBM process, shown in Fig. 3a, because the powder flows onto the powder bed by gravity and is raked into a requisite layer by a precision- straight metal bar. Correspondingly, in the SLM process, shown in Fig. 3b, the powder is rolled onto 
the bed after being pushed up from canisters at the edge of the bed.

Because the raking or rolling of powders to create efficient energy absorbing layers requires rigid mechanical arms to assure flat layer surfaces, there are intrinsic limits in using large powder beds to fabricate large products, regardless of their complexity because at some point these mechanisms may not maintain required tolerances. Nonetheless, many contemporary EBM and SLM processes can produce compressed layers having thicknesses ranging from 50 to $100 \mu \mathrm{m}$, with good energy absorption for achieving layer melting. Summarizing the literature tends to indicate average particle sizes ranging from 20 to $50 \mu \mathrm{m}$ for a wide range of metals and alloys (Fig. 4). Skewed distributions containing smaller particles tend to promote layer densification by filling larger particle packing interstices.

While commercial EBM sand SLM processing does not always pay a great deal of attention to powder contamination by oxygen, water vapor, or both, these issues can have significant effects on build optimization, residual microstructures, properties, and performance. Copper as illustrated in Fig. 4a is a notable example to be discussed in more detail later [42]. While EBM employs a vacuum environment and SLM employs an inert gas (nitrogen or argon) environment for product fabrication, some attention often needs to be directed toward powder processing (such as the atomization environment), powder outgassing, and transfer protection (container-to-cassette transfer). This is often difficult in EBM vacuum systems. There are even situations in the SLM process where the gas environment (nitrogen or argon) dictates the specific crystal structure or phase of the fabricated product [43].

Figures 5 and 6 illustrate this feature for the SLM of 17-4 PH stainless steel. In Fig. 4, complex, directional-like, low-angle boundaries occur for an alpha-phase (bcc) structure for the SLM of argon-atomized powder fabricated in an argon (Ar) environment. Melt layer bands observed in Fig. 4 are unique to the SLM process as observed on comparing Figs. 7 and 8. Figure 5b shows a transmission electron microscope (TEM) image of the microstructure associated with the bec 17-4 PH build in Fig. 5a; characterized by directional, low-angle grain boundaries and dense dislocation structures. Figure 6 compares x-ray diffraction spectra for 17-4 PH steel samples fabricated from nitrogen $\left(\mathrm{N}_{2}\right)$-atomized powder in $\operatorname{argon}\left(\mathrm{N}_{2}-\mathrm{Ar}\right)$ resulting in a bcc (alpha) structure as in Fig. 5a, with similar 17-4 PH stainless steel powder fabricated in nitrogen $\left(\mathrm{N}_{2}-\mathrm{N}_{2}\right)$, where an fcc (gamma) structure is formed. This variance in fabricating 17-4 PH steel occurs because nitrogen has a thermal conductivity $40 \%$ greater than argon. As illustrated later, conductivity and associated cooling rate difference can have a significant effect on
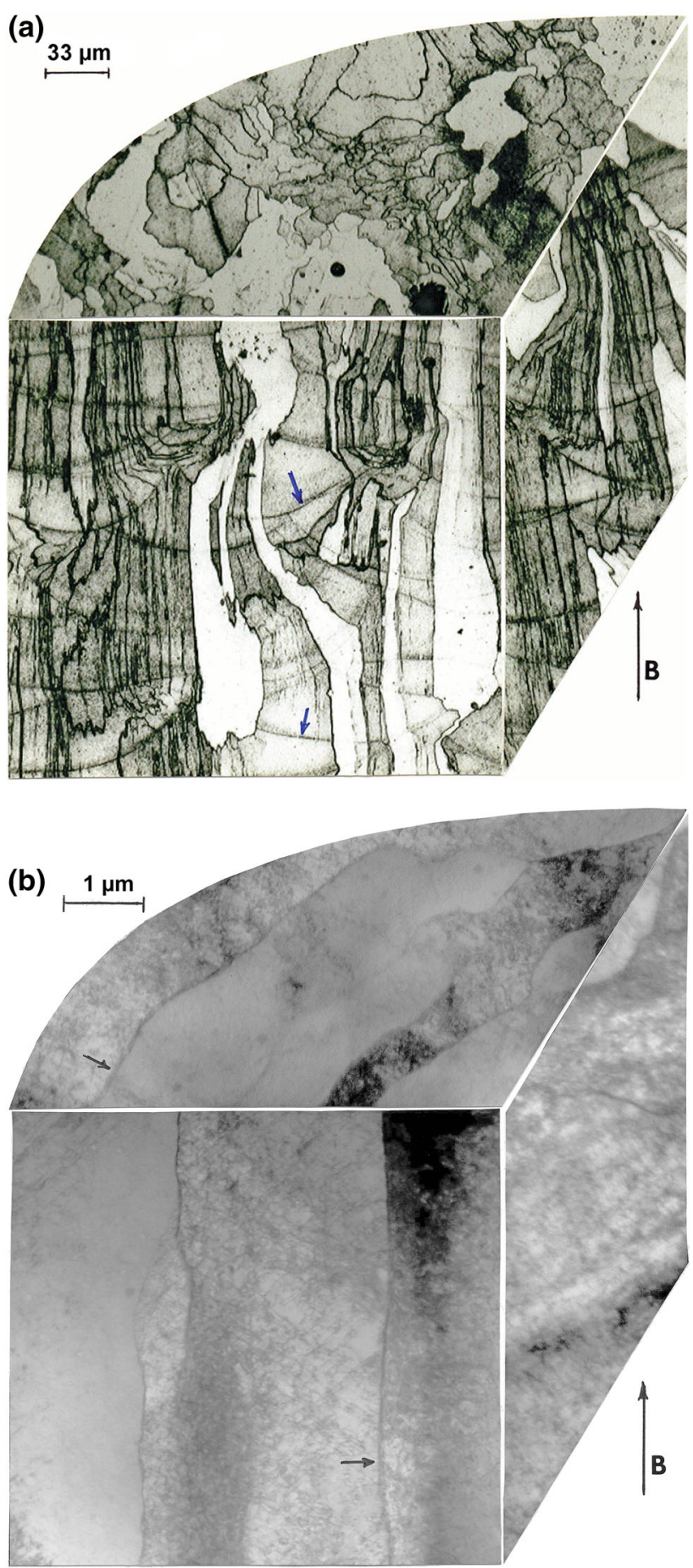

Fig. 5 Microstructure for bcc (alpha) 17-4 PH steel powder atomized in argon and fabricated by SLM in an argon gas atmosphere. (a) Light microscope image. Note melt pool, layer demarcations (striations) at arrow. B indicates the build direction (z-direction). (b) TEM image of (a) showing low-angle grain boundaries (arrows) and dislocation structure. From Murr [22], courtesy of Springer

essentially all fabricated product microstructures. Differences in heat conduction (or thermal conductivity) is of some consequence generally in both the EBM and SLM 
(a)

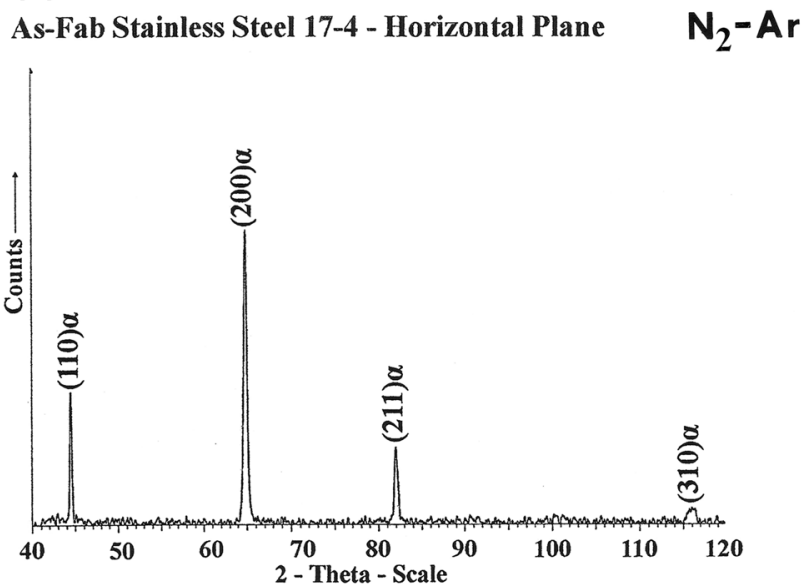

As-Fab Stainless Steel 17-4 - Vertical Plane

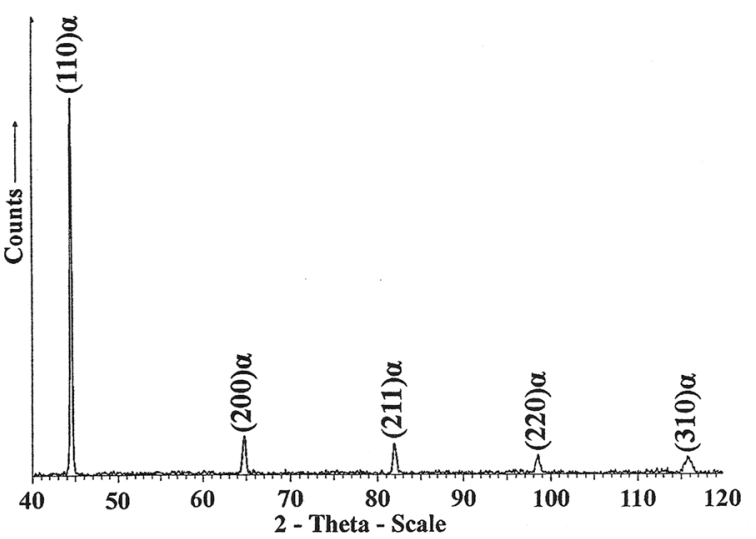

Fig. 6 17-4 PH stainless steel XRD spectra for SLM products fabricated in different inert gas atmospheres using nitrogen-atomized pre-alloyed powder. (a) Fabricated in argon $\left(\mathrm{N}_{2}-\mathrm{Ar}\right)$ showing

processes because of the consideration for product cooling, often depending on its size (volume) and complexity. In the EBM process, helium is bled into the vacuum as a thermal control measure.

Powder recycling is sometimes an important concern either for unmelted powder in the powder bed or powder recovered from complex, interior structure fabrication. This can involve some concerns for powder oxidation or related impurity issues as discussed by Gaytan et al. [44].

In addition to concerns for powder purity, contamination, size, size distribution and morphology, there have been issues with atomization gas (particularly nitrogen and argon) trapped within the powder particles during the powder production process [44]. Refinements and process optimization have generally eliminated this phenomenon, which becomes an issue during SLM or EBM fabrication because the gas is retained in the melt and can lead to gas bubbles or an interruption in layer building, creating porosity [44]. (b)

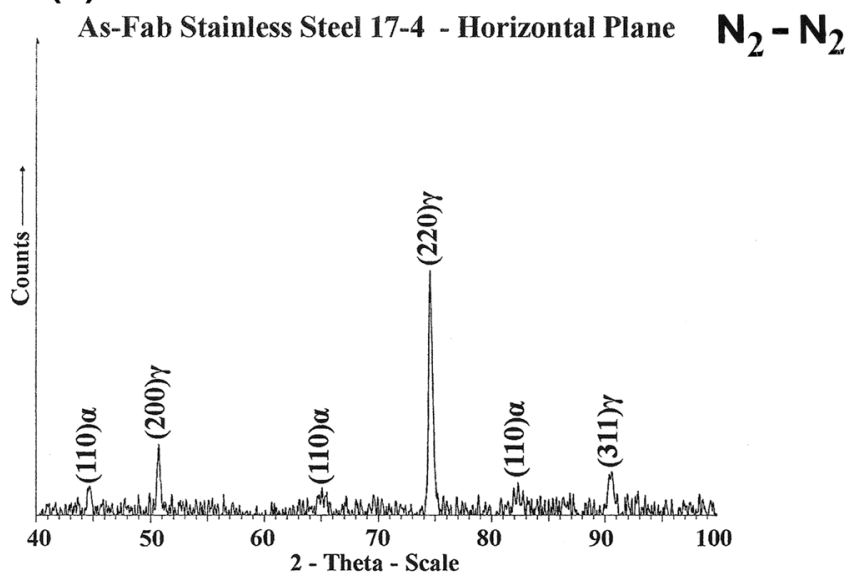

As-Fab Stainless Steel 17-4 - Vertical Plane

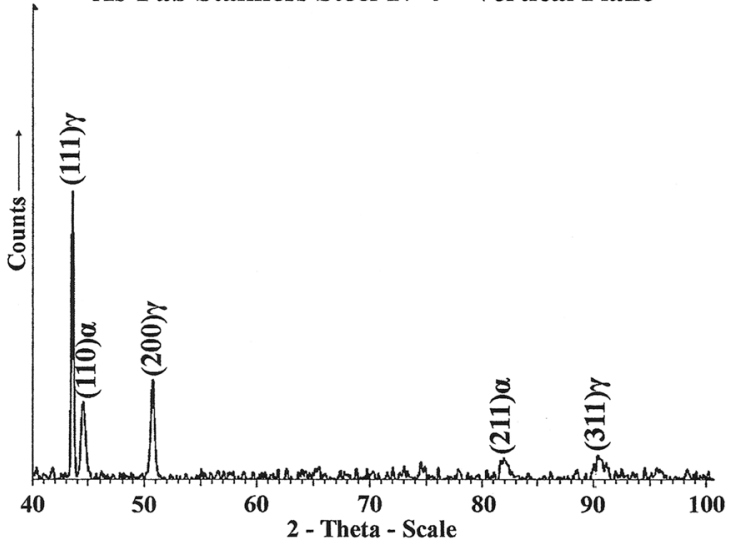

horizontal and vertical plane XRD spectra for sections as shown in Fig. 5a. (b) Fabricated in nitrogen $\left(\mathrm{N}_{2}-\mathrm{N}_{2}\right)$ showing horizontal and vertical plane XRD spectra. From Murr [22], courtesy of Springer

Of course the crucial layer building issues for powder bed EBM or SLM processes involve the efficiency and optimization of melting. This involves the build (layer building) scan strategies: beam focus (or radius, $r$ ), layer thickness $(t)$, beam scan rate (speed, $v$ ), scan line spacing $(s)$ or the so-called hatching distance, and the scan sequence (geometry) in the $\mathrm{x}-\mathrm{y}$ plane. These process parameters along with the beam power $(P)$ or power absorption in Eq 1 can define the power density $(Q)$ generally as $[21,45,46]$ :

$Q=P /(v \times s \times t)$

Generally, the beam shape or profile is considered to be a Gaussian shape distribution of intensity, but shaped beam profiles can of course have an effect on melt zone development [47].

The EBM process requires a starter plate and preheating of each raked powder layer, usually at temperatures around $0.4 T_{\mathrm{M}}\left(T_{\mathrm{M}}\right.$ is the absolute melting temperature). Layer preheating occurs in multiple (11-13) 


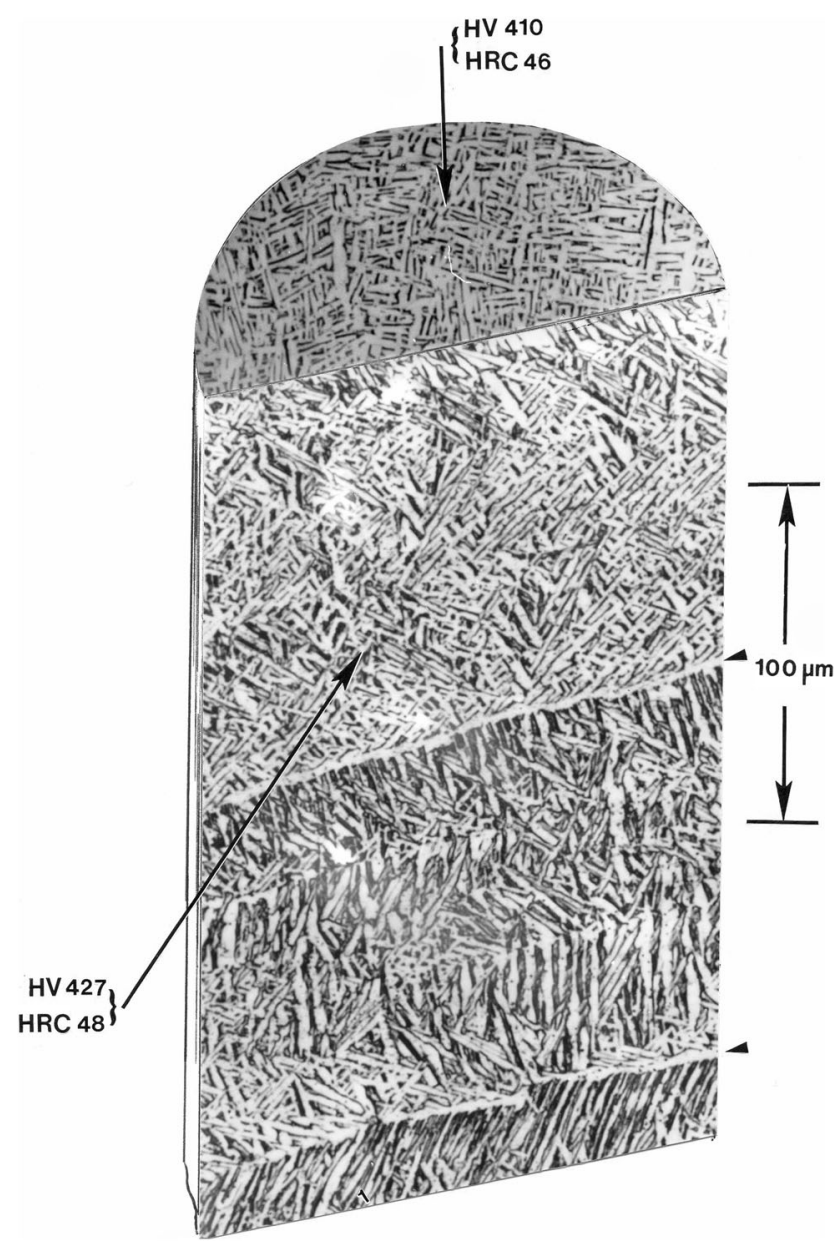

Fig. 7 3D optical metallographic section showing microstructure and layer striations (arrows) in EBM-fabricated Ti-6Al-4V product. The layer thickness is $\sim 100 \mu \mathrm{m}$ as shown. Note Vickers (HV) and Rockwell C scale (HRC) hardnesses (note HV $100 \sim 1 \mathrm{GPa}$ ). From Murr [22], courtesy of Springer

beam scans at reduced power density by using scan rates (or raster speeds) of $\gtrsim 10^{4} \mathrm{~mm} / \mathrm{s}$ at high beam current (20-50 mA), while the melt scan rate is $\gtrsim 10^{2} \mathrm{~mm} / \mathrm{s}$ at beam currents between 5 and $10 \mathrm{~mA}$ [44], depending primarily upon the powder melting point. For SLM, the preheat temperature is much lower than the powder melting point, and the melt scan strategy is different from EBM $[45,46]$. Consequently, in addition to the differences in fundamental beam properties and energy absorption features, layer melting can be quite different as evidenced in the examples shown for comparison in Figs. 7 and 8; variations in beam power and scan strategies can affect considerably different layer structures and microstructures. (compare Figs. 5a and 8, for example). Similar controls have been developed for other powder processes such as direct laser deposition involving very different powder properties (especially powder sizes) and other laser beam properties [48-51].

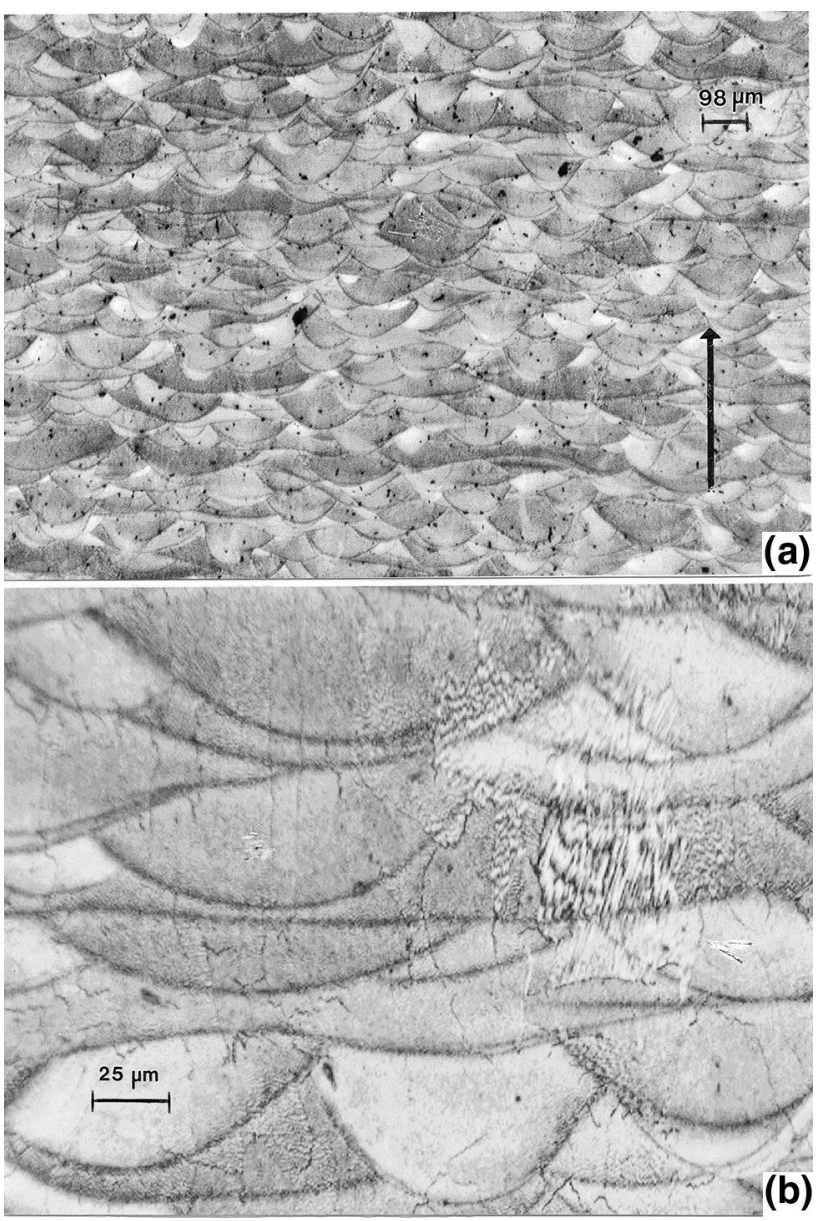

Fig. 8 Vertical section views of melt pool banding and layer striations in Inconel 718 powder $(53.5 \mathrm{Ni}-19 \mathrm{Cr}-18.3 \mathrm{Fe}-5 \mathrm{Nb}-3 \mathrm{Mo}-$ $1 \mathrm{Ti}-0.4 \mathrm{Al}$ ) fabricated by SLM in argon. (a) Low-magnification light microscope image. Arrow indicates build direction. (b) Magnified view of (a). From Murr [22], courtesy of Springer

As noted previously, process thermal kinetics, including heat conduction and corresponding cooling rates, can significantly alter the AM product microstructure and associated properties and performance issues. This is often evident even on comparing the upper regions of a product in contrast to lower regions, as a consequence of temperature differences (thermal gradients). This feature is evident to some extent in Fig. 7, as shown by residual hardness differences: somewhat softer at the hotter top regions for EBM fabrication of Ti-6Al-4V components.

Figure 9 provides an example of microstructure variations for Ti-6Al-4V fabricated by EBM for a large component $\left(\sim 10 \mathrm{~cm}^{3}\right)$ built at a melt scan rate of $300 \mathrm{~mm} / \mathrm{s}$ and beam current of $6 \mathrm{~mA}$ (Fig. 9a) compared to a mesh component built at a melt scan rate of $400 \mathrm{~mm} / \mathrm{s}$ and a reduced beam current of $4 \mathrm{~mA}$ (Fig. 9b). These process parameter changes, in addition to the more open (lower relative density) structure component, led to a significant 

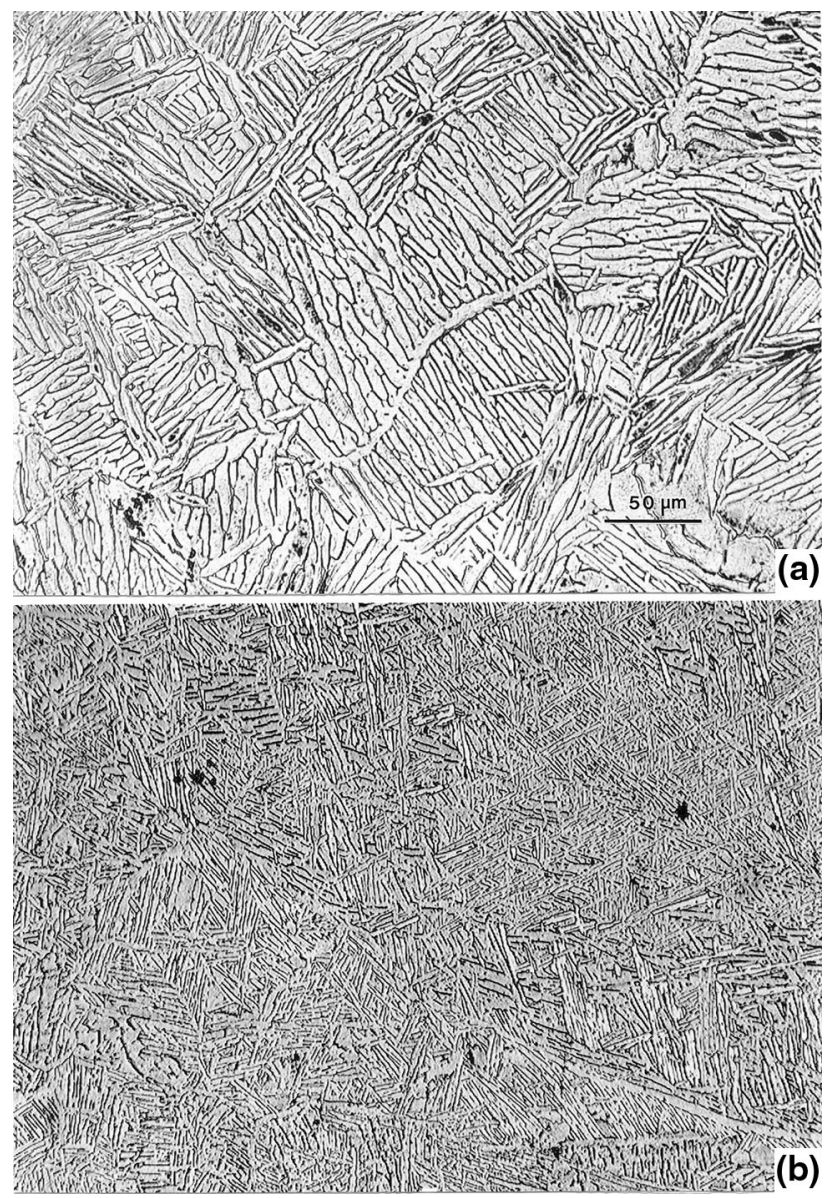

Fig. 9 Variations in lenticular, hcp-alpha-phase platelets composing $\mathrm{Ti}-6 \mathrm{Al}-4 \mathrm{~V}$ alloy microstructures for EBM-fabricated products at different build and cooling conditions. (a) $300 \mathrm{~mm} / \mathrm{s}$ melt scan at $6 \mathrm{~mA}$ beam current. (b) $400 \mathrm{~mm} / \mathrm{s}$ melt scan at $4 \mathrm{~mA}$ beam current. Note the magnification marker in (b) is the same as in (a). From Murr [22], courtesy of Springer

increase in cooling rate, and a corresponding reduction in the lenticular alpha (hcp) phase size (especially phase width), as shown in Fig. 9a and b: an average width of $\sim 6$ versus $2 \mu \mathrm{m}$, respectively. A notable variation was also observed for the Vickers microindentation hardness (HV), on comparing Fig. 9a and b: 3.4 versus $4.3 \mathrm{GPa}$, respectively $(100 \mathrm{HV} \sim 1 \mathrm{GPa})$.

Figure 10a shows a Ti-6Al-4V SEM mesh structure image, equivalent to the light microstructure image in Fig. 9b. Mesh strut thickness is $\sim 0.7 \mathrm{~mm}$, with an overall more rapid cooling rate than the sample illustrated in Fig. 9b. Figure 10b shows a martensitic (alpha prime) Ti$6 \mathrm{Al}-4 \mathrm{~V}$ microstructure consisting of thin platelets having a thickness of roughly $50 \mathrm{~nm}$, a microstructure refinement roughly 40 times smaller than Fig. 9b. This microstructure variation with temperature and cooling rates is readily observed by comparing the three light microscopy images shown in Figs. 9a, b, and 10b.
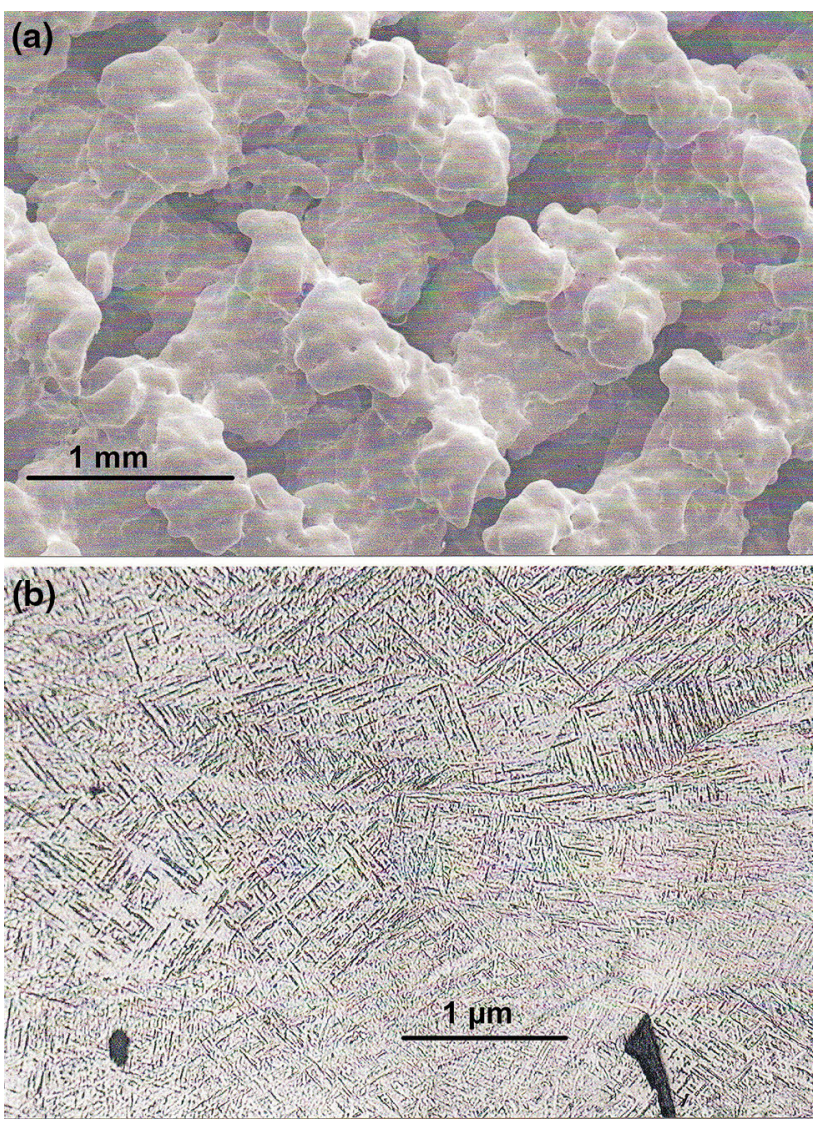

Fig. 10 Rapidly cooled Ti-6Al-4V mesh fabricated by EBM. (a) SEM image showing strut and open-mesh structure. (b) Light microscope image of a strut section in (a) showing fine, alpha prime martensite platelet microstructure

The ability of powder bed fusion processes to fabricate complex, especially internal structures such as reticulated mesh, foam, and articulated channels, is one of the most significant features of AM. Figure 10a illustrates essentially the limits of mesh or foam fabrication where feature dimensions such as open channels, struts, and ligaments approach $\sim 0.5 \mathrm{~mm}$. Such small, internal dimensions, and in fact all AM-created internal structures, require open, articulated channels or articulated regimes in order to remove the unmelted powder. For very small openings in very large components or products, this can pose considerable challenges. The most effective strategies involve high-energy ultrasonic cleaning combined with dry air blasts as originally described by Medina et al. [52] and illustrated in Fig. 11 for a Co-Cr-Mo superalloy mesh product fabricated by EBM. Such AM product development offers considerable advantages over more conventional fabrication such as casting. Figure 12 shows an example of an open-channel structure concept for a turbine blade, which allows far more efficient cooling, thereby extending high-temperature blade life. In addition, and as 

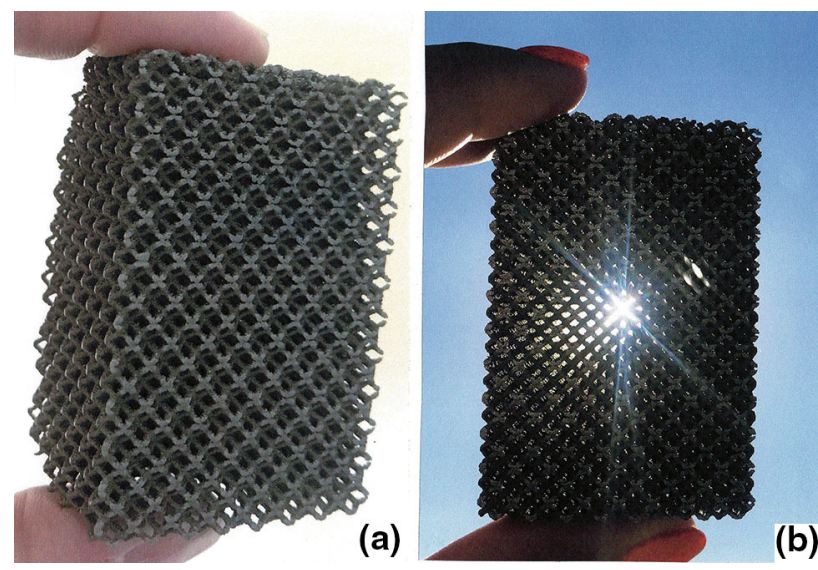

Fig. 11 Co-Cr-Mo superalloy mesh fabricated by EBM from atomized, pre-alloyed powder. (a) shows the overall mesh product structure having strut thickness and open cell dimensions of $\sim 1 \mathrm{~mm}$. (b) Tilted view of (a) showing light transmission through the thickness indicative of complete unmelted interior powder recovery

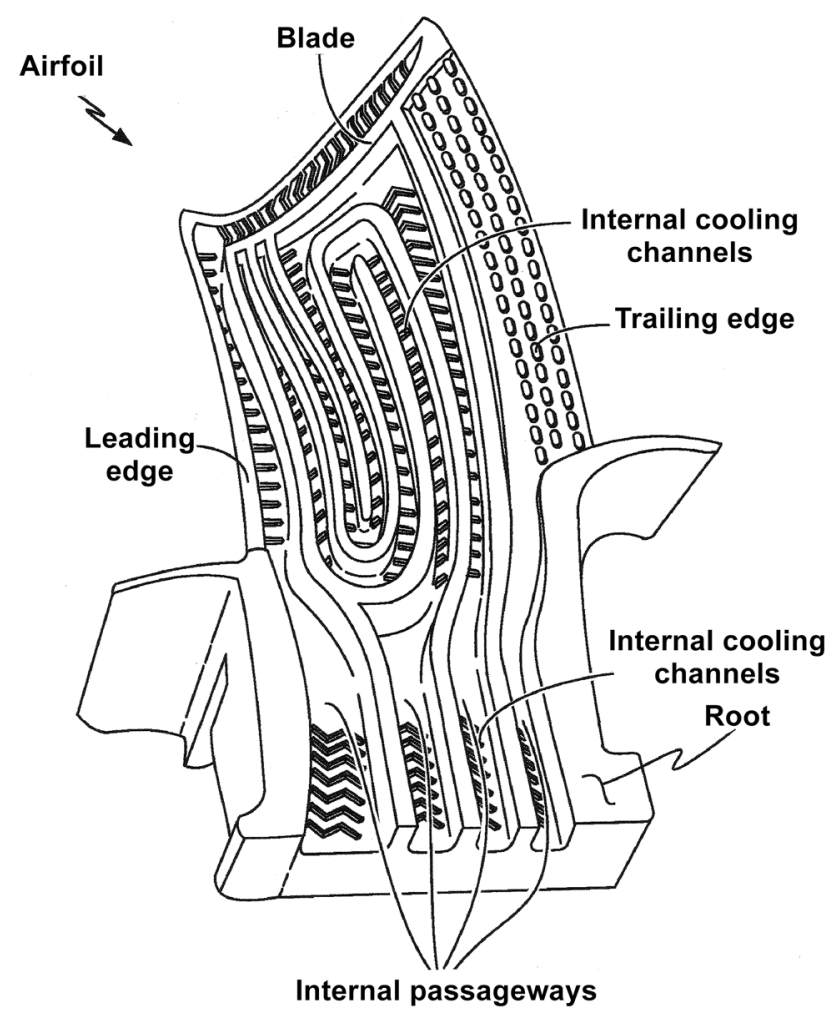

Fig. 12 Gas turbine airfoil design having internal cooling channels fabricated from superalloy powder. Adapted from patent by Bales et al. [53]

illustrated previously in Fig. 2, optimal processing parameter adjustments might also allow for specialized columnar grain or a single-crystal structure to be achieved in turbine blade AM fabrication [37, 38, 54]. These features can even be achieved in Ti-6Al-4V as recently described by Han et al. [48] who demonstrated the effect of laser
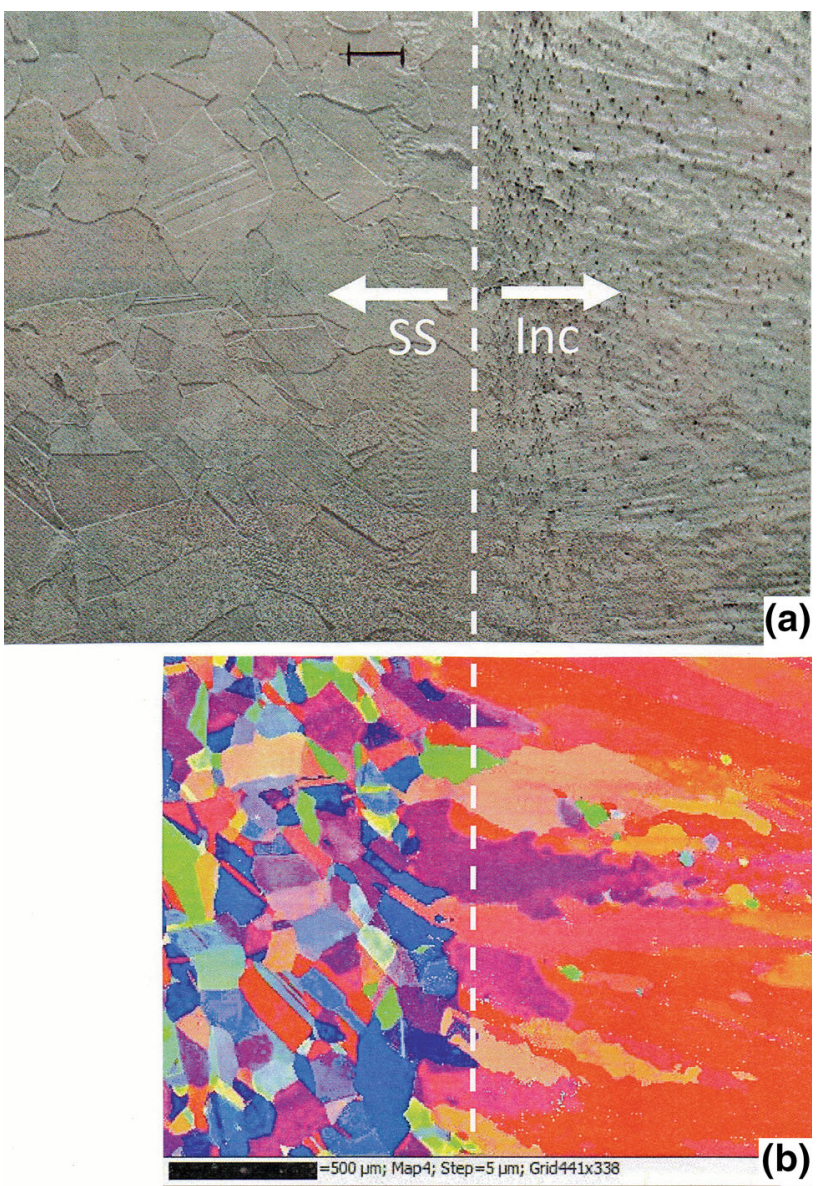

Fig. 13 Directional Inconel 718 (INC) grain structure on polycrystalline, equiaxed 316 stainless steel (SS) substrate. (a) SEM image. (b) Electron backscatter diffraction (EBSD) image of (a) showing [001] texture (red) Inconel 718 grains. Adapted from Hinojos et al. [55]. Courtesy of J. Mireles, W.M. Keck Center for 3D Innovation, University of Texas at El Paso. Note: magnification marker in (a) is $100 \mu \mathrm{m}$. The marker at bottom left in (b) is $500 \mu \mathrm{m}$

parameters (in an argon atmosphere) on the microstructure of $\mathrm{Ti}-6 \mathrm{Al}-4 \mathrm{~V}$, achieving columnar grains extending $\sim 10 \mathrm{~mm}$ or more, heavy grain widths as large as $\sim 1 \mathrm{~mm}$, grown on equiaxed grains $(200-800 \mu \mathrm{m})$ of Ti-6Al-4V starter plates. Similar, directional grains $(>1 \mathrm{~mm}$ ) of Inconel 718 alloy (see "Glossary of Alloy Compositions") have been grown on an equiaxed, grain structure $(\sim 60 \mu \mathrm{m})$ of type $316 \mathrm{~L}$ stainless steel (see "Glossary of Alloy Compositions") by electron beam melting as well [55]. An example of these results is reproduced in Fig. 13.

It is interesting to note that other related directional microstructures/architectures are often observed in association with the melt zone geometries, including the scan spacing, s, in Eq 2. Figure 14 illustrates this phenomenon in contrast to Fig. 13, which shows $\gamma^{\prime \prime}\left(\mathrm{Ni}_{3}(\mathrm{Al}, \mathrm{Ti}, \mathrm{Nb})\right)$ fcc precipitates forming directional, columnar architectures in the build (Z) direction for EBM-fabricated Inconel 625 


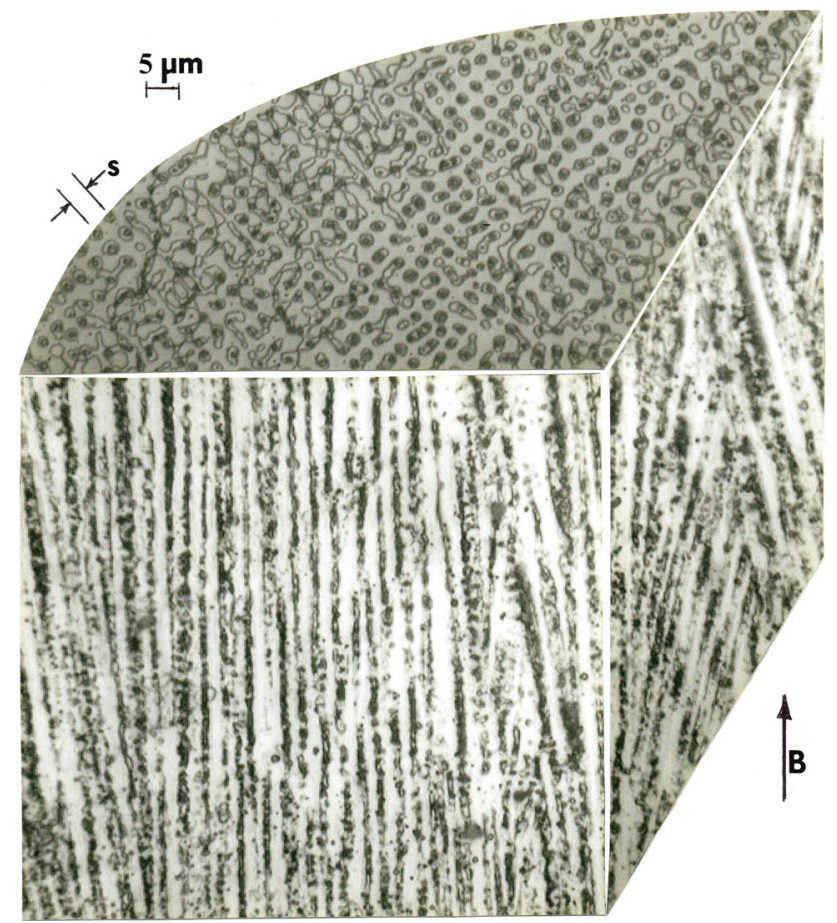

Fig. 14 Directional columns of $\gamma^{\prime \prime}\left(\mathrm{Ni}_{3} \mathrm{Nb}\right)$ precipitates in EBMfabricated Inconel 625 superalloy. The scan spacing is designated "s" in the horizontal $(\mathrm{x}-\mathrm{y})$ plane section. The arrow at lower right indicates the build (z-axis) direction. The sample was over-etched to exaggerate the columnar architecture

alloy (see "Glossary of Alloy Compositions"). The melt zone which defines the $\gamma^{\prime \prime}$ columns is roughly $2 \mu \mathrm{m}$ in diameter, while the scan spacing is roughly $3 \mu \mathrm{m}$ [56]. The continuous, melt zone thermo-kinetics create these often interrupted $\gamma^{\prime \prime}$ precipitate columns, which will be illustrated in more detail later in this review.

While numerous examples of light and electron micrographs have illustrated the variations in microstructures which can be achieved in a variety of metal and alloy components fabricated by electron and laser beam melting technologies as a consequence of process parameter variations (Figs. 5, 6, 7, 8, 9, and 10), it is also important to establish standards and specifications accepted for a variety of products fabricated by more traditional subtractive manufacturing processes. Gaytan et al. [44] earlier suggested including tabs at critical locations on AM-fabricated products and components, which could be easily removed without altering the part, and analyzed for microstructure development, hardness, chemistry, and other properties. More recently, various US professional societies, such as the America Society for Testing Materials (ASTM) International and the American Society for Mechanical Engineers (ASME), have developed committees to address the establishment of standards and certification in collaboration with various industries, especially those serving the aircraft and aerospace industries [57]. Recent aspects have been described and reviewed by Seifi et al. [58].

\section{Direct Metal Droplet 3D Printing Concepts}

To some extent, Fig. 1d actually illustrates a 3D printer concept where powder is emitted from a nozzle to create an $\mathrm{x}-\mathrm{y}$ powder bed, while a suitable binder is selectively printed in a CAD-driven pattern from a printing jet (nozzle) similar to an ink-jet printer head. Such systems can work well for fluids, but complexities arise when liquid metal drops are to be selectively printed to create a 3D object. In ink-jet printer heads, liquid ink droplets are pulsed from an orifice in a reservoir containing the ink, often using piezoelectric-driven pulsing schemes at room or low temperature. These inks usually possess a low surface tension which allows efficient spreading of even nano-size droplets on the printed surface. However, for metals, higher temperatures are required for useful structural metals such as aluminum, which melts at $\sim 660^{\circ} \mathrm{C}$, and has a surface tension at its melting point of around $850 \mathrm{~mJ} / \mathrm{m}^{2}$ ) [59].

Some of the earliest efforts to develop a 3D metal droplet printer were undertaken by Orme and Muntz [60] three decades ago, including a patent published in 1990 [24]. Additional work using aluminum, aluminum alloys, and other lower melting point metals continued for ten years [61-63], with related research continuing on drop-ondemand metal 3D printer systems [64-67], including fundamental droplet research [68, 69]. Murr and Johnson [19] have reviewed these prospects in some detail, while Wang et al. [70] have also very recently described an aluminum droplet (jet) 3D printing process employing the magnetohydrodynamic property of liquid metal in an alternating magnetic field.

Figure 15a illustrates the metal droplet generator design of Murr and Johnson [19] which utilizes a small diameter (1-2 $\mathrm{mm}$ ) wire spool to feed the melt crucible. A pulsing concept releases a Rayleigh jet as a charging electrode charges each forming droplet. Charged droplets can then be deflected by additionally charged arrays to form required object geometries. However, complex geometries would require multi-axis arrays, or droplet generators forming scaffolds which would have to be removed in a manner similar to unmelted powder in complex powder bed product fabrication. To a large extent, such systems would be mainly CAD limited. The major advantages of direct droplet deposition would be the ability to build closed-cell structures, such as foams, which cannot be fabricated using powder bed processing. In addition, drop-on-demand droplet generators could be clustered as shown in Fig. 15b to increase the volume of metal deposited to many times that for powder bed technologies. Multi-material and multimetal deposition would also be possible with clustered 
Fig. $153 \mathrm{D}$ metal droplet generator design. (a) Metal wire feed single droplet jet printer head. (b) Cluster droplet generator design. From Murr and Johnson [19], courtesy of Elsevier

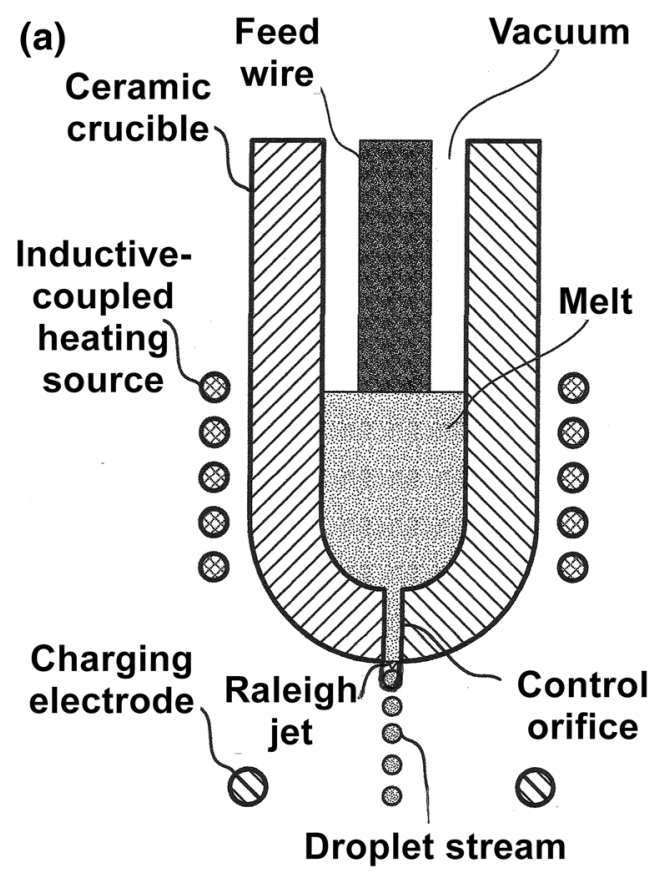

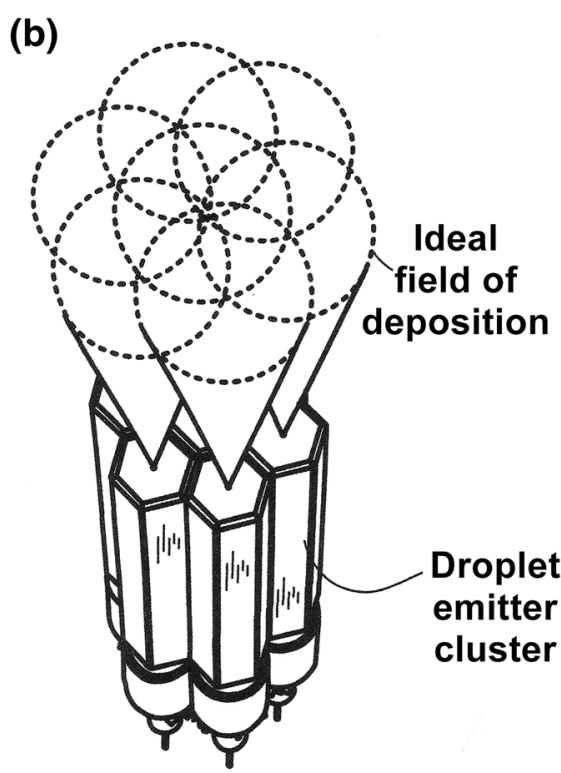

printer heads as shown in Fig. 15b as well. Such highvolume deposition could be further coordinated in large manufacturing arenas to fabricate a multitude of large products and associated components [19].

As illustrated schematically in Fig. 16c 3D metal droplet deposition would also be fundamentally different from powder bed layer building where each superheated droplet would cool rapidly and independently when deposited. Amorphous structures could possibly be produced, or microstructures that in some cases could be systematically manipulated using auxiliary laser or electron beam heating or annealing. Figure $16 \mathrm{a}$ and $\mathrm{b}$ contrasts traditional melt solidification by a moving solidification front in processes, such as directional casting or crystal growth, (Fig. 16a) with powder bed or related melt solidification layer building (Fig. 16b), which can create the directional microstructures or architectures illustrated in Figs. 8, 13, and 14 , for example [23].

While direct metal droplet 3D printing poses many advantages and novel or unique AM prospects, few significant advances have been achieved over the past three decades. Nonetheless, continued developments may accrue more attractive commercial realities in the future.

\section{Examples of Contemporary, Additive/3D Printed Component Microstructures}

Metallography, particularly light and electron microscopy (especially scanning and transmission electron microscopy, SEM and TEM, respectively), has largely provided the key driver for the structure-property-processing-performance paradigm, which continues to define materials science and engineering as interdisciplinary [22]. Over the past several decades, this has been demonstrated to be true for AM technologies as well.

As in more contemporary manufacturing technologies, product performance is almost always decided by process variable control and post-processing thermo-mechanical (TM) treatments, which are usually carefully assessed by metallographic (microstructure) analysis. "Powder Bed Technologies: Electron and Laser Beam Melting" section of this review provides some limited examples of process differences and process control parameters on residual AM product microstructures (e.g., Figs. 2, 5, 6, 7, 8, 9, 10, 13, and 14). In addition, numerous examples of AM-related microstructures and microstructure control have been described in numerous references cited: $[8,10,13,37,38,48-51,55,56]$. In this section, additional microstructure examples will illustrate some of the novel, especially directional architectures unique to SLM- and EBM-fabricated products.

\section{Copper EBM}

As noted previously, copper powder bed fabrication includes challenges in precursor powder purity, particularly oxidation as discussed by Frigola et al. [42]. Earlier work by Ramirez et al. [71] for EBM-fabricated products from copper powder (shown in Fig. 4a) illustrates copper oxide $\left(\mathrm{Cu}_{2} \mathrm{O}\right.$-cuprite $)$ cubic precipitates arranged in continuous columns in the $\mathrm{z}$-direction (build direction), including 
(a)

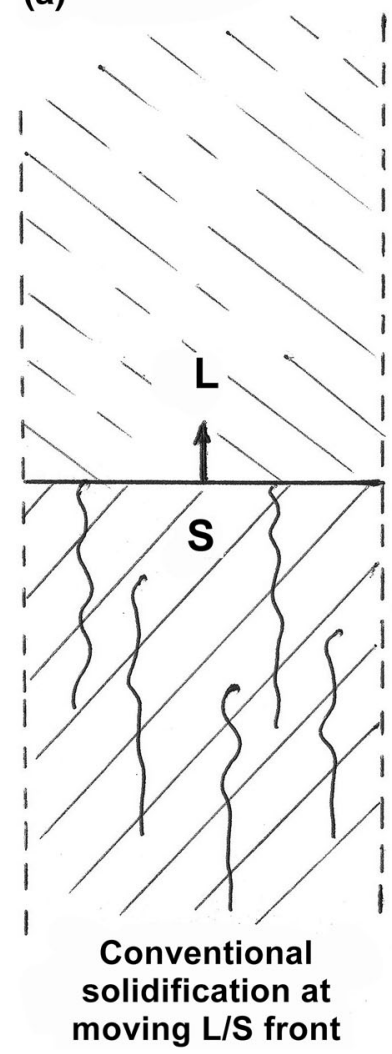

Fig. 16 Comparison of melt solidification concepts. (a) solid-liquid (melt) zone movement. (b) Alternating liquid-solid layer building AM process. (c) Metal droplet (liquid) deposition AM manufacturing.

connecting regimes of oxide precipitates and dislocations. Figure 17 reproduces an example of these oxide architectures which, at lower magnification using light microscopy, resemble the directional precipitate architectures illustrated in Fig. 14 [71]. Like those directional architectures in Fig. 14, the directional oxide precipitates in the TEM image in Fig. 17 generally lie within the continuous melt zone columns generated during EBM melt scan strategy, or scan spacing indicated by "s" in Fig. 14.

By using a more purified (99.99\%) copper precursor powder and higher beam currents to create a hotter build process, Frigola et al. [42] produced a more equiaxed grain structure by EBM without measurable oxide precipitates. The yield strength for these EBM-fabricated components was observed to be $0.76 \mathrm{GPa}$ in contrast to $0.69 \mathrm{GPa}$ for wrought copper products.

\section{Superalloy Microstructures}

Superalloys, especially nickel-base and cobalt-base alloys have continued to find a wide range of applications over the past decades in aerospace and industries involving extreme environments, and applications suited to these (c)

Residual laserl electron beam thermal processing

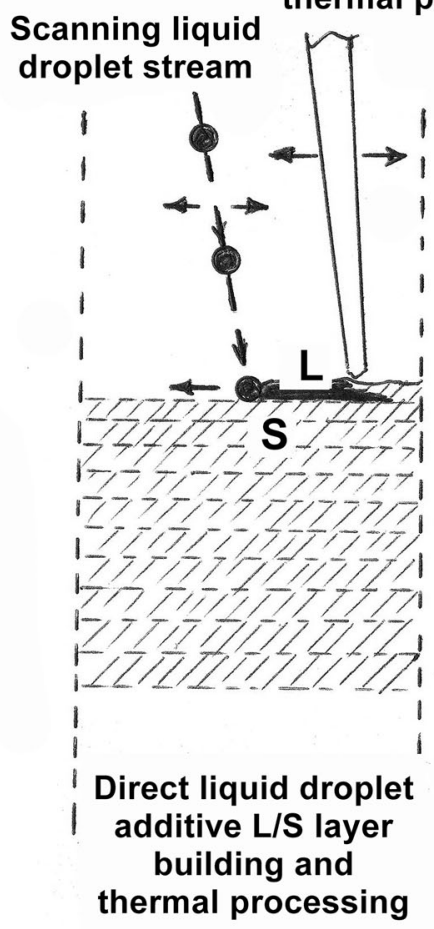

The depositing droplets are superheated to assure molten droplets reach the building object

environments: corrosion and oxidation in particular [72-74]. High-temperature applications involving turbine blades and rotor components in jet engines began in the 1960s when novel strategies for maintaining creep life were developed using carbide precipitate microstructures in Co-base alloys and a variety of $\mathrm{Ni}_{3} \mathrm{X}$ eutectic precipitate phase microstructures in Ni-base alloys such as Inconel 718 and Inconel 625 [75-78].

While Co-base alloy carbide precipitation is homogeneously distributed in more conventional cast products, EBM fabrication (using pre-alloyed powder shown in Fig. 3c) produces directional architectures composed of cubic $\mathrm{Cr}_{23} \mathrm{C}_{6}$ precipitates illustrated in Figs. 18 and 19. In Fig. 18, the carbide precipitates are formed in the melt columns (spaced s) in the build (B) direction. Figure 19 illustrates the cubic, nano-carbides comprising the directional architectures in Fig. 18. In addition to carbide precipitation, fcc Co-base alloys exhibit extended stacking faults during fabrication and especially when heat-treated to dissolve the carbide precipitates. This feature also occurs upon HIP annealing $\left(4 \mathrm{~h} @ 1100{ }^{\circ} \mathrm{C}\right.$ ) of the EBM product shown in Figs. 18 and 19, and is illustrated in Fig. 20 $[79,80]$. The residual yield stress corresponding to Fig. 20 


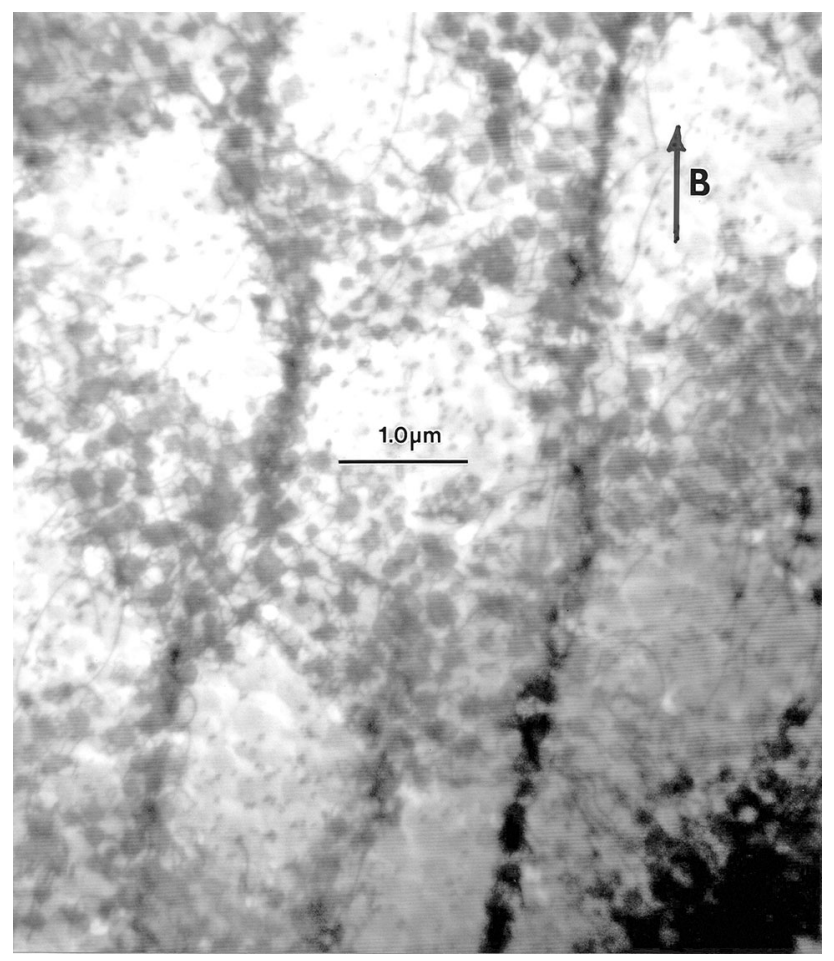

Fig. 17 Copper oxide columnar architectures in EBM-fabricated copper components

was measured to be $0.6 \mathrm{GPa}$ in contrast to $0.51 \mathrm{GPa}$ for Fig. 18. However, the yield stress for the Co-base alloy fabricated by EBM as shown in Fig. 18 was measured to be $0.71 \mathrm{GPa}$ in the $\mathrm{x}-\mathrm{y}$ plane, perpendicular to the build direction (z-axis).

In contrast to Co-base superalloys, Ni-base alloys can be chemically and thermodynamically manipulated to produce a variety of eutectic precipitates, notably gamma prime $\left(\gamma^{\prime}\right)$ $\left(\mathrm{Ni}_{3} . \mathrm{Al}:\right.$ fcc, $\left.a=036 \mathrm{~nm}\right)$, gamma double prime $\left(\gamma^{\prime \prime}\right)$ $\left(\mathrm{Ni}_{3} \mathrm{Nb}\right.$ : bct, $\left.a=0.34, c=0.70 \mathrm{~nm}\right)$, and delta $(\delta)\left(\mathrm{Ni}_{3-}\right.$ $\mathrm{Nb}$ : orthorhombic, $a=0.51, b=0.42, c=0.45 \mathrm{~nm})$ [76-78]. Optimized gamma prime precipitates are cuboids, semi-coherent oriented in a cube-cube relationship with the fcc NiCr matrix $(a=0.36 \mathrm{~nm})$. The gamma double prime precipitates are usually variously disk-shaped and coincident with the cube planes of the matrix. Under some conditions, the $\gamma^{\prime \prime}$ phase decomposes to delta needles coincident with the fcc matrix $\{111\}$ planes [81]. However, as illustrated for the EBM fabrication of Inconel 625 alloy in Fig. 21, gamma double prime plate-like precipitates $\left(\mathrm{Ni}_{3} \mathrm{Nb}\right)$ are coincident with the $\mathrm{NiCr}$ (fcc) matrix $\{111\}$ planes and form columnar architectures in the build (B) direction. Murr et al. [56] have examined these precipitation microstructures in some detail in order to establish the phase specifics. It is also notable to observe that Figs. 14 and 21 are the same EBM-fabricated product. Figure 21 , by contrast with Fig. 14, is an optimized

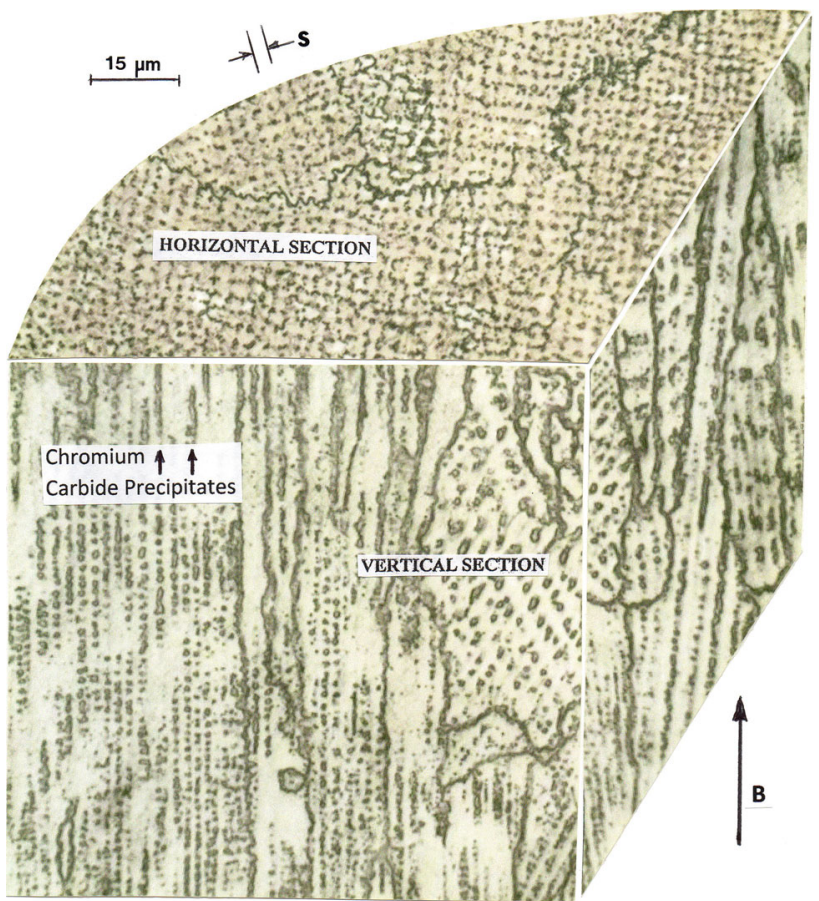

Fig. 18 Columnar $\mathrm{Cr}_{23} \mathrm{C}_{6}$ carbide architecture in EBM-fabricated Cobase (fcc) superalloy $(\mathrm{Co}-26 \mathrm{Cr}-6 \mathrm{Mo}-0.2 \mathrm{C})$. s indicates the melt scan spacing. B indicates the build direction (z-direction in Fig. 1)

metallographic etch which reveals the precipitate features, while higher-resolution TEM and x-ray diffraction analysis have provided even more specific microstructural and crystallographic corroboration [56].

Mignanelli et al. [82] have recently noted that the $\mathrm{Al} / \mathrm{Nb}$ elemental composition ratio determines the eutectic phase in Ni-base superalloys: a low ratio produces $\gamma^{\prime \prime}$, while a ratio from 2 to 1 favors $\gamma^{\prime}$, even forming gamma-gamma prime/gamma double prime dual superlattice microstructures in specific cases. Figure 22 shows $\gamma^{\prime \prime}\left(\mathrm{Ni}_{3} \mathrm{Nb}\right)$ disklike precipitates coincident with the $\mathrm{NiCr}$ (fcc) cube $\{100\}$ planes in SLM-fabricated Inconel 718, following a HIP annealing. The selected area electron diffraction (SAED) pattern inset in the TEM image of Fig. 22 shows the [100] zone axis in the vertical plane section, while D shows a $\gamma^{\prime \prime}$ disk-like precipitate in the (001) horizontal surface plane. A schematic view of the coincident $\{100\} \gamma^{\prime \prime}$ precipitates is shown in the image right face (010) plane [82]. Similar results were observed by Strondl et al. [83] for EBM fabrication of Inconel 718 components.

Single-crystal Ni-base superalloy, cast turbine blades have become the standard for high-temperature environments where creep life is a limiting feature. As shown in Fig. 2, these products are characterized by microdendritic $\langle 100\rangle$ microstructures, which are ultimately controlled by a gamma prime $\left(\gamma^{\prime}\right) \mathrm{Ni}_{3} \mathrm{Al}$ cuboidal precipitation hardening microstructure [78]. These cuboidal $\gamma^{\prime}$ eutectic phase 
Fig. 19 TEM examples of $\mathrm{Cr}_{23} \mathrm{C}_{6}$ cubic precipitates composing the columnar architecture in Fig. 18. Note that the magnification marker in (c) is the same as (b)
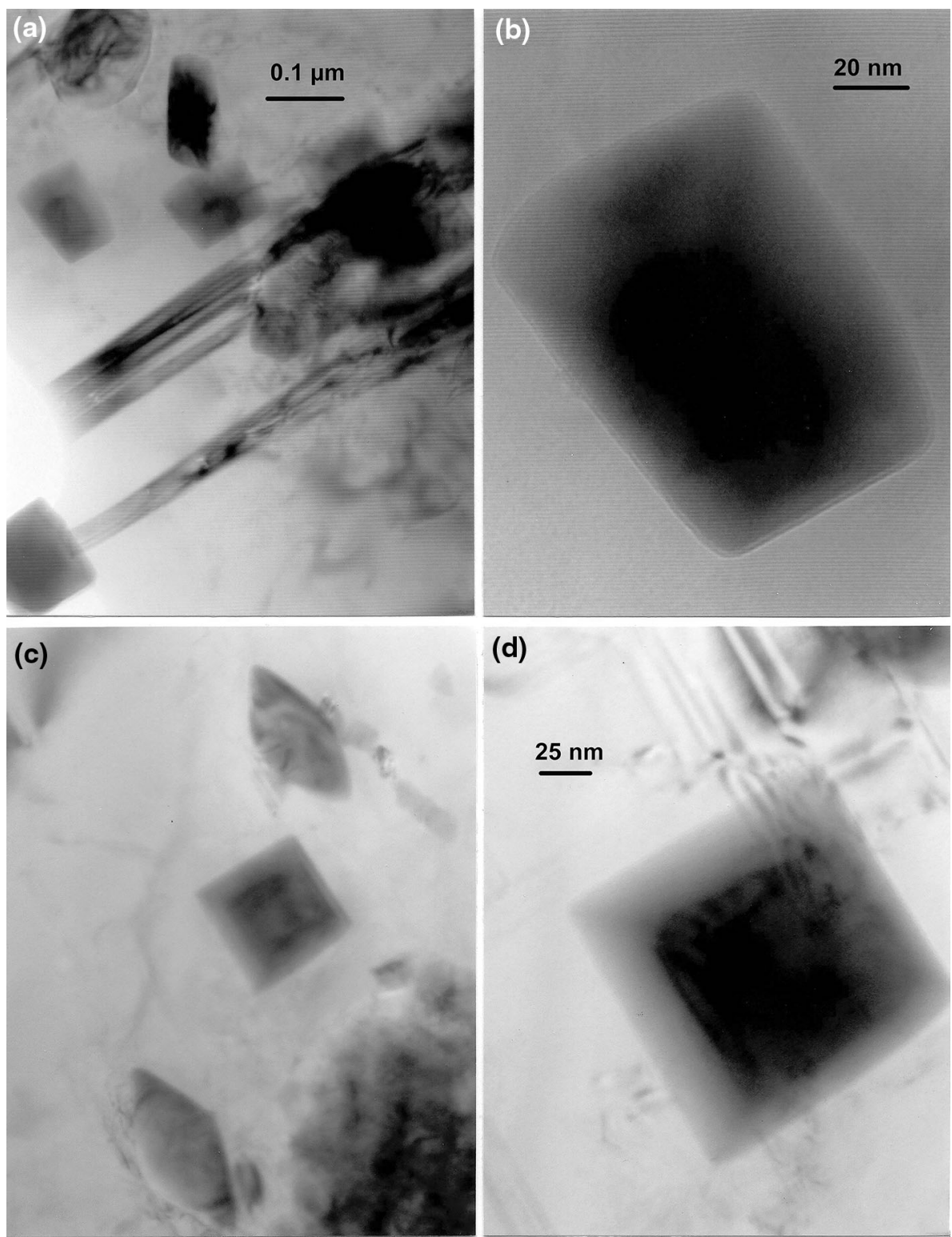

(d)

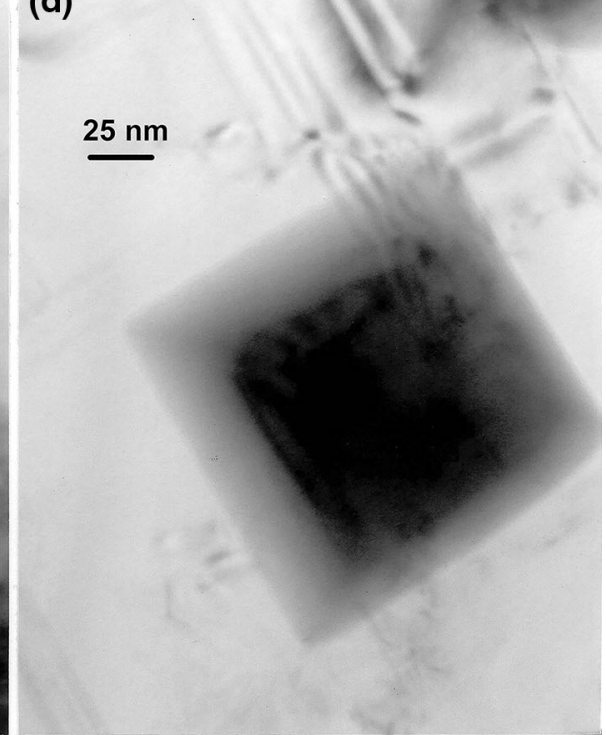

microstructures are semi-coherent with the $\{100\} \mathrm{NiCr}$ (fcc) matrix planes, and optimized design strategies have involved assuring specific $\gamma / \gamma^{\prime}$-phase relationships; including cubic or strict cuboidal $\gamma^{\prime}$ precipitate shapes, size, volume fraction and $\gamma / \gamma^{\prime}$ channel or interfacial regime spacing [78, 84-86]. These features are usually achieved by multiple and often complex (multi-step) heat treatments after casting.

Figures $23,24,25$, and 26 show a sequence of metallographic images for EBM-fabricated René 142, a Ni-base superalloy (see "Glossary of Alloy Compositions") originally developed for turbine blade production in the early 1990s.

Figure 23 shows microdendritic columns coincident with the melt columns, with the microdendrites oriented in the [001] direction, having [100] and [010] branches (observable in the horizontal plane section and the inserted schematic at "p"). A magnified view shows these columnar architectures to be composed of $\gamma^{\prime}\left(\mathrm{Ni}_{3} \mathrm{Al}\right)$ cuboidal precipitates in the inset of Fig. 24. Figure 25 shows a magnified TEM image of a region similar to the inset in Fig. 24, which shows the $\gamma^{\prime}$ precipitates having coherent fringe contrast and dislocations primarily in the $\gamma$ matrix region between the precipitates [87]. Figure 26 shows a magnified view of Fig. 25 tilted to eliminate dislocation images and retain only contrast fringes at the $\gamma / \gamma^{\prime}$ interface, corresponding to a misfit of $\sim 0.3 \%$. These contrast features were originally described in detail more than 50 years ago $[88,89]$ for cast products. Detailed examination of the images in Figs. 25 and 26 indicated an average $\gamma^{\prime}$ cuboidal 


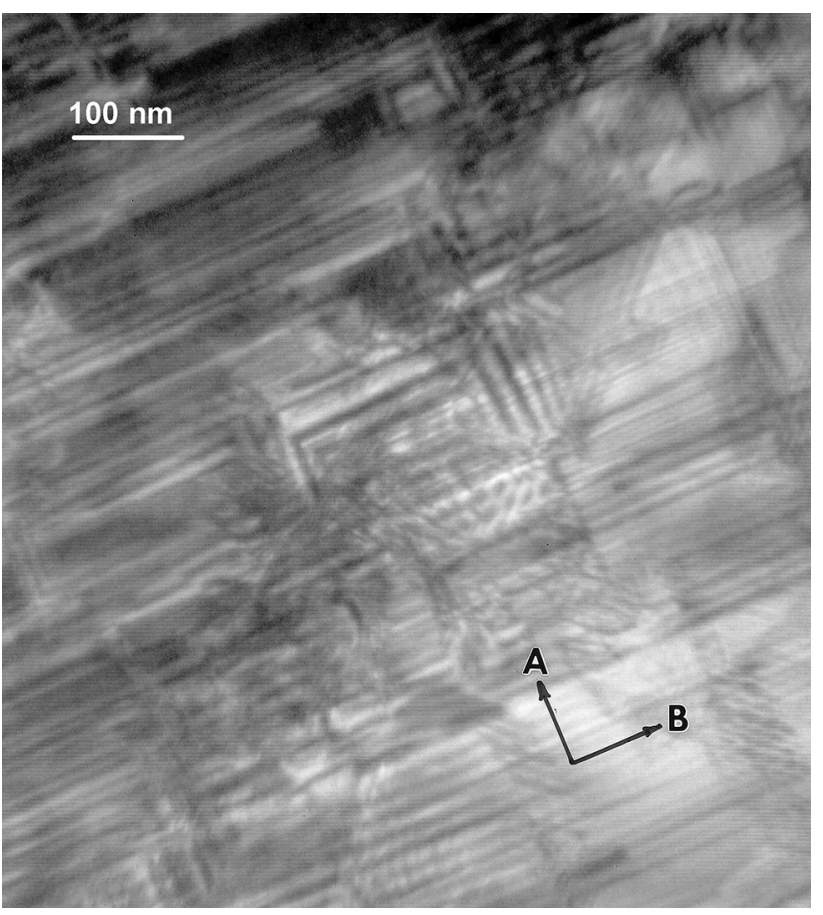

Fig. 20 Dense stacking faults in HIP-annealed Co-base EBM component in Fig. 18. The grain surface orientation in the TEM image is (100). A and B indicated the [022] and [0ㄹ2] directions for the corresponding fcc $(11 \overline{1})$ and (111) planes, respectively

size of $\sim 275 \mathrm{~nm}$, with a $\gamma / \gamma^{\prime}$ channel spacing ranging from 25 to $75 \mathrm{~nm}$, with a $\gamma^{\prime}$ volume fraction of $\sim 59 \%$. This is essentially optimal for this alloy [85]. As a consequence, the EBM-fabricated René 142 alloy illustrated in Figs. 23, 24, 25, and 26 represents a basically optimized product, albeit essentially serendipitous in the context of EBM processing parameters and pre-alloyed René 142 powder properties.

Kear and Oblak [76] have meticulously described the mechanism underlying creep, such as optimization in $\gamma / \gamma^{\prime}$ microstructures in Ni-base superalloys like René 142 (Figs. 25 and 26). Low-temperature deformation first involves slip (dislocation glide) on $\{111\}$ planes of paired $\mathrm{a}\langle 110\rangle / 2$ dislocations followed by viscous cutting of the gamma prime $\left(\gamma^{\prime}\right)$ cuboids by paired $\mathrm{a}\langle 110\rangle / 2$ dislocations in climb configurations at high temperature. a $a\langle 112\rangle / 3$ stacking fault modes of shear are also important in primary creep and at intermediate temperatures where the motion of superlattice intrinsic/extrinsic stacking fault pairs becomes creep rate controlling. Ultimately it is blocking of glide motion which inhibits noticeable creep.

This section has illustrated that strategies to optimize turbine blade creep performance have relied upon metallography principles for more than a half century and that AM technologies such as SLM and EBM have not fundamentally altered this for superalloy products. Nonetheless,

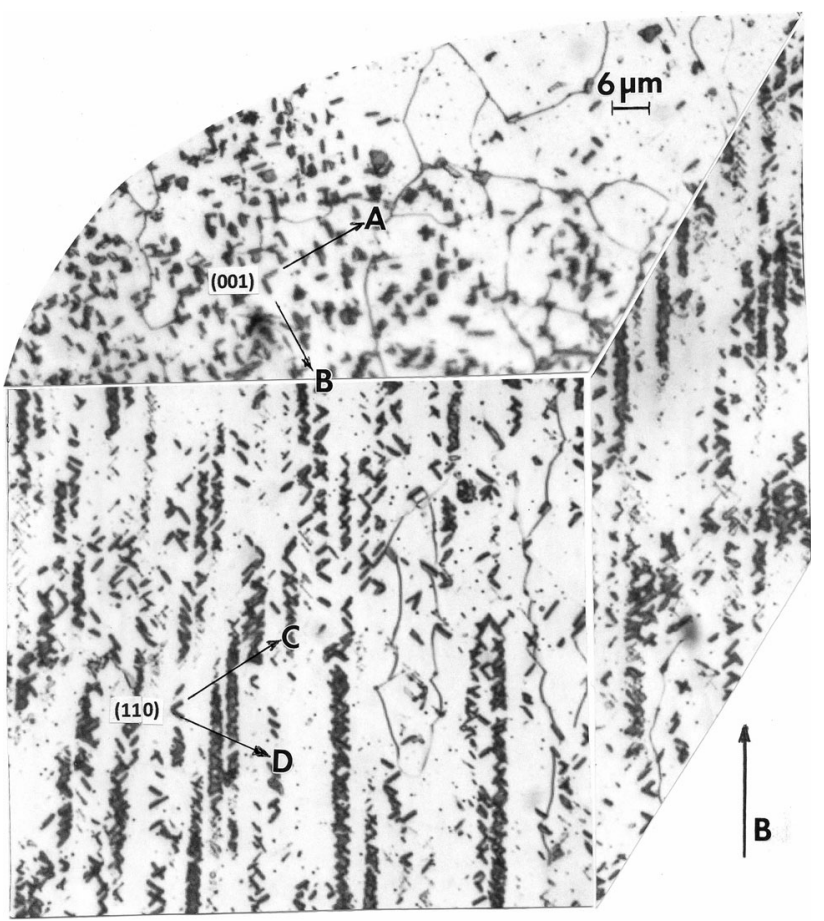

Fig. 21 3D optical metallographic section showing $\gamma^{\prime \prime}$ precipitate disks coincident with the $\mathrm{NiCr}$ (fcc) $\{111\}$ planes in Inconel 625 alloy fabricated by EBM. The horizontal plane section is (100), and A and $\mathrm{B}$ denote the traces of [022] and [012] corresponding to the fcc (111) and (111) planes, respectively. The vertical plane section is (111), and

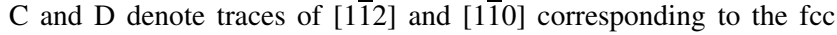
(111) and (111) planes, respectively

there are often some significant variations in mechanical properties for EBM and SLM products in contrast to more commercial, wrought or cast products. Some examples of these will be outlined in a later section.

\section{Examples of Other High-Temperature Metals Microstructures}

Superalloys such as Inconel 718, 625 and René 142 described above have melting points ranging from 1260 to $1350{ }^{\circ} \mathrm{C}$. These melting points can be compared with $\mathrm{Ti}$ and $\mathrm{Ti}-6 \mathrm{Al}-4 \mathrm{~V}$ where the melting temperatures are 1670 and $1650{ }^{\circ} \mathrm{C}$, respectively. The $\mathrm{Co}-\mathrm{Cr}-\mathrm{Mo}$ alloy represented in Figs. 18, 19 and 20 melts around $1330^{\circ} \mathrm{C}$. By contrast, stainless (300 series) steels melt between 1360 and $1455^{\circ} \mathrm{C}$.

Murr et al. [90] have recently described the EBM fabrication of pure iron components where the microstructure exhibited delta $(\delta)$ bcc iron platelet-like phases coincident with the alpha $(\alpha)$ bec iron matrix $\{110\}$ and $\{100\}$ planes. These microstructures were observed to be created on rapid cooling of the atomized powder and retained in the residual, fabricated components. Figure 27 illustrates these novel microstructure features. 


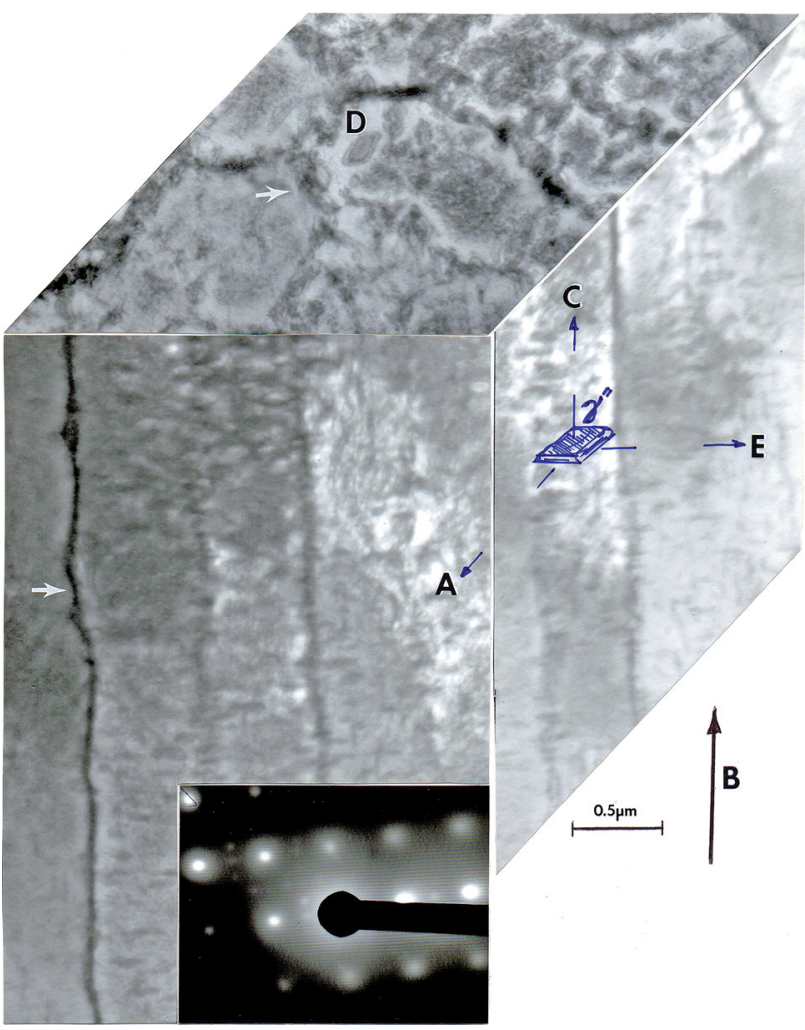

Fig. 22 3D TEM section view of SLM (argon) fabricated and HIPed Inconel 718 component. The white arrows indicate low-angle boundaries while D shows the lenticular, disk-like $\gamma^{\prime \prime}$ precipitate morphology coincident with the $\mathrm{NiCr}$ matrix fcc $\{001\}$ planes. A, C, and $\mathrm{E}$ represent [100], [001] and [010] zone axes, respectively. The SAED pattern inset shows the fcc matrix [100] zone axis. Precipitate reflections are not easily recognized in the diffraction pattern inset. B denotes the build direction

One of the highest melting metals fabricated by EBM is niobium ( $\sim 247{ }^{\circ} \mathrm{C}$ ) as described by Martinez et al. [91]. Niobium products have applications in superconducting cavity designs, and niobium alloys, some of which ( $\mathrm{Nb}-\mathrm{Ti}$ ) continue to be the commercial superconducting wire of choice, have been investigated as the next-generation hightemperature components [92, 93]. Figure 28 reproduces an EBM-fabricated niobium product microstructure image showing low-angle grain boundary and dislocation substructures. Dislocation densities ranged from $10^{9}$ to $10^{10} /$ $\mathrm{cm}^{2}$, and the residual Vickers microindentation hardness ranged from 0.9 to $1.1 \mathrm{GPa}$. These values can be compared with commercial, annealed $\mathrm{Nb}$ (sheet) products where the microindentation hardness values range from 0.13 to 0.3 GPa for grain sizes around $300 \mu \mathrm{m}$ [94].

\section{Aluminum and Aluminum Alloy AM Fabrication and Microstructural Issues}

Like nickel-base superalloys, aluminum alloys rely upon precipitation hardening/strengthening for their properties

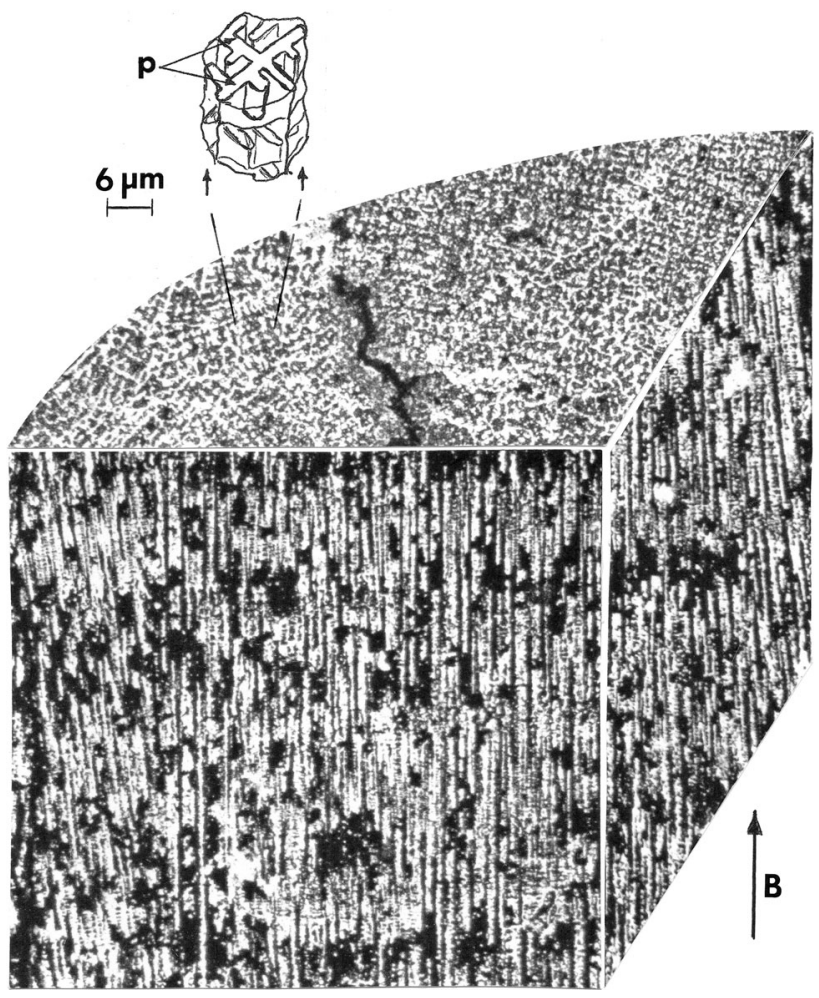

Fig. 23 3D optical microscope composite section for EBM-fabricated Rene $142 \mathrm{Ni}$-base superalloy showing microdendritic [001] columnar architecture. B denotes the build direction (z-axis). The inset sketch (top) shows these microdendritic columns, where "p" indicates the primary dendrite arms along [100] and [010]

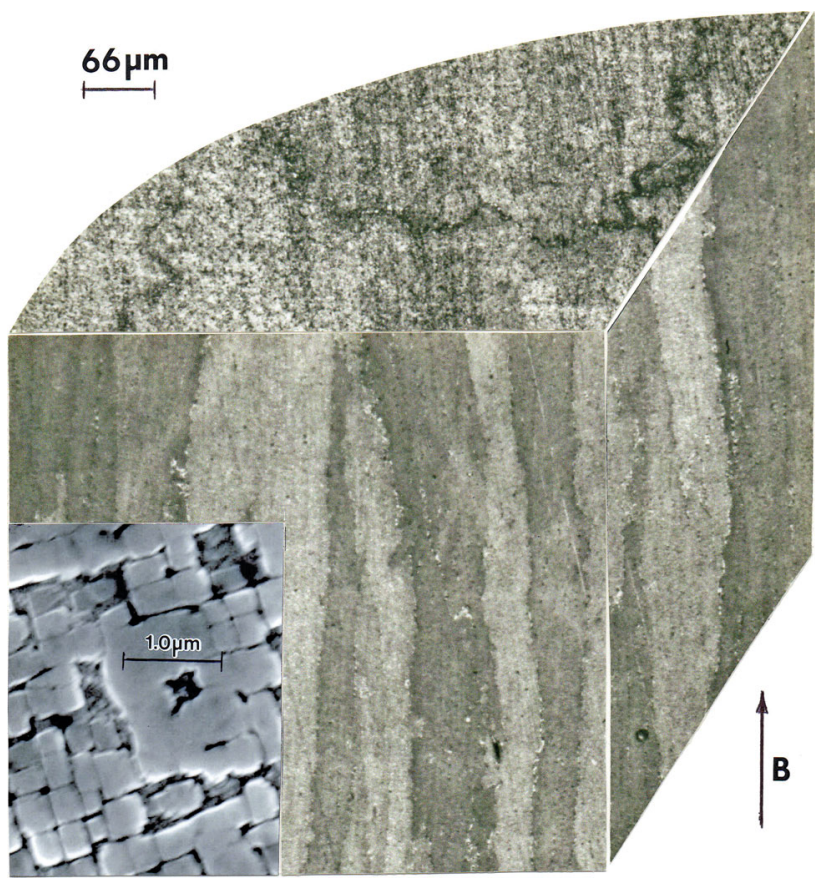

Fig. 24 Magnified view of columnar microstructure in Fig. 23 showing $\gamma^{\prime}$ precipitates in the magnified SEM image inset. B denotes the build direction 


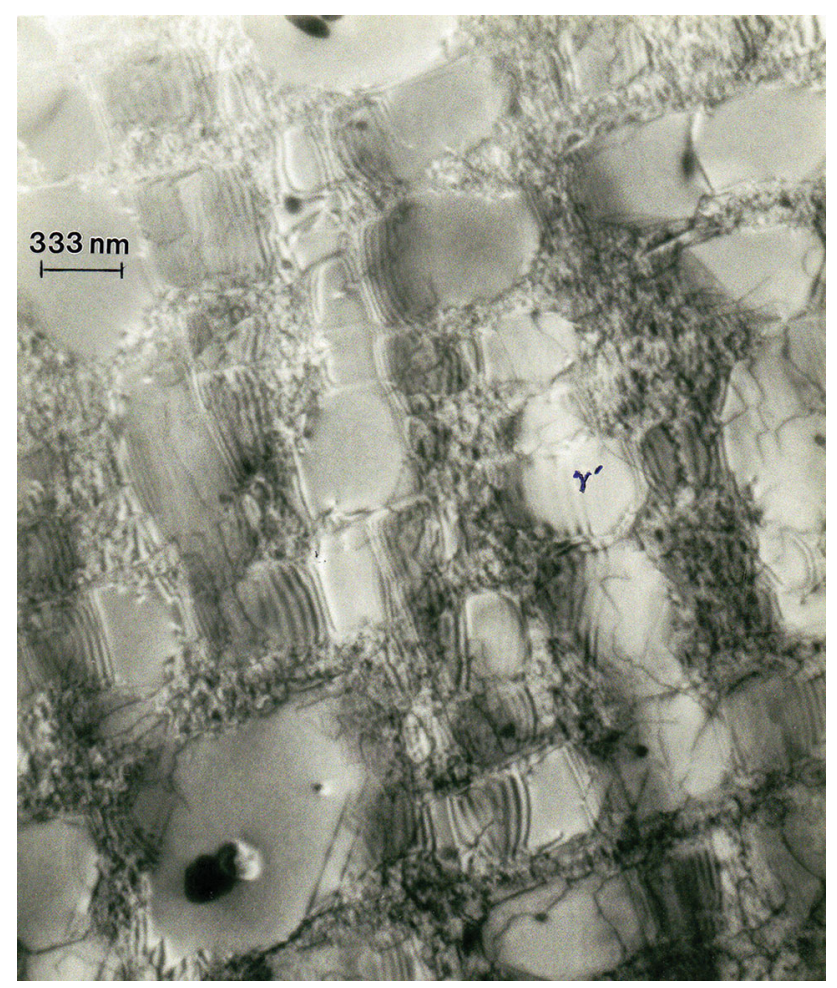

Fig. 25 TEM view of $\gamma^{\prime}$ cuboidal microstructure characterizing the inset in Fig. 24. Coherency fringe contrast at $\gamma / \gamma^{\prime}$ interfaces is intermixed with dislocation image contrast

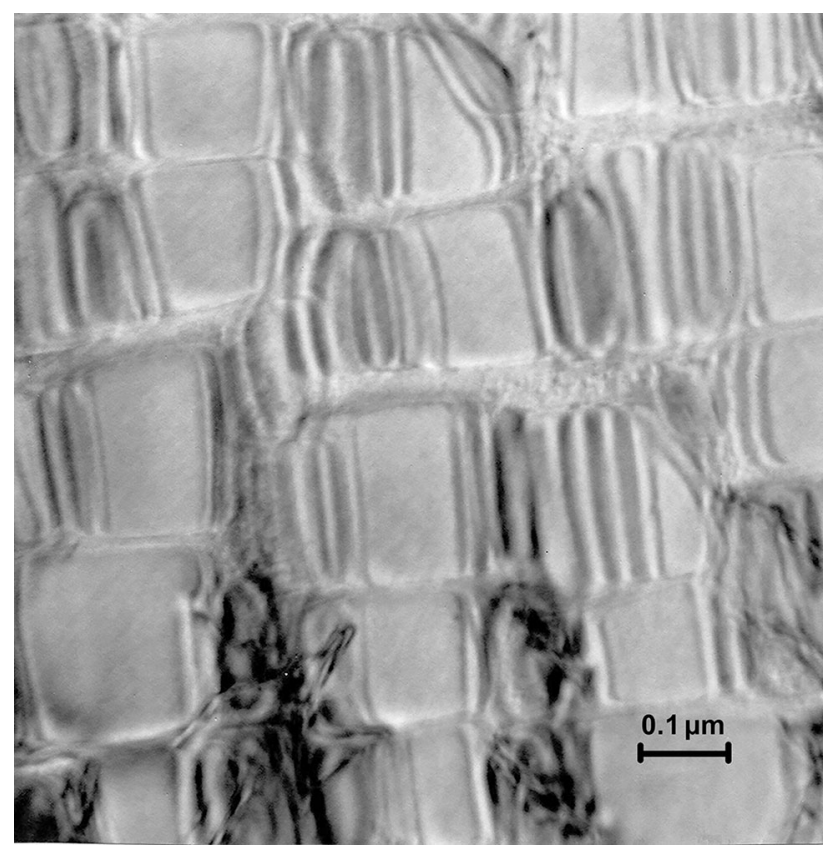

Fig. 26 TEM magnified and tilted view of region similar to Fig. 25 showing misfit contrast fringes at $\gamma / \gamma^{\prime}$ interfaces. Dislocation images are at no contrast diffraction conditions

and performance. But although aluminum and its array of alloys have low melting points in contrast to superalloys,

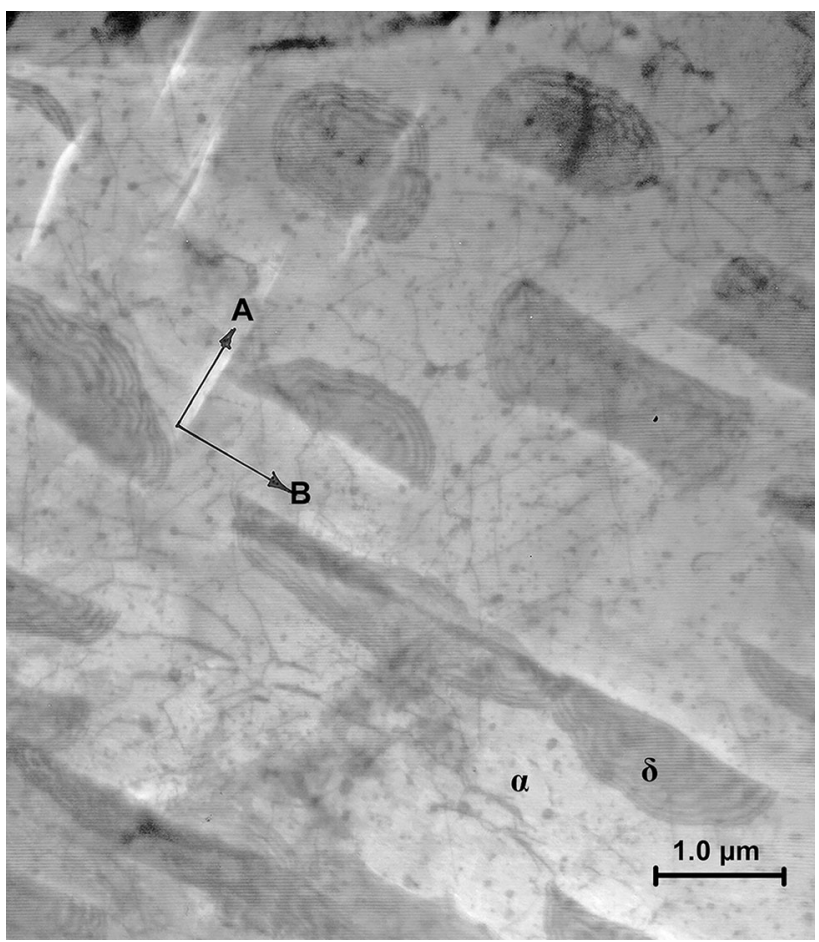

Fig. 27 TEM image for EBM-fabricated $\mathrm{Fe}\left(1535^{\circ} \mathrm{C}\right.$ melt) component showing delta $(\delta)$ phase (irregular) platelets coincident with the alpha $(\alpha)$ iron (bcc) (100) (a) and $\{101\}$ (b) planes. Adapted from Murr [21]

their fabrication by AM, especially powder bed processes, is especially challenging because of oxidation issues, thermal conductivity, and the fact that the heat of fusion for aluminum, the energy required for melting, is one of the highest for metals. For example, the latent heats of fusion for $\mathrm{Ni} \mathrm{Nb}, \mathrm{Fe}$, and $\mathrm{Cu}$ are 297, 285/kg 272, and $205 \mathrm{~kJ} / \mathrm{kg}$, respectively, while $\mathrm{Al}$ is $398 \mathrm{~kJ} / \mathrm{kg}$. For comparison, the corresponding ratios of (latent heat of fusion)/(melting temperature) are $0.59,0.20$, and $0.12 \mathrm{~kJ} / \mathrm{kg}{ }^{\circ} \mathrm{C}$ for $\mathrm{Al}, \mathrm{Ni}$, and $\mathrm{Nb}$, respectively. This requires special bed heating arrangements for aluminum and its alloys. In addition, aluminum is a fairly good thermal conductor and this feature complicates the thermal budget for powder melting and is also compensated by bed heating.

As noted earlier, Orme et al. [60,63] were among the first to experiment with aluminum and aluminum alloy AM using direct droplet deposition (Fig. 15). However, their products were characterized by grain sizes commensurate with droplet sizes and surrounded by a heavy oxide. Lousis et al. [95] described similar concerns for SLM of aluminum components. More recent powder bed (EBM) fabrication of Al-2024 and 7075 alloys by Mahale et al. [96] produced directional (columnar grain) microstructures composed of $\sim 20$-micron-diameter substructures (Fig. 29). Recent efforts describing SLM of Al-Si-Mg alloys [97] and related aluminum alloys [98, 99], as well as Al-6061, 2024, 


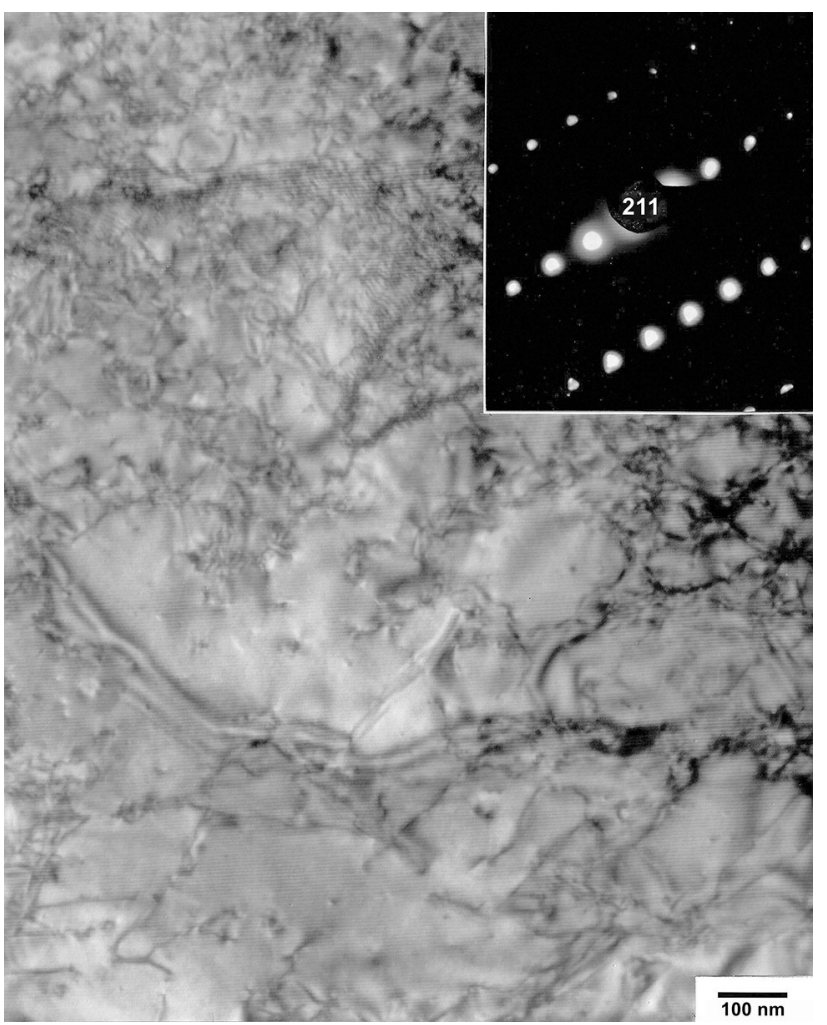

Fig. 28 TEM image of EBM-fabricated niobium component. The selected area electron diffraction (SAED) pattern inset shows a [211] bcc zone axis orientation. Adapted from Murr [21]

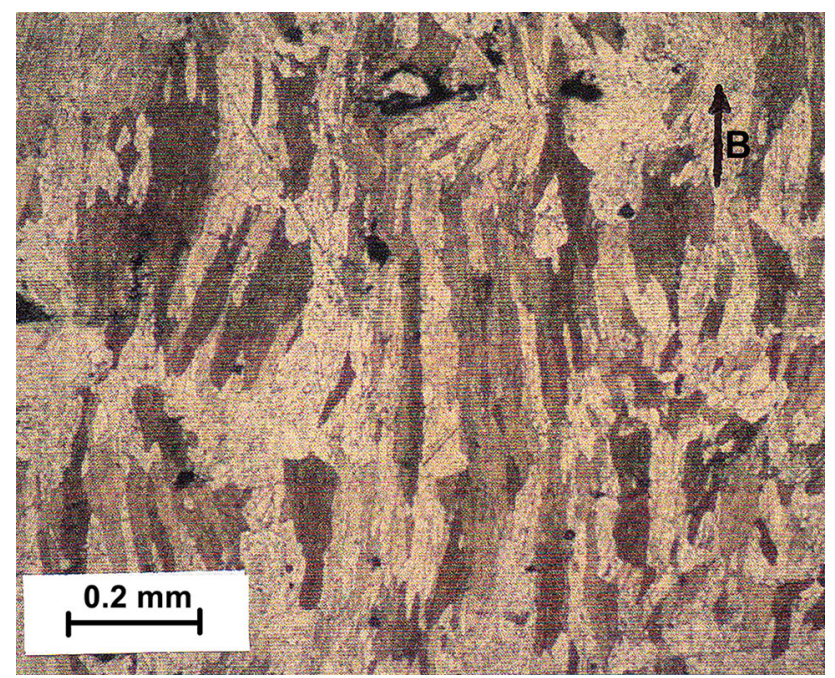

Fig. 29 Light microscope image showing columnar grains and substructure in Al-7075 alloy fabricated by EBM. B denotes the build direction. Adapted from Mahale et al. [96]

and 7075 by EBM have described challenges for AM of precipitation hardenable $\mathrm{Al}$ alloys where standard metallurgy treatments are not always applicable, although some post-processing heat treatments can be successful in some instances. Unfortunately, there are no systematic studies which have examined precipitation phenomena in AMfabricated aluminum alloys by TEM.

Although Fig. 29 shows columnar (directional) grain structure often typical for EBM fabrication (Figs. 5b, 14, 18, 21, 22 and 25), the precipitation microstructures are not visible. These may occur in precipitate columns where the thermo-kinetics associated with the melt zone columns are conducive to specific precipitation phenomena. It should be noted that just as in cast structures, grain refiners such as solute nanoparticles or other nanoparticles can be added to the powder bed to act as nucleating agents during layer melting, creating an equiaxed structure rather than columnar and microdendritic structure. These additions can also act as strengthening agents.

While precipitation in aluminum alloys can vary in morphology, crystallography, and composition, the more common alloys: 6061, 2024, and 7075 (see "Glossary of Alloy Compositions"), are heat-treated or tempered to produce a systematic evolution of precipitates: GP (Guinier-Preston) zones (composed of $\mathrm{Cu}$ atom clusters) $\rightarrow \theta^{\prime \prime}$ $\left(\mathrm{Al}_{3} \mathrm{Cu}\right.$ needles or platelets coincident (coherent) with fcc matrix $\{100\}$ planes) $\rightarrow \theta^{\prime}$ (larger platelets coincident (semi-coherent) with fcc matrix $\{110\}$ planes $) \rightarrow \theta$ (coarse, globular particles and platelet, non-coherent precipitates of various compositions which contribute minimally to strengthening). This $\theta$ sequence is specific to Al6061, while similar precipitation sequences occur for Al2024 and 2075 alloys depending on temper: Solutionizing (homogenizing), quenching, and aging [100]. For example, the optimum hardening in Al-6061 occurs for a T6 temper: homogenizing at $450{ }^{\circ} \mathrm{C}$ for $\sim 4 \mathrm{~h}$, quenching, and then aging at $170{ }^{\circ} \mathrm{C}$ for $24 \mathrm{~h}$, producing fine needles and rods creating a Widmanstatten structure. Similar temper treatments produce optimum strength in 2024 and 7075 aluminum alloys as well. Natural aging for some $\mathrm{Al}$ alloys can also provide for an increase in mechanical properties without concern for oxidation and other problems. Comparative tensile strengths typically achieved are: 6061 (0.3 GPa), 2024 (0.47 GPa), and 7075 (0.57 GPa).

Figures 30 and 31 illustrate a range of precipitate features in friction-stir-welded Al-6061 [101]. While frictionstir welding (FSW) does not incur melting, temperatures vary from a maximum at the weld zone $\left(0.8 T_{\mathrm{M}}\right.$, where $T_{\mathrm{M}}$ is the absolute melting temperature) to more systematic cooling throughout the stir-affected zone. These thermomechanical variances produce a full range of precipitation throughout the weld zone as shown typically in the examples of TEM microstructure image in Figs. 30 and 31.

Jacobs [102] in very early TEM studies (nearly a half century ago) has illustrated Guinier-Preston zone structures and other precipitation phenomena in aluminum alloys in great detail, while more recent descriptions of heat treatments and associated precipitation phenomena for 
Fig. 30 TEM images showing $\{100\}$ coincident precipitates in FSW 6061 aluminum.

Diffraction pattern insets are [100] zones. (a) and (b) show Guinier-Preston zone precipitates which evolve as copper-rich clusters in $\{100\}$ planes. (c) and (d) show platelet evolution $\left(\theta^{\prime}: \mathrm{Al}_{2} \mathrm{Cu}\right)$ in $\{100\}$ planes. Adapted from Murr [22], courtesy of Springer
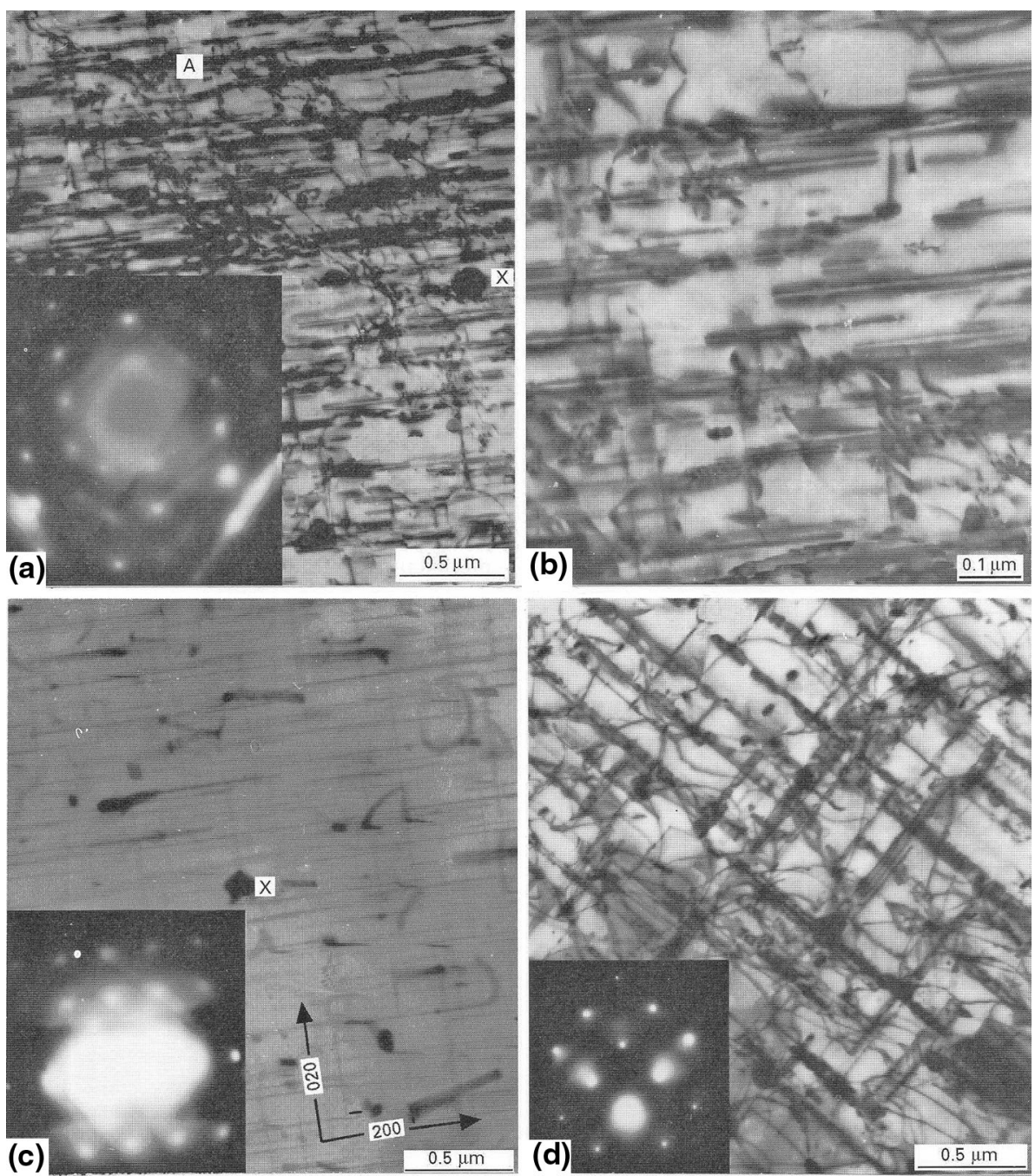

aluminum alloys, and illustrated generally in Figs. 30 and 31 for aluminum 6061, can be found in Wang and Starink [103] and Ber et al. [104].

\section{Biomedical Applications for AM Open- Cellular Metal Products}

One of the most apparent advantages of $\mathrm{AM} / 3 \mathrm{D}$ printing technologies, especially powder bed melting processes, (Fig. 1c) involves the ability to produce complex, metal products having open-cellular mesh or foam structures, such as that represented in Fig. 11, and complex, articulated internal channel structures as shown in Fig. 12. Figure 32 illustrates a few examples of CAD models and EBM-fabricated components built from unit cell elements. Such processing software is available from several software suppliers. Foam models as shown in Fig. 32d have their origin in Kelvin cells [105], or micro-CT scans of existing foam structures as described by Murr et al.
[106, 107] for biomedical materials applications. Heinl et al. [108], among others, have also described similar interconnected, porous implant structures fabricated by EBM.

While mesh and foam structures in orthopedic implant design can be fabricated with strut or ligament sizes, as well as pore sizes, as small as $0.2 \mathrm{~mm}$, optimal bone cell ingrowth into such porous components has been observed to be around $0.4 \mathrm{~mm}$ (or larger) to bridge the pores through cytoplasmic extensions and migration [109-111] and to allow for vascular structures to form in order to provide a living environment. Although bone cell ingrowth into porous implants provides for cement less and more stable insets, porous implants also provide greater mechanical stability by significant reductions in the elastic (Young's) modulus, thereby significantly reducing or eliminating stress shielding caused by significant differences in solid metal implant elastic moduli (210 GPa for $\mathrm{Co}-\mathrm{Cr}-\mathrm{Mo}$ and $110 \mathrm{GPa}$ for $\mathrm{Ti}-6 \mathrm{Al}-4 \mathrm{~V}$ ) and trabecular (soft) and cortical (hard) bone which range from 0.1 to 1 


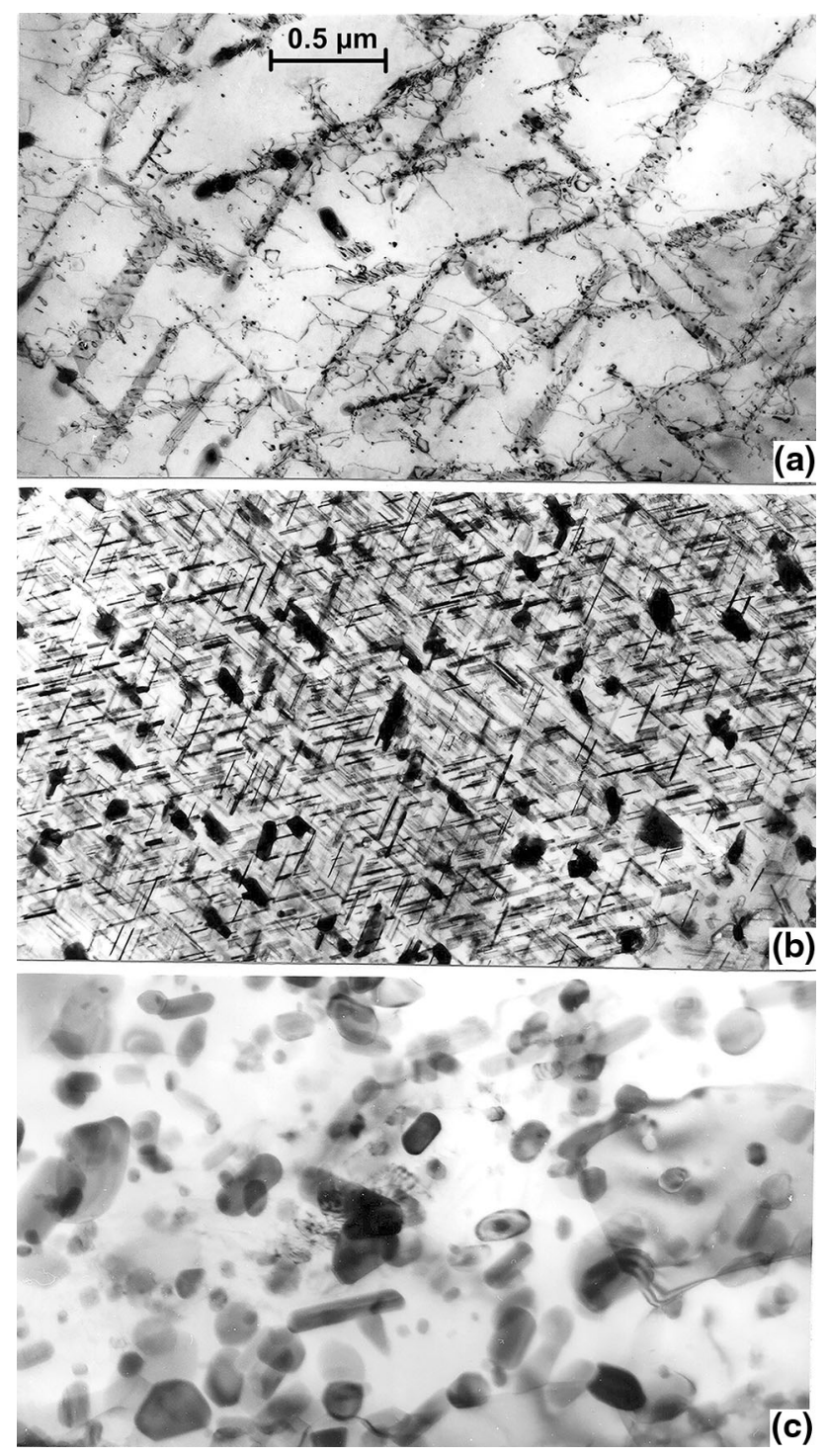

Fig. 31 TEM images of precipitation evolution in FSW 6061-aluminum alloy stir-affected zone. (a) $\theta^{\prime}$ platelets in $\{110\}$ planes. (b) Dense needle precipitates in $\{110\}$ planes creating Widmanstatten patterns. (c) Random, globular, and platelet non-coherent (theta) precipitates. Note magnification is given in (a). Adapted from Murr [22], courtesy of Springer

and 18 to $20 \mathrm{GPa}$, respectively. This is due to the fact that a wide range of materials, including metals and alloys, have been observed to follow the classical Gibson-Ashby relationship [112]:

$E / E_{r m s}=C\left(\rho / \rho_{\mathrm{s}}\right)^{\mathrm{n}}$

where $E_{\mathrm{s}}$ and $E$ are the solid and porous Young's modulus, $\rho_{\mathrm{s}}$ and $\rho$ are the corresponding densities, and $C$ is $\sim 0.9$ and $n \cong 2$. This is particularly true for $\mathrm{Co}-\mathrm{Cr}$ alloy and $\mathrm{Ti}-$ $6 \mathrm{Al}-4 \mathrm{~V}$ alloy mesh and foam products fabricated by EBM as shown in data reproduced in Fig. 33.
There has also been some effort to produce biologically compatible Ti alloys having significantly lower Young's modulus than Ti-6Al-4V (110 GPa) [113], and recent work by Hao et al. [114] and Hernandez et al. [115] has described a beta-phase Ti-24 Nb-4 Zr-7.9 Sn alloy (Ti2448) having a Young's modulus as low as $42 \mathrm{GPa}$. Figure 34 shows a TEM image of this alloy containing $\alpha^{\prime \prime}$ martensite. This alloy, following the Gibson-Ashby relationship in Eq 3, would allow reduced open-cellular pore sizes and increased mesh or ligament thicknesses, resulting in increased implant density, but maintaining requisite stress shielding properties. While this may not be a significant consequence in implant structures not incurring large operating stresses, such as maxillofacial or skull implants implicit in Fig. 35, it would make a difference for implants undergoing fatigue and compressive stress environments, such as knee implants (Fig. 36) or hip implants, especially in the femoral stem or in long rod implants. Figure 37 shows some related fatigue and compression strength data for Ti-6Al-4V open-cellular mesh components fabricated by EBM [116, 117]. The implications of these results are that for the same maximum fatigue and compression strength shown for Ti-6Al-4V (Ti64) at $\sim 7$ GPa Young's modulus, the corresponding modulus for porous Ti-24 Nb-4 Zr-7.9 Sn (Ti2448) could be less than half that value.

The compressive collapse strength, $\sigma^{*}$, for open-cellular structures is given generally by $[112,116]$ :

$\sigma * / \sigma_{s}=c^{\prime}\left(\rho / \rho_{\mathrm{s}}\right)^{\mathrm{n}}$

where $\sigma_{\mathrm{s}}$ is the solid compressive strength, $\mathrm{c}^{\prime}$ is a constant, and $n \sim 1.5$. The constant $\mathrm{c}^{\prime}$ can vary for mesh or foam structures from 0.1 to 1 and tends toward 1 for closed-cell structures where the cell faces and trapped gases can enhance compressive (crushing) strength. Li et al. [117] have also recently shown that reticulated $\mathrm{Ti}-6 \mathrm{Al}-4 \mathrm{~V}$ mesh structures with different build elements (Fig. 32a-c) can affect the compressive deformation behavior which is related to coupled mechanisms of buckling and bending.

Although metal implants are nearly a century old, the use of electron or laser melt fabricated, porous appliances of various types has been very limited in the USA (hip appliances and cranial implants as in Fig. 35) and other parts of the world [119-121]. However, significant surgical implant applications began in China over the past decade [122], and many Chinese hospitals are using powder bed processing (SLM and EBM) to fabricate a wide variety of patient-specific, open-cellular implants for orthopedic surgical and related procedures. Li et al. [123] and Murr $[107,124]$ have recently illustrated clinical examples of novel implant successes. Similar examples have also been described by Ackland et al. [125] for orthopedic programs in Australia. 


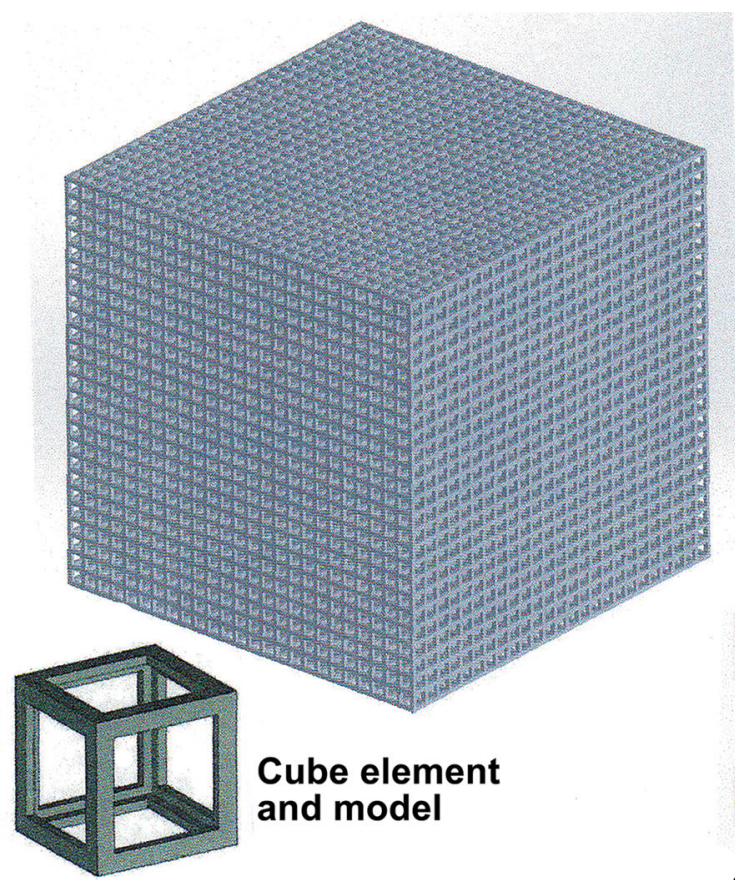

(a)

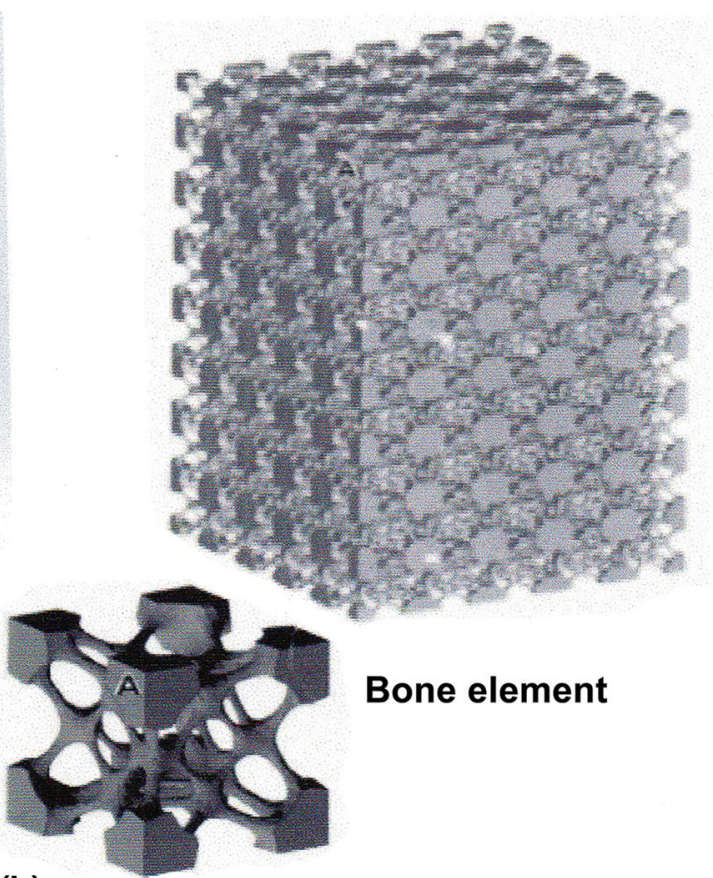

(b)

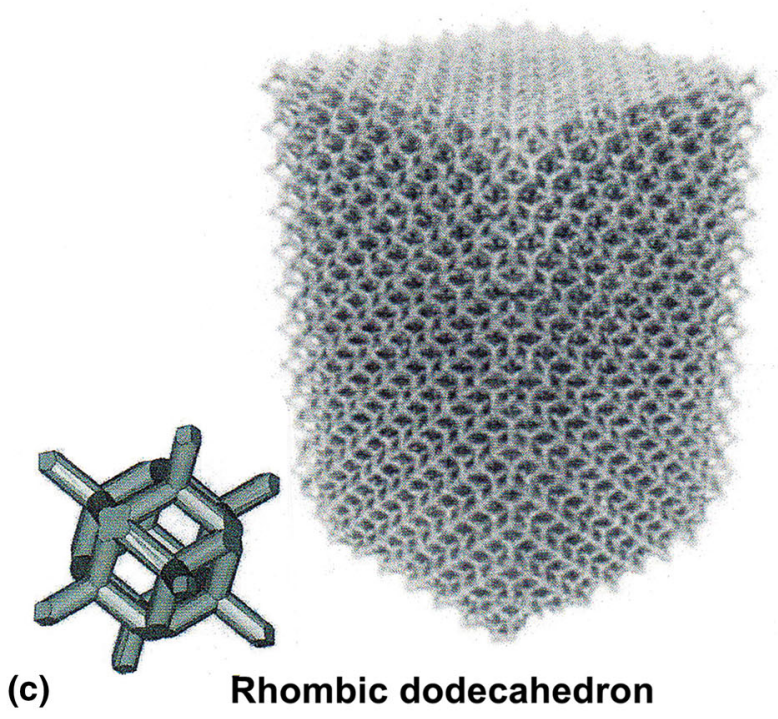

Fig. 32 Open-cellular mesh and foam models and EBM-fabricated components (Ti-6Al-4V). (a) Cubic unit cell. (b) Materialise software bone element. (c) Rhombic dodecahedron unit cell and

\section{Mechanical Properties and Comparisons of SLM and EBM-Fabricated Metals and Alloys}

Beginning with Fig. 2, laser and electron beam AM processes are shown to adhere to the well-tested and welldocumented materials science and engineering paradigm relating structures, properties, processing, and performance of materials [22]. In the case of powder bed AM

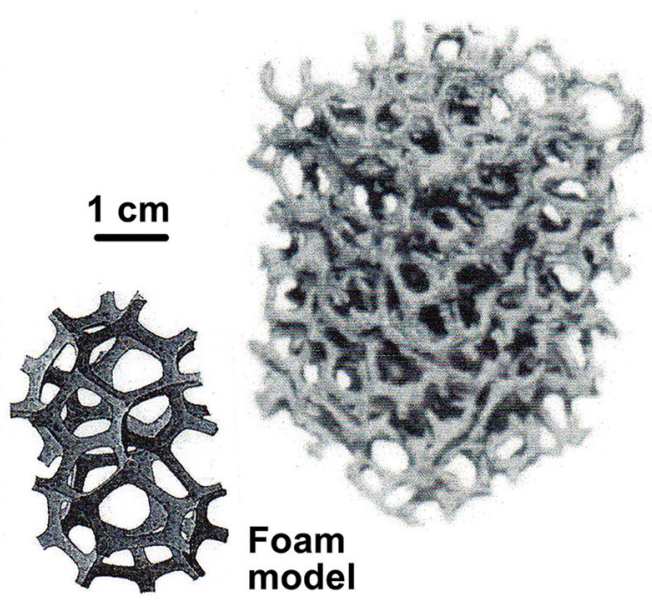

(d)

fabricated product. (d) Foam model and fabricated product. Adapted from Murr [107], courtesy of Elsevier

fabrication, component size impacts scaling relationships which differ for electron or laser beam interactions as well as scan strategies and process environment (gas or vacuum) cooling issues (Fig. 6). Figures 9 and 10 illustrate simple size effects in cooling-related microstructures for Ti-6Al$4 \mathrm{~V}$, and these relate to the structures and related properties of open-cellular component applications in biomedical appliances described above and illustrated in Figs. 35 and 36. In this sense, Figs. 33 and 37 show related mechanical 


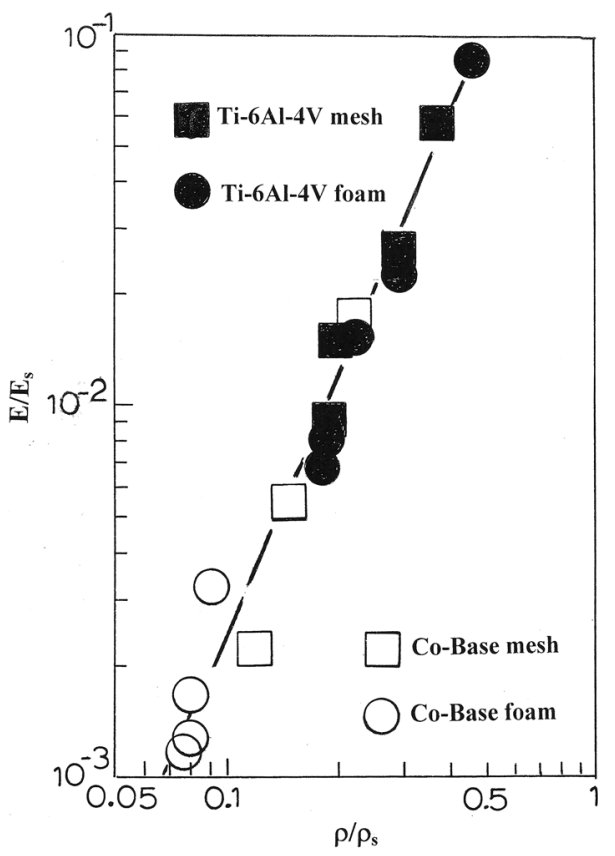

Fig. 33 Relative Young's modulus $\left(E / E_{s}\right)$ vs. relative density $\left(\rho / \rho_{s}\right)$ plots for Ti-6Al-4V and $\mathrm{Co}-\mathrm{Cr}-\mathrm{Mo}$ alloy mesh and foam samples fabricated by EBM

properties for $\mathrm{Ti}-6 \mathrm{Al}-4 \mathrm{~V}$ as these apply strategically to biomechanical compatibility. Weissmann et al. [126], among others, have recently illustrated differences in roughness and other related features for Ti-6Al-4V struts for SLM and EBM-fabricated mesh structures. Surface finish, especially for small geometries, is better for SLM than EBM in most cases. Where roughness is related to crack nucleation, mechanical properties and performance can be affected (Fig. 10a).

Figures 33 and 37 illustrate the ability to systematically manipulate the elastic (Young's) modulus and related mechanical properties such as compressive and fatigue strength for open-cellular structures, for powder bed AM processes. Gibson and Ashby [116] have demonstrated Eq 3 to be applicable for a wide range of open-cellular materials, including aluminum, and Ramirez et al. [127] have demonstrated this response for the Young's modulus for EBM-fabricated, open-cellular copper, while Murr et al. [128] have shown that the elastic modulus for both $\mathrm{Co}-\mathrm{Cr}-$ Mo and Inconel 625 alloys fabricated as open-cellular structures also follow Eq 3, with $n \cong 2$.

It is interesting to note that in many instances, metals and alloys have elastic moduli that tend to increase with melting temperature: $\mathrm{Al}$ and $\mathrm{Al}$ alloys such as 6061, 2024, and 7075 (see "Glossary of Alloy Compositions"), where $E=70 \mathrm{GPa}$; $\mathrm{Cu}$ where $E=116 \mathrm{GPa}$; Ni, where $E=170$; 316 stainless steel, where $E=195 \mathrm{GPa} ; \mathrm{Fe}$, where $E=210 \mathrm{GPa}$; Inconel 718 and 625 , where $E \cong 212 \mathrm{GPa}$. However, as in many physical phenomena, exceptions

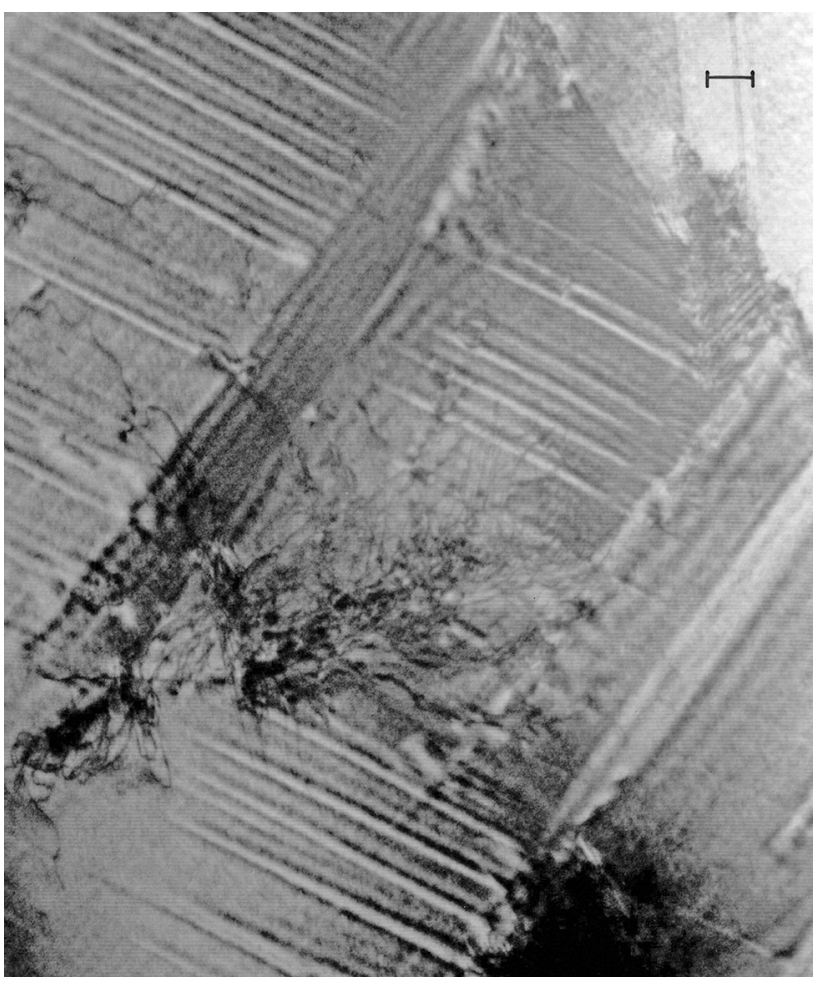

Fig. 34 TEM image showing $\alpha^{\prime \prime}$ (orthorhombic) martensite in EBMfabricated $\mathrm{Ti}-24 \mathrm{Nb}-4 \mathrm{Zr}-7.9 \mathrm{Sn}$ alloy. The magnification marker represents $500 \mathrm{~nm}$

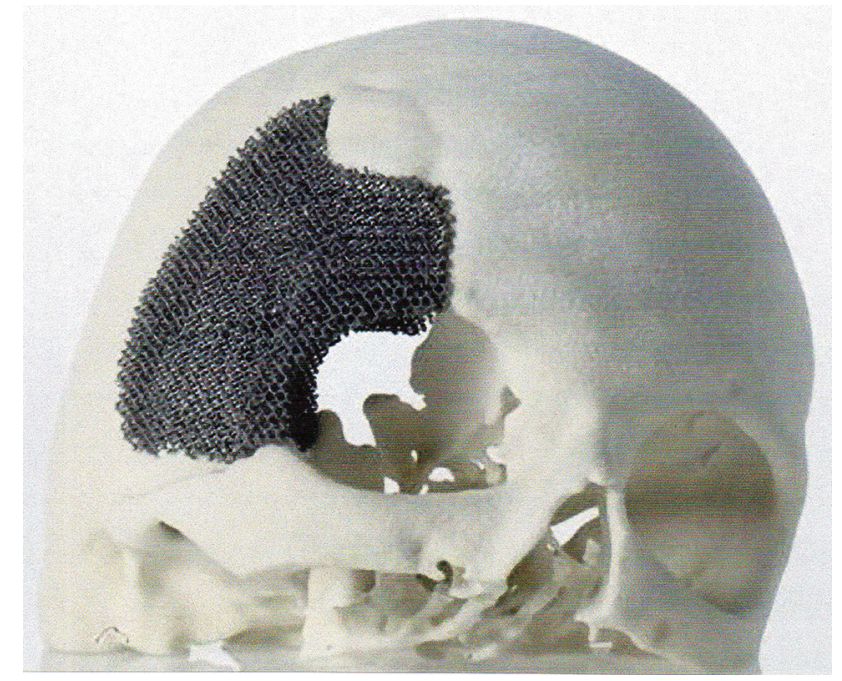

Fig. 35 Reticulated mesh $\mathrm{Ti}-6 \mathrm{Al}-4 \mathrm{~V}$ skull replacement prototype fabricated by EBM

occur such as in the case of niobium, where $E=105 \mathrm{GPa}$. Similarly, there is generally a linear relationship between the bulk (solid) elastic modulus and the surface free energy for metals [59].

It is generally shown that the mechanical (engineering) properties of metals and alloys (e.g., yield stress, tensile (ultimate) stress, elongation and hardness) are as good or 
Fig. $36 \mathrm{Co}-\mathrm{Cr}-\mathrm{Mo}$ alloy femoral (knee replacement) implant. (a) and (c) show outer (contact) surface finish and inner (femoral contact) mesh structure. $\mathrm{F}$ and $\mathrm{T}$ in $\mathrm{X}$-ray image of (b) denote femur and tibia bones. The highly crosslinked polyethylene inset (artificial meniscus) is invisible to $\mathrm{x}$-rays. Adapted from Murr [107], courtesy of Elsevier

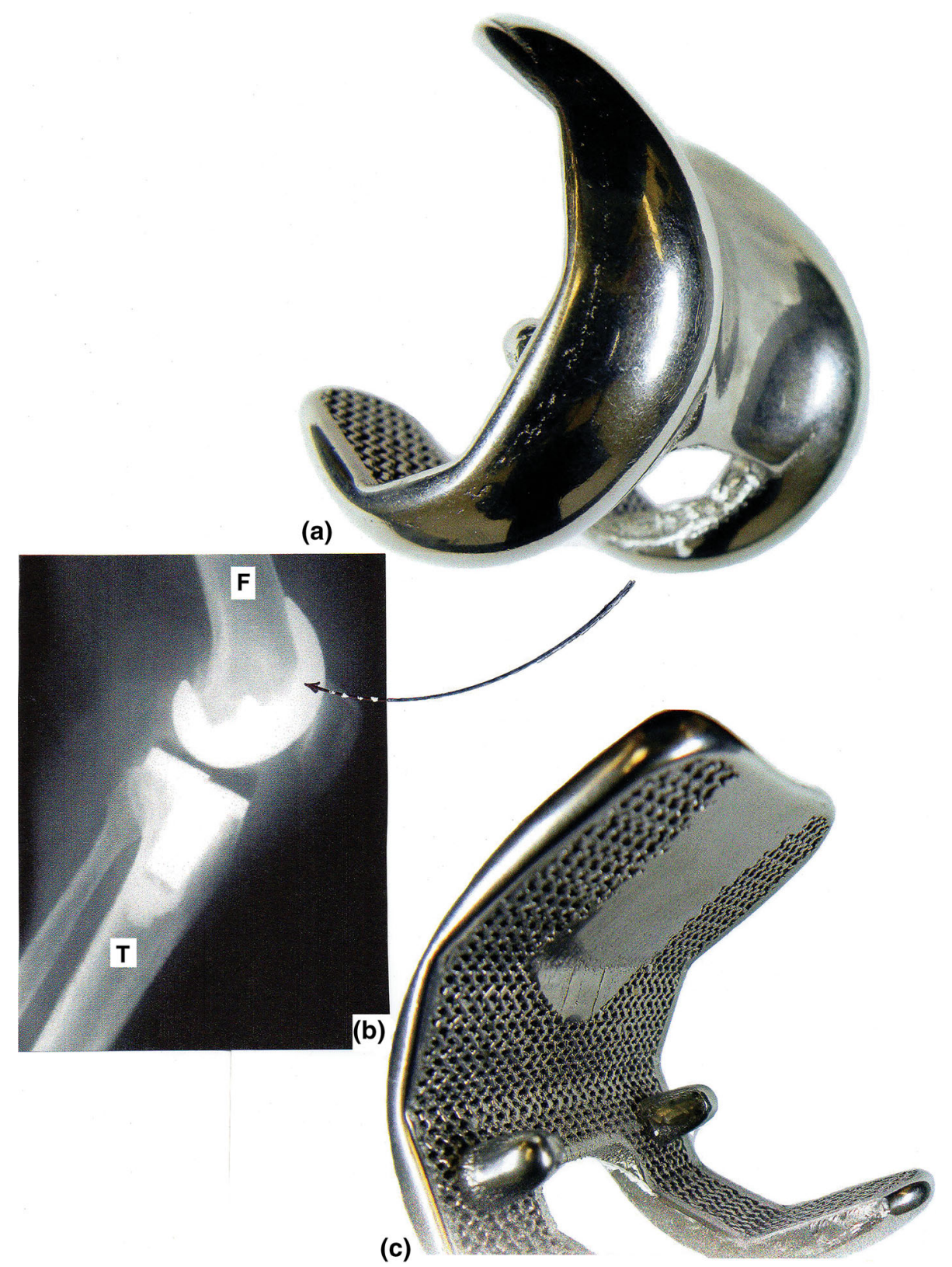

(c) better in as-fabricated SLM or EBM products as more traditionally cast, wrought, or forged products [129], and also generally related to the solid (fully dense) product elastic modulus. While microstructure is also generally related to mechanical properties as in solid products, some variances can occur for directional architectures as shown in Figs. 14, 18, 21, and 23, especially with regard to the tensile (or stress geometry) axis relative to these directional architectures (or the build direction: $\mathrm{z}$-axis versus $\mathrm{x}$ - and y-axes).

Figures 38, 39, and 40 compare the mechanical properties for a number of EBM- and SLM-fabricated, solid (fully dense) metal alloy products. Comparing Fig. 38a and b (left portion of graph), both EBM and SLM produce Ti-
$6 \mathrm{Al}-4 \mathrm{~V}$ products having $0.2 \%$ engineering offset (strain) yield stress and ultimate tensile stress (UTS) similar to wrought or cast products. Similar results were also recently demonstrated by Zhao et al. [129], although elongation is notably higher for EBM and HIPed Co-Cr-Mo alloy. Figure 39a shows similar properties for annealed wrought and EBM (z)-fabricated Inconel 625 alloy, while the $\mathrm{EBM}+\mathrm{HIP}$ product also exhibits greater elongation. SLM and SLM + HIPed Inconel 625 alloy products in Fig. 39b show similarities, although the as-fabricated SLM products exhibit considerably increased hardness values over corresponding EBM (z)-fabricated products. These differences are somewhat consistent with differences in residual (precipitation) microstructures for EBM versus SLM-fabricated 


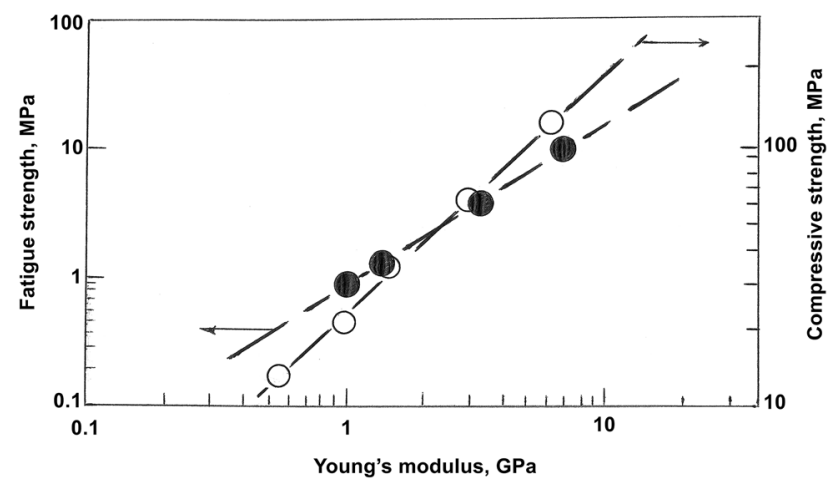

Fig. 37 Plots of fatigue and compressive strength vs. Young's modulus for $\mathrm{Ti}-6 \mathrm{Al}-4 \mathrm{~V}$ mesh components (varying density) fabricated by EBM. Data from Li et al. [117, 118]
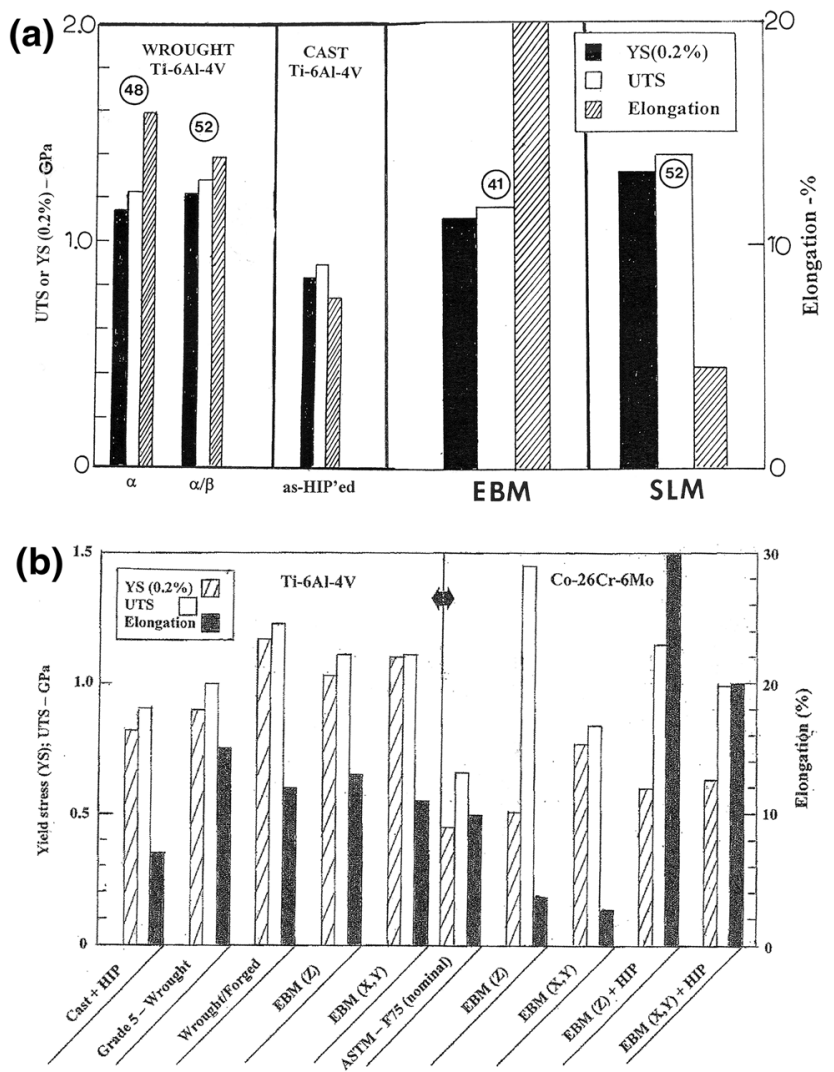

Fig. 38 Comparisons of mechanical properties for EBM and SLM $\mathrm{Ti}-6 \mathrm{Al}-4 \mathrm{~V}$ (a) and EBM of $\mathrm{Ti}-6 \mathrm{Al}-4 \mathrm{~V}$ and $\mathrm{Co}-\mathrm{Cr}-\mathrm{Mo}$ superalloy (b). In (a) Ti-6Al-4V samples fabricated in the $\mathrm{z}$-axis (build) direction are compared with wrought and cast alloys. The circled numbers refer to Rockwell C scale hardness (HRC). In (b), EBM Ti$6 \mathrm{Al}-4 \mathrm{~V}$ and $\mathrm{Co}-\mathrm{Cr}-\mathrm{Mo}$ alloys are compared in the $\mathrm{z}$-axis and $\mathrm{x}-, \mathrm{y}-$ axis orientations. ASTM-F75 is Co-Cr-Mo cast + HIP. HIP refers to anneal at $1200{ }^{\circ} \mathrm{C} @ 4 \mathrm{~h}$ in $0.1 \mathrm{GPa} \mathrm{Ar}$ atmosphere. (a) is adapted from Murr et al. [130]. (b) is adapted from Murr [21], courtesy of Elsevier

Inconel 625 alloy [131]. In Fig. 40a, SLM (z)-fabricated Inconel 718 alloy exhibits similar mechanical properties in comparison with cast and forged products, while Fig. 40b
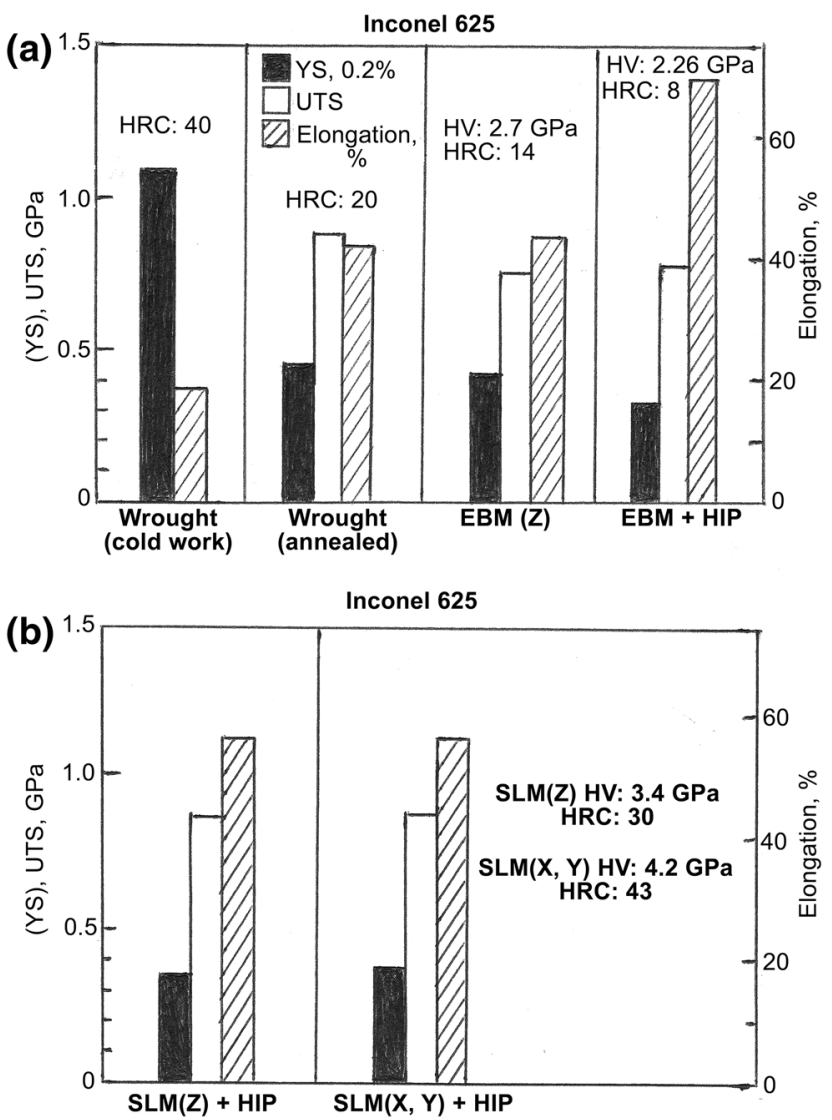

Fig. 39 Comparisons of mechanical properties for EBM (a) SLM and (b) Inconel 625 alloy. (a) shows EBM z-axis properties as-fabricated and after HIP, compared with wrought products. Corresponding Vickers (HV) and Rockwell C scale (HRC) microindentation hardness values are noted (note HV $100 \sim 1 \mathrm{GPa}$ ). (b) compares SLM + HIP properties. Corresponding, as-fabricated SLM hardness values are shown. YS $(0.2 \%)$ refers to $0.2 \%$ engineering strain offset yield point. Based on data in Amato et al. [131]

shows a significant increase in yield stress for SLM (z) 316L stainless steel in contrast to forged 316L stainless steel. The corresponding Vickers microindentation hardness (HV) values corroborate this difference.

In Fig. 39b, there is a notable difference between the $\operatorname{EBM}(\mathrm{z})$ and $\operatorname{EBM}(\mathrm{x}, \mathrm{y})$ Co-Cr-Mo alloy components: increase in yield and decrease in UTS. This can be rationalized in terms of the directional (z-axis) carbide architecture, while EBM $(\mathrm{x}, \mathrm{y})$ denotes a tensile axis perpendicular to this carbide architecture. However, when the architecture is eliminated by HIP (EBM (z) and (EBM $(\mathrm{x}, \mathrm{y}))+\mathrm{HIP}$ for $\mathrm{Co}-\mathrm{Cr}-\mathrm{Mo})$, the yield stress is essentially the same. Generally, it appears that relationships between microstructure and properties for more conventionally fabricated metals and alloys (cast, wrought, forged) are also characteristic of SLM and EBM-fabricated metals and alloys. The differences are that the scan strategies and especially the melt volumes in AM-fabricated products provide a unique thermo-kinetic environment often 

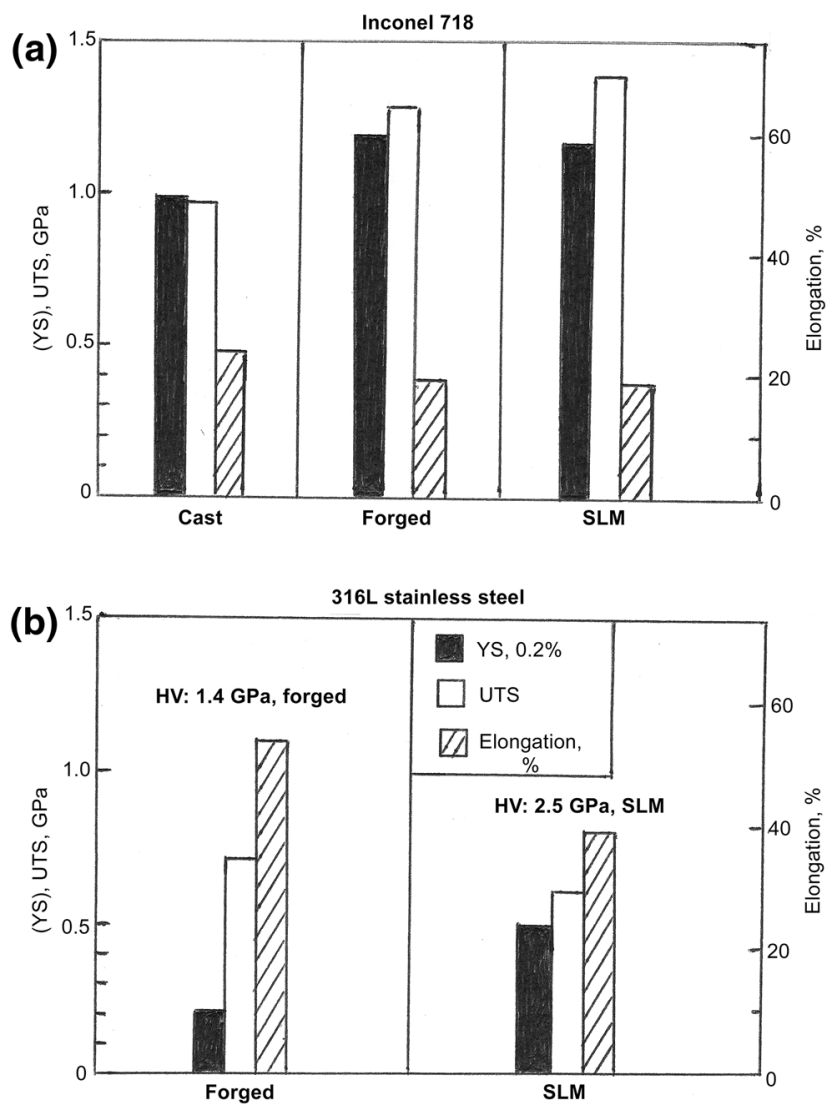

Fig. 40 Comparison of mechanical properties for conventional and SLM-fabricated Inconel 718 alloy (a) and 316L stainless steel (b). YS $(0.2 \%)$ is $0.2 \%$ engineering strain offset yield stress. Vickers (HV) microindentation hardness is shown in (b) (note HV $100 \sim 1 \mathrm{GPa}$ ). (a) is based on data in Trosch et al. [132]. (b) is based on data in Sing et al. [133]

conducive to specific and unique microstructures and directional architectures composed of these microstructures. As a consequence, the proper selection of scan strategies and parameters may produce optimized or specific microstructures which are only achieved in more conventional metal and alloy products by post process heating treatments and treatment schedules.

\section{Discussion and Summary}

It is aphoristic to note that metallography, considered to be the birth of applied microscopy, had its origins in early work (1863) of Henry Clifton Sorby, who was the first to etch (with nitric acid) iron and steel to reveal its microstructure as observed by light microscopy [134-136].
Using this technique, Sorby was the first to show that small carbon additions were responsible for the strength of steel, paving the way for steel mass production. This novelty in observing microstructural features in iron is illustrated in Fig. 27 which shows nano-thin delta $(\delta)$ iron platelets formed by rapid cooling in both the atomized, precursor powder and preserved in EBM-fabricated components [90]. Similarly, precipitation phenomena crucial for creep behavior optimization in very early (ca. 1965) Ni-base superalloys have also been observed in EBM- and SLMfabricated products using metallographic imaging (Figs. 21, 22, 23, 24, 25, and 26), while Figs. 30 and 31 provide prospects for observing a plethora of precipitation and precipitation evolution in popular aluminum alloys, which are becoming increasingly of interest in AM processes, especially for complex, small products. Surely, without metallographic guidance, great advances in manipulating microstructures in optimizing performance characteristics of metals and alloys over the past century or more would not have been possible. Similarly, and as outlined briefly in this review, metallography will play a vital role in the fabrication and performance optimization of AM-fabricated metals and alloys.

Without metallographic diagnosis, AM product processing strategies are difficult if not impossible to develop in the same way microstructure evolution has been, and continues to be crucial for the optimal processing and performance design for more conventional metal and alloy manufacturing. It has been demonstrated in this review that metallography, as applied microscopy involving light and electron microscopies, must continue to play a central role in AM/3D printing of metal and alloy products. The long tradition and expectation for structure (especially microstructure)-property relationships of AM-processed parts to be as good or better than cast, wrought, or forged products, as these apply to conventional processing of metals and alloys, continue to be vindicated. These features are supported in the range of SLM- and EBM-fabricated alloys shown in the graphical representations in Figs. 38, 39 , and 40 . However, because of the unique thermo-kinetic features within the broad spectrum of AM, there are many novel microstructures and microstructural architectures unique to AM processes. These are often responsible for enhanced AM mechanical properties in contrast to more conventional manufacturing process mechanical properties represented in examples provided in Figs. 38, 39, and 40. 
Acknowledgments The author is grateful for contributions to this review by many students and colleagues over the past 50 years. Many of these have been acknowledged in the figure captions and other references in the narrative. Special thanks to Dr. Chris Bagnall who critically reviewed the manuscript and contributed to valuable insights.

\section{Glossary of Abbreviations and Acronyms}

\begin{tabular}{ll}
\hline AM & Additive (layer) manufacturing \\
bcc & Body-centered cubic crystal structure \\
CAD & Computer-aided design \\
DMD & Direct metal deposition (also same as LENS) \\
E & Elastic modulus or stiffness $(E=$ stress/strain) \\
EBM & Electron beam melting \\
fcc & Face-centered cubic crystal structure \\
GPa & Gigapascal (109 Pascals); 1 GPa $\sim$ 100 HV $\sim 100$ \\
& kgf/mm ${ }^{2}$ \\
hcp & Hexagonal close-packed crystal structure \\
HIP & Hot isostatic pressing (thermal treatment under \\
& pressure) \\
HRC & Rockwell hardness C scale \\
HV & Vickers hardness (microindentation hardness, \\
& sometimes designated VHN-Vickers hardness \\
& number) $\sim$ 0.01 GPa \\
LENS & Laser-engineered net shaping (laser additive \\
manufacturing process) \\
SH Stainless & Precipitation hardened stainless steel \\
SAED & Selected area electron diffraction \\
SEBM & Selective electron beam melting \\
SEM & Scanning electron microscopy \\
SLM & Selective laser melting \\
SLS & Selective laser sintering \\
TEM & Transmission electron microscopy \\
TM & Thermo-mechanical treatments \\
XRD & Ultimate tensile strength \\
YS & X-ray diffraction/x-ray diffractometry \\
&
\end{tabular}

Glossary of Alloy Compositions (wt.\%)

\begin{tabular}{|c|c|}
\hline Al-2024 & $\begin{array}{l}0.05 \mathrm{Si}, 0.5 \mathrm{Fe}, 0.5 \mathrm{Cu}, 3.14-4.9 \mathrm{Mn}, 1.2-1.8 \mathrm{Mg} \text {, } \\
0.1 \mathrm{Cr}, 0.25 \mathrm{Zn}, 0.15 \mathrm{Ti}, 0.15 \text { other, balance Al }\end{array}$ \\
\hline Al-6061 & $\begin{array}{l}0.4-0.8 \mathrm{Si}, 0.7 \mathrm{Fe}, 0.15-0.4 \mathrm{Cu}, 0.15 \mathrm{Mn}, 0.8-1.2 \mathrm{Mg} \text {, } \\
0.04-0.35 \mathrm{Cr}, 0.25 \mathrm{Zn}, 0.15 \mathrm{Ti}, 0.15 \text { other, balance } \\
\text { Al }\end{array}$ \\
\hline Al-7075 & $\begin{array}{r}0.4 \mathrm{Si}, 0.5 \mathrm{Fe}, 1.2-2.0 \mathrm{Cu}, 0.3 \mathrm{Mn}, 2.1-2.9 \mathrm{Mg}, 0.18- \\
0.28 \mathrm{Cr}, 5.1-6.1 \mathrm{Zn}, 0.2 \mathrm{Ti}, 0.15 \text { other, balance } \mathrm{Al}\end{array}$ \\
\hline CMSX-4 Alloy & $\begin{array}{l}\text { Ni-base superalloy; } \mathrm{Ni}, 10 \mathrm{Co}, 6.5 \mathrm{Cr}, 6 \mathrm{~W}, 6 \mathrm{Ta} \text {, } \\
\text { 5.6Al, } 1 \mathrm{Ti}, 3 \mathrm{Re}, 0.6 \mathrm{Mo}, 0.1 \mathrm{Hf}\end{array}$ \\
\hline $\begin{array}{l}\mathrm{Co}-\mathrm{Cr} / \mathrm{Co}-\mathrm{Cr}- \\
\mathrm{Mo}\end{array}$ & $\begin{array}{l}\text { Co-base superalloy; } \mathrm{Co}, 26 \mathrm{Cr}, 6 \mathrm{Mo}, 0.7 \mathrm{Si}, 0.5 \mathrm{Mn} \text {, } \\
0.25 \mathrm{Ni}, 0.12 \mathrm{C}\end{array}$ \\
\hline Inconel 625 & $\begin{array}{l}\text { Ni-base superalloy; } 58 \mathrm{Ni}, 22 \mathrm{Cr}, 9 \mathrm{Mo}, 4 \mathrm{Fe}, 3.5 \mathrm{Nb} \text {, } \\
3.5 \text { other }\end{array}$ \\
\hline Inconel 718 & $\begin{array}{l}\text { Ni-base superalloy; } 54 \mathrm{Ni}, 19 \mathrm{Cr}, 18.3 \mathrm{Fe}, 5 \mathrm{Nb}, 3 \mathrm{Mo} \text {, } \\
\text { 1.0Ti, 0.43Al, balance other }\end{array}$ \\
\hline $\begin{array}{l}\text { 17-4 PH } \\
\text { Stainless St. }\end{array}$ & $\begin{array}{l}\text { Precipitation hardened; } 17.5 \mathrm{Cr}, 4 \mathrm{Cu}, 4 \mathrm{Ni}, 1 \mathrm{Mn} \text {, } \\
0.5 \mathrm{Nb} \text {, balance } \mathrm{Fe}\end{array}$ \\
\hline Rene 142 & $\begin{array}{l}\text { Ni-base superalloy; } 12.0 \mathrm{Co}, 6.8 \mathrm{Cr}, 1.5 \mathrm{Mo}, 4.9 \mathrm{~W} \text {, } \\
\text { 2.8Re, } 6.2 \mathrm{Al}, 6.4 \mathrm{Ta}, 1.5 \mathrm{Hf}, 0.12 \mathrm{C}, 0.015 \mathrm{~B}, \\
0.02 \mathrm{Zr} \text { balance } \mathrm{Ni}\end{array}$ \\
\hline $\begin{array}{l}304 \text { Stainless } \\
\text { Steel }\end{array}$ & $\begin{array}{l}0.08 \mathrm{C}, 0.75 \mathrm{Si}, 2 \mathrm{Mn}, 0.05 \mathrm{P}, 0.3 \mathrm{~S}, 18-20 \mathrm{Cr}, 8-10 \mathrm{Ni} \text {, } \\
0.1 \mathrm{~N} \text {, balance } \mathrm{Fe}\end{array}$ \\
\hline $\begin{array}{l}\text { 316L Stainless } \\
\text { Steel }\end{array}$ & $\begin{array}{l}0.03 \mathrm{C}, 0.75 \mathrm{Si}, 2 \mathrm{Mn}, 0.05 \mathrm{P}, 0.03 \mathrm{~S}, 16-18 \mathrm{Cr} \\
10-14 \mathrm{Ni}, 2-3 \mathrm{Mo}, 0.1 \mathrm{~N} \text {, balance } \mathrm{Fe}\end{array}$ \\
\hline $\begin{array}{l}\text { Ti-6Al-4V/ } \\
\text { Ti64 }\end{array}$ & 90Ti, 6Al, $4 \mathrm{~V}$, nominal \\
\hline Ti2448 & $62.1 \mathrm{Ti}, 24 \mathrm{Nb}, 4 \mathrm{Zr}, 7.9 \mathrm{Sn}$ \\
\hline
\end{tabular}

\section{References}

1. D.D. Gu, W. Meiners, K. Wissenbach, R. Poprawe, Laser additive manufacturing of metallic components: materials, processes and mechanisms. Int. Mater. Rev. 57(3), 133-164 (2012)

2. S. Mellor, L. Hao, D. Zhang, Additive manufacturing: a framework for implementation. Int. J. Prod. Econ. 149, 194-201 (2014)

3. Y. Zhai, D.A. Lados, J.I. Lagoy, Additive manufacturing: making imagination the major limitation. JOM 6, 808-816 (2014)

4. W.E. Frazier, Metal additive manufacturing: a review. J. Mater. Eng. Perform. 23, 1917-1928 (2014)

5. D. Ding, Z. Pan, D. Caluri, H. Li, Wire-feed additive manufacturing of metal components: technologies, developments and future interests. Adv. Manuf. Technol. 81(1), 465-481 (2015)

6. C. Klahn, B. Leutenecker, M. Mebold, Design strategies for the process of additive manufacturing. Procedia CIRP 36, 230-235 (2015)

7. E.O. Olakanmi, R.F. Cochrane, K.W. Dalgarno, A review on selective laser sintering/melting (SLS/SLM) of aluminum alloy powders: processing, microstructure and properties. Prog. Mater Sci. 74, 401-477 (2015)

8. S. Das, D.C. Dowrell, S.S. Babu, Metallic materials for 3D printing. MRS Bull. 41(10), 729-741 (2016) 
9. D.C. Bourell, Perspectives on additive manufacturing. Ann. Rev. Mater. Res. 46, 1-18 (2016)

10. L.E. Murr, S.J. Li, Electron beam manufacturing of high-temperature metals. MRS Bull. 41, 752-757 (2016)

11. L.E. Murr, Frontiers of 3D printing/additive manufacturing: from human organs to aircraft fabrication. J. Mater. Sci. Technol. 32, 987-995 (2016)

12. S. Ford, M. Despeisse, Additive manufacturing and sustainability: an exploratory study of the advantages and challenges. J. Clean. Prod. 137, 1573-1587 (2016)

13. D. Herzog, V. Seyda, E. Wycisk, C. Emmelmann, Additive manufacturing of metals. Acta Mater. 117, 371-392 (2016)

14. W.J. Sames, F.A. List, S. Pannela, R.R. Dehoff, S.S. Babu, The metallurgy and processing science of metal additive manufacturing. Int. Mater. Rev. 61(5), 315-360 (2016)

15. A. Thomson, D. McNally, I. Maskery, R.M. Leach, X-ray computed tomography and additive manufacturing in medicine: a review. Int. J. Metrol. Qual. Eng. 8, 17-42 (2017)

16. A.B. Badiru, V.V. Valencia, D. Liu (eds.), Additive manufacturing handbook: product development for the defense industry (CRC Press/Taylor \& Francis Group, Boca Raton, 2017)

17. N.T. Abonlkhair, N.M. Everitt, I. Maskery, I. Ashcroft, Selective laser melting of aluminum alloys. MRS Bull. 42(4), 311-319 (2017)

18. C. Wen (ed.), Metallic Foam Bone (Woodhead Publishing/Elsevier, Duxford, 2017)

19. L.E. Murr, W.L. Johnson, 3D metal droplet printing development and advanced materials additive manufacturing. J. Mater. Res. Technol. 6(1), 77-89 (2017)

20. T. Wohlers, T. Caffrey, Additive MANUFACTURING: THE state of the industry. Adv. Manuf. Org (Soc. Manuf. Eng. Magazine), May, 45-52 (2016)

21. L.E. Murr, Metallurgy of additive manufacturing: examples from electron beam melting. Add. Manuf. 5, 40-53 (2015)

22. L E. Murr, Handbook of Materials Structures, Properties, Processing and Performance Vols. 1 \& 2, Springer, Heidelberg (2015)

23. L.E. Murr, E. Martinez, S.M. Gaytan, D.A. Ramirez, Contributions of light microscopy to contemporary materials characterization: The new directional solidification. Metallog. Microstruct. Anal. 1, 45-55 (2012)

24. M. Orme, E. P. Muntz, Method and apparatus for droplet steam manufacturing. U.S. Patent Publication No. US5226948A; publication date: July 13, (1990)

25. W. A. Harkness, J. H. Goldschmid, Free-form spatial 3D printing using part levitation. U.S. patent publication No. US2016/0031156Al, published Feb. 4, (2016)

26. W.L. Johnson, L.E. Murr, M. Halpin, P. Frantz, Additive manufacturing systems and methods. U.S. Provisional Patent Application No. 62308821, March 15, (2016)

27. G.F. Deyer, D. Deyer, Surface phenomena in fusion welding processes (CRC Press/Taylor \& Francis Group, London, 2005)

28. H. Shultz, Electron beam welding (Woodhead Publishing/The Welding Institute, Cambridge, 1993)

29. J.W. Hill, M.J. Lee, I.J. Spalding, Surface treatments by laser. Optical Laser Technol. 6(6), 276-278 (1974)

30. R. Vilar, Laser cladding. J. Laser Applic. 11, 64-80 (1999)

31. A.J. Herbert, Solid object generation. J. Appl. Photo. Eng. 8(4), 185-188 (1982)

32. S. Ashley, Rapid prototyping systems. Mech. Eng. 113(4), 34-43 (1991)

33. D.C. Bourell, J.J. Beaman, Chronology and current processes for freeform fabrication. J. Jpn. Soc. Powder Metal. 50(11), 981-991 (2003)

34. D.M. Keicher, J.E. Smugeresky, J.A. Romero, M.L. Griffith, L.D. Harwell, Using laser engineered net shaping (LENS) process to produce complex components from a CAD solid model. Proc. SPIE 2293, 91-97 (1997)

35. W. Hofmeister, M. Griffith, Solidification in direct metal deposition by LENS processing. JOM 53(9), 30-34 (2001)

36. P. Ding, Z. Pan, D. Caluri, H. Li, Wire-feed additive developments and future interests. Int. J. Adv. Manuf. Technol. 81(1), 465-480 (2015)

37. A. Basak, R. Acharya, S. Das, Additive manufacturing of singlecrystal Superalloy CMSX-4 through scanning laser epitaxy: computational, modeling experimental process development and process parameter optimization. Metall. Mater. Trans. A 47(8), 3845-3859 (2016)

38. A. Basak, S. Das, Epitaxy and microstructure evolution in metal additive manufacturing. Ann. Rev. Mater. Res. 46, 125-149 (2016)

39. S. Meteyer, X. Xu, N. Perry, Y.F. Zhao, Energy and material flow analysis of binder-jetting additive manufacturing processes. Proc. CIRP 15, 19-25 (2014)

40. T. Wohlers, T. Garnet, History of additive manufacturing. Wohlers Report (Wohlers Associates Co, Fort Collins, 2014)

41. H.E. Cline, T.R. Anthony, Heat treating and melting material with a scanning laser beam or electron beam. J. Appl. Phys. 49, 3895-3900 (1997)

42. R. Frigola, O.A. Harrysson, T.J. Horn, H.A. West, R.L. Aman, J.M. Rigsbee, D.A. Ramirez, L.E. Murr, F. Medina, R.B. Wicker, E. Rodriguez, Fabricating copper components with electron beam melting. Adv. Mater. Processes July, 20-24, (2014)

43. L.E. Murr, E. Martinez, J. Hernandez, S. Collins, K.N. Amato, S.M. Gaytan, P.W. Shindo, Microstructures and properties of $17-4 \mathrm{pH}$ stainless steel fabricated by selective laser melting. J. Mater. Res. Technol. 1(3), 167-177 (2012)

44. S.M. Gaytan, L.E. Murr, F. Medina, E. Martinez, M.I. Lopez, R.B. Wicker, Advanced metal powder based manufacturing of complex components by electron beam melting. Mater. Technol. 24(3), 180-190 (2009)

45. J.P. Kruth, G. Levy, F. Klocke, T.H.C. Childs, Consolidation phenomena in laser and powder bed based layered manufacturing. CIRP Ann. Manuf. Technol. 56, 730-759 (2007)

46. N. Read, W. Wang, K. Essa, M.M. Attallah, Selective laser melting of AlSi10 $\mathrm{Mg}$ alloy: process optimization and mechanical properties development. Mater. Dev. 65, 417-424 (2015)

47. T.D. Bennett, D.J. Krajnovich, C.P. Grigorspoulos, P. Baumgart, A.C. Tam, Marangori Mechanism in pulsed laser texturing of magnetic hand discs. J. Heat Transfer 119(3), 589-596 (1997)

48. Y. Han, W. Lu, T. Jarvis, J. Shurrinton, X. Wu, Investigation on other microstructure of direct laser additive manufacturing of Ti-6Al-4V alloy. Mater. Res. 18(1), 8 pp (2015)

49. I. Yadroitsev, P. Bertrand, I. Smurov, Parametric analysis of the selective laser melting process. Appl. Surface Sci. 253(19), 8064-8069 (2007)

50. C.L. Qiu, G.A. Ravi, C. Danu, A. Ranson, S. Dilworth, M.M. Attallah, Fabrication of large Ti-6Al-4V structures by direct laser deposition. J. Alloys Compounds 629, 351-361 (2015)

51. M. Yan, P. Yu, An overview of densification, microstructure and mechanical property of additive manufactured $\mathrm{Ti}-6 \mathrm{Al}-4 \mathrm{~V}$ comparison among selective laser melting, electron beam melting and laser metal deposition and selective laser sintering with conventional powder. Chap. 5, in Sintering Techniques of Materials, ed. by A. Lakshmanan (Rijeka, Croatia, Intech, 2015), pp. 77-106

52. F. Medina, L.E. Murr, R.W. Wicker, S.M. Gaytan, Reticulated mesh arrays and dissimilar array monoliths by additive layered manufacturing using electron and laser beam melting, U.S. 
Patent filed May 10, 2010 (publication U.S. 2010/0291401A1; Nov. 18, 2010. Patent No. US 8,828,311B2, Sept. 9, (2014)

53. D. A. Bales, A. Klucha, G.M. Dolansky, Uber-cooled turbine section component made by additive manufacturing. U.S. Patent Application No. US 20140169981A1, June 14, (2014)

54. G. Das, L. Cerratescu, D.M. Shah, Method for preparation of a Superalloy having a crystallographic texture controlled microstructure by electron beam melting. U.S. Patent Publication No. EP3015706A2-Sept. 14, 2016; filing date Oct. 28, (2014)

55. A. Hinojos, J. Mireles, A. Reichardt, P. Frigola, P. Hosemann, L.E. Murr, R.W. Wicker, Joining Inconel 718 and 316 stainless steel using electron beam melting additive manufacturing technology. Mater. Des. 94, 17-27 (2016)

56. L.E. Murr, E. Martinez, S.M. Gaytan, D.A. Ramirez, B.I. Machado, P.W. Shindo, J.L. Martinez, F. Medina, J. Wooten, D. Ciscel, U. Ackelid, R.B. Wicker, Microstructural architecture, microstructures, and mechanical properties of a nickel-base Superalloy fabricated by electron beam melting. Metall. Mater. Trans. A 42A, 3491-3508 (2011)

57. A. Uriando, M. Esperm-Miguez, S. Perinpanayagam, The present and future of additive manufacturing in the aerospace sector: a review of important aspects. Proc. Inst. Mech. Eng. G J. Aerosp. Eng. 229(11), 2132-2147 (2015)

58. M. Seifi, M. Gorelik, J. Waller, N. Hrabe, N. Shamsaci, S. Dariewicz, J.J. Lewandowski, Progress towards metal additive manufacturing standardization to support qualification and certification. JOM 69(3), 439-455 (2017)

59. L.E. Murr, Interfacial Phenomena in Metals and Alloys (Addison-Wesley, Reading, 1975)

60. M. Orme, E.P. Muntz, A new technique for producing highly uniform droplet stream over an extended range of disturbance wave number. Rev. Sci. Instrum. 58, 279-284 (1978)

61. M. Orme, On the genesis of droplet stream microspeed dispersions. Phys. Fluids 312, 2936-2947 (1991)

62. M. Orme, C. Huang, J. Courter, Precision droplet based manufacturing and material synthesis: fluid dynamics and thermal control issues. ILASS J. Atom. Sprays 6, 305-329 (1996)

63. M. Orme, Q. Liu, R. Smith, Molten aluminum micro-droplet formation and deposition for advanced manufacturing applications. Alum. Trans. 3(1), 95-103 (2000)

64. A.A. Tseng, M.H. Lee, B. Zhao, Design and generation of a droplet deposition system for freeform fabrication of metal parts. Trans. ASME 132, 74-84 (2001)

65. S.X. Cheng, T. Li, S. Chandra, Producing molten metal droplets with a pneumatic droplet-on-demand generator. J. Mater. Process. Technol. 159(3), 295-302 (2005)

66. X.-S. Jiang, L.-H. Qi, J. Luo, H. Huang, J.-M. Zhou, Research on accurate droplet generation for microdroplet deposition manufacture. Int. J. Adv. Manuf. Technol. 49(5), 535-541 (2010)

67. Y-P. Chao, 3D printing and manufacture micro-channel structure by metal micro-droplet-on-demand deposition. Adv. Mater. Rev. 940, 311-315 (2014)

68. J.B. Lee, D. Derome, A. Dolatabadi, J. Carmeliet, Energy budget of liquid drop impact at maximum spreading: Numerical simulations and experiments. Langmuir 32(5), 1279-1288 (2016)

69. B. Ballinger, R. S. Abbari, Excitation and dynamics of liquid tin micrometer droplet generation. Phys. Fluids 28, 074105 (1-20) (2016)

70. T. Wang, T.-H. Kusok, C. Zhou, In-situ droplet inspection and control system for liquid metal jet 3D printing process. Procedia Manuf. 10, 968-991 (2017)

71. D.A. Ramirez, L.E. Murr, E. Martinez, D.H. Hernandez, J.L. Martinez, B.I. Machado, F. Medina, R.B. Wicker, P. Frigola,
Novel precipitate microstructural architecture developed in the fabrication of solid copper components by additive manufacturing using electron beam melting. Acta Mater. 59, 4088-4099 (2011)

72. H.E. Collins, Superalloys (ASM International, Metals Park, 1968)

73. S.D. Antolovich, R.W. Stasrad, R.A. Mackay, D.L. Anton, T. Khan, R.D. Kissinger, D.L. Klanstrom (eds.), Superalloys 1992 (The Minerals, Metals and Materials Society (TMS), Warrendale, 1992)

74. R.C. Reed, The superalloys: fundamentals and applications (Cambridge Univ. Press, Cambridge, 2008)

75. D. F. Poulonis, J. M. Oblak, D. S. Duvall, D.S. Precipitation in nickel base alloy 718. ASM Trans. Quart. 62, C11-C22 (1969)

76. B.H. Kear, J.M. Oblak, Deformation modes in $\gamma^{\prime}$ precipitation hardened nickel-base alloys. J. de Physique 12(35), C1-C35 (1974)

77. M. Durand-Charre, The microstructure of superalloys (Gordon \& Breach, Amsterdam, 1977)

78. G.R. Leverant, B.H. Kear, J.M. Oblak, Creep of precipitationhardened, nickel-base alloy single crystals at high temperature. Metall. Mater. Trans. B B4(1), 355-362 (1973)

79. S.M. Gaytan, L.E. Murr, E. Martinez, J.L. Martinez, B.I. Machado, D.A. Ramirez, Comparison of microstructures and mechanical properties of solid and mesh cobalt-base alloy prototypes fabricated by electron beam melting. Metall. Mater. Trans. A 41A, 3216-3227 (2010)

80. L.E. Murr, S.M. Gaytan, in Electron beam melting. ed. by S. Masoad. Comprehensive materials processing, vol. 10 (Elsevier Ltd., London, 2010), pp. 135-161

81. A. Niang, J. Huez, J. Lacase, B. Viguier, Cauterizing precipitation defects in nickel base 718 alloy. Mater. Sci. Forum 636-637, 517-522 (2010)

82. K.N. Amato, S.M. Gaytan, L.E. Murr, E. Martinez, P.W. Shindo, J. Hernandez, Microstructures and mechanical behavior for Inconel 718 fabricated by selective laser melting. Acta Mater. 60, 2229-2239 (2012)

83. A. Strondl, R. Fischer, G. Frommeyer, A. Schneider, Investigations of MX and $\gamma / \gamma^{\prime}$ precipitates in the nickel-based Superalloy 718 produced by electron beam melting. Mater. Sci. Eng. A 480A, 138-147 (2008)

84. T. Murakumo, T. Kobayashi, Y. Koizumi, H. Harada, Creep behavior of Ni-base single-crystal superalloys with various gamma prime volume fraction. Acta Mater. 52(12), 3737-3744 (2004)

85. T.M. Pollock, S.J. Tin, Nickel-based Superalloys for advanced turbine engines: chemistry, microstructure and properties. J. Propulsion Power 22(2), 361-374 (2006)

86. P. Caron, O.J. Lavigne, Recent studies at Oneva on Superalloys for single crystal turbine blades. J. Aeorspace Lab 3, 1-14 (2001)

87. L.E. Murr, E. Martinez, X.M. Pan, S.M. Gaytan, J.A. Castro, C.A. Terrazas, F. Medina, R.B. Wicker, D.H. Abbott, Microstructures of Rene 142 nickel-based Superalloy fabricated by electron beam melting. Acta Mater. 61(11), 4289-4296 (2013)

88. R. Gevers, P. Delavignette, H. Blank, J. Van Landuyt, S. Amelinckx, Electron microscopy transmission images of coherent domain boundaries I. Dyn. Theory. Phys. Stat. Sol. B 4, 383-410 (1964)

89. R. Gevers, P. Delavignette, H. Blank, J. Van Landuyt, S. Amelinckx. Electron microscope transmission images of coherent domain boundaries II. Observations. Phys. Stat. Solid 5(3), 595-633 (1964)

90. L.E. Murr, E. Martinez, X.M. Pan, C.M. Wang, J. Yang, S.J. Li, F. Yang, Q. Xu, J. Hernandez, W. Zhu, S.M. Gaytan, F. Medina, 
R.B. Wicker, Properties of solid and reticulated mesh components of pure iron fabricated by electron beam melting. J. Mater. Res. Technol. 2(4), 76-88 (2013)

91. E. Martinez, L.E. Murr, J. Hernandez, X.M. Pan, K.N. Amato, P. Frigola, C. Terrazas, S.M. Gaytan, E. Rodriguez, F. Medina, R.B. Wicker, Microstructures of niobium components fabricated by electron beam melting. Metallog. Microstruct. Anal. 3(2), 183-189 (2013)

92. S. Natividad, A. Acosta, K.N. Amato, J. Ventura, B. Portillo, S.K. Varma, Heat treatment and oxidation characteristics of Nb20Mo-15Si-5B-20 (Cr, Ti) alloys from 700 to $1400 \mathrm{C}$. Mater. Sci. Forum 638-642(638-642), 2351-2356 (2010)

93. B. Portillo, S.K. Varma, Oxidation behavior of Nb-20Mo-15Si$25 \mathrm{Cr}$ and $\mathrm{Nb}-20 \mathrm{Mo}-15 \mathrm{Si}-25 \mathrm{Cr}-5 \mathrm{~B}$ alloys. Metall. Mater. Trans. A 43A, 147-154 (2012)

94. H. Conrad, S. Feuerstein, L. Rice, Effects of grain size on the dislocation density and flow stress of niobium. Mater. Sci. Eng. 2, 157-168 (1967)

95. E. Louvis, P. Fox, C.J. Sutcliffe, Selective laser melting of aluminum components. J. Mater. Process. Technol. 211, 275-284 (2011)

96. T. Mahale, D. Cormier, O. Harrysson, K. Ervin, Advances in electron beam melting of aluminum alloys. Proc. Solid Freeform Fabrication (SFF) Symp. pp. 312-324 (2007) Univ Texas, Austin, TX

97. F. Tresisan, F. Calignano M. Lorusso, J. Pakkanen, A. Arersa, E. P. Ambrosia, M. Lombardi, P. Fino, D. Manpreb, On the selective laser melting (SLM) of the Al-Si-Mg alloy: process, microstructure and mechanical properties. Materials 10(1), 76-90 (2017)

98. L. Brice, R. Shenry, M. Kral, K. Buchannan, Precipitation behavior of aluminum alloy 2139 fabricated by additive manufacturing. Mater. Sci. Eng. A 648A, 9-14 (2015)

99. N.T. Abrulkhair, N.M. Everitt, I. Maskery, I. Ashcroft, Selective laser melting of aluminum alloys. MRS Bull. 42(4), 311-319 (2017)

100. A. Kelly, R.B. Nicholson, in Precipitation Hardening, ed by B. Chalmers, Progress in Materials Science, vol. 10, No. 3, (Pergamon Press, New York, 1963)

101. L.E. Murr, G. Liu, J.C. McClure, A TEM study of precipitation and related microstructures in friction-stir welded 6061 aluminum. J. Mater. Sci. 33, 1243-1251 (1998)

102. M. H. Jacobs, The nucleation and growth of precipitates in aluminum alloys. Ph.D. Thesis (Physics Dept., Univ. of Warwick, 1969)

103. S.C. Wang, M.J. Starink, Precipitates and intermetallic phases in precipitation hardening $\mathrm{Al}-\mathrm{Cu}-\mathrm{Mg}(\mathrm{Li})$ based alloys. Int. Mater. Rev. 51, 193-215 (2015)

104. L.B. Ber, N. Kolobnev, E.-N. Kablov, Heat Treatment of Aluminum Alloy (CRC Press/Taylor \& Francis, Boca Raton, 2015)

105. K.A. Bakke, The surface evolver. Exp. Mech. 1, 141-165 (1992)

106. L.E. Murr, K.N. Amato, S.J. Li, Y.-X. Tian, X.-Y. Cheng, S.M. Gaytan, E. Martinez, P.W. Shindo, F. Medina, R.B. Wicker, Microstructure and mechanical properties of open-cellular biomaterials prototypes for total knee replacement implants fabricated by electron beam melting. J. Mech. Behav. Biomed. Mater. 4(7), 396-1411 (2011)

107. L.E. Murr, Open cellular metal implant design and fabrication for biomechanical compatibility with bone using electron beam melting. J. Mech. Behav. Biomed. Mater. 76, 164-177 (2017)

108. P. Heinl, L. Muller, C. Korner, R.F. Singer, F.A. Muller, Cellular Ti-6Al-4V structures with interconnected macros porosity for bone implants fabricated by selective electron beam melting. Acta Biomater. 4, 1536-1544 (2008)

109. V. Karageorgio, D. Kaplan, Porosity of 3D biomaterial scaffolds and osteogenesis. Biomaterials 26, 5474-5491 (2005)
110. K.C. Nune, R.D.K. Misra, S.M. Gaytan, L.E. Murr, Biological response of next generation of $3 \mathrm{D}$ Ti- $6 \mathrm{Al}-4 \mathrm{~V}$ biomedical devices using additive manufacturing of cellular and functional mesh structures. J. Biomater. Tissue Eng. 4(10), 755-771 (2014)

111. A. Kumar, K.C. Nune, L.E. Murr, R.D.K. Misra, Biocompatibility and mechanical behavior of three-dimensional scaffolds for biomedical devices: process-structure-property paradigm. Int. Mater. Rev. 61(1), 20-45 (2016)

112. L.J. Gibson, M.F. Ashby, The mechanics of three-dimensional cellular materials. Proc. Roy. Soc. Lond. Math. Phys. Sci. 383, 43-49 (1982)

113. M. Niinomi, Mechanical properties of biomedical titanium alloys. Mater. Sci. Eng. A A243, 231-236 (1998)

114. Y.C. Hao, S.J. Li, S.Y. Sun, C.Y. Zheng, R. Yang, Elastic deformation behavior of Ti-24Nb-4Zr-7-9Sn for biomedical applications. Acta Biomater. 3, 277-286 (2007)

115. J. Hernandez, S.J. Li, E. Martinez, L.E. Murr, X.M. Pan, K.N. Amato, X.Y. Cheng, F. Yang, C.A. Terrazas, Y.C. Hao, R. Yang, F. Medina, R.B. Wicker, Microstructures and hardness properties for \& $\beta$-phase Ti-24Nb-4Zr-7.9Sn alloy fabricated by electron beam melting. J. Mater. Sci. Technol. 29(11), 1011-1017 (2013)

116. L.J. Gibson, M.F. Ashby, Cellular Solids: Structure and Properties, 2nd edn. (Cambridge Univ. Press, Cambridge, 1997)

117. S.J. Li, L.E. Murr, X.Y. Cheng, Z.B. Zhang, Y.L. Hao, R. Yang, F. Medina, Compression fatigue behavior of Ti-6Al-4V mesh arrays fabricated by electron beam melting. Acta Mater. 60, 793-802 (2012)

118. S.J. Li, Q.S. Xu, Z. Wang, W.T. Hou, Y.L. Hao, R. Yang, L.E. Murr, Influence of cell shape on mechanical properties of Ti$6 \mathrm{Al}-4 \mathrm{~V}$ meshes fabricated by electron beam melting. Acta Biomater. 10, 4537-4547 (2014)

119. P.F. Gomez, J.A. Morcuende, Early attempts at hip arthroplasty: 1700s to 1950s. Iowa Orthoped. J. 25, 25-29 (2005)

120. S.R. Knight, R. Aujla, S.P. Biswas, Total hip arthroplasty-over 100 years of operative history. Orthoped. Rev. 3(2), 1-16 (2011)

121. M.H. Kremer, D.R. Larson, C.S. Crawson, W.K. Krema, R.E. Washington, C.A. Skiner, C Prevalence of total hip and knee replacement in the United States. J. Bone Jt. Surg. Amer. 97(17), 1386-1397 (2015)

122. H. Cai, Application of 3D pointing in orthopedics: Status quo and opportunities in China. Ann. Transl. Med. 3(Suppl 1), S12S15 (2015)

123. S. J. Li, X. K. Hou, K. C. Nune, R. D. K. Misra, V. L. CorreaRodriguez, Z. Guo, Y. L. Hao, R. Yang, L. E., Fabrication of open-cellular (porous) titanium alloy implants: osseointegration, vascularization and preliminary human trials. Sci. China Mater. Published online 4 August (2017)

124. L.E. Murr, Additive Manufacturing of Biomedical Devices: An Overview (Mater, Technol, 2018)

125. D.C. Ackland, D. Robinson, M. Redhead, P. VeeSinLi, A. Moskaljuk, G. Dimitroulis, A personalized 3D printed prosthetic joint replacement for the human temporomandibular joint: From implant design to implantation. J. Mech. Behav. Biomed. Mater. 69, 404-411 (2017)

126. V. Weissmann, P. Drescher, R. Bader, H. Seitz, H. Hansmann, N. Laufer, Comparison of single Ti-6Al-4V struts made using selective laser melting and electron beam melting subject to part orientation. Metals 7, 91-98 (2017)

127. D.A. Ramirez, L.E. Murr, S.J. Li, E. Tian, E. Martinez, B.I. Machado, S.M. Gaytan, F. Medina, R.B. Wicker, Open-cellular copper structures fabricated by additive manufacturing using electron beam melting. Mater. Sci. Eng. A 528A, 5379-5386 (2011) 
128. L.E. Murr, S.J. Li, Y. Jian, K.N. Amato, E. Martinez, F. Medina, Open-cellular Co-base and Ni-base Superalloys fabricated by electron beam melting. Materials 4, 782-790 (2011)

129. X. Zhao, S.J. Li, M. Zhang, Y. Liu, T.B. Sercombe, S. Wang, Y.L. Hao, R. Yang, L.E. Murr, Comparison of the microstructures and mechanical properties of $\mathrm{Ti}-6 \mathrm{Al}-4 \mathrm{~V}$ fabricated by selective laser melting and electron beam melting. Mater. Des. 95, 21-31 (2016)

130. L.E. Murr, S.A. Quinones, S.M. Gaytan, M.I. Lopez, A. Rodela, E.Y. Martinez, D.H. Hernandez, E. Martinez, F. Medina, R.B. Wicker, Microstructure and mechanical behavior of Ti-6Al-4V produced by rapid-layer manufacturing, for biomedical applications. J. Mech. Behav. Biomed. Mater. 2, 20-32 (2010)

131. K.N. Amato, J. Hernandez, L.E. Murr, E. Martinez, S.M. Gaytan, P.W. Shindo, Comparison of microstructures and properties for a Ni-base Superalloy (Alloy 625) fabricated by electron and laser beam melting. J. Mater. Res. 1(2), 3-15 (2012)
132. T. Trosch, J. Strossner, R. Volkl, U. Glatzel, Microstructure and mechanical properties of selective laser melted Inconel 718 compared to forging and casting. Mater. Lett. 164, 428-431 (2016)

133. S.L. Sing, J. An, W.Y. Yeong, F.E. Wirier, Laser and electronbeam powder-bed additive manufacturing of metallic implants: a review on processes, materials and designs. J. Othoped. Res. 34(3), 369-385 (2016)

134. D. Hardwick, W.M. Williams, The birth of metallography-The work of Henry Clifton Sorby (1826-1908). Bull. Canad. Inst. Min. Metall. 73(813), 143-144 (1980)

135. C.S. Smith, A history of metallography: the development of ideas on the structure of metals before 1890 (University of Chicago Press, Chicago, 1960)

136. C.S. Smith, Metallography-How it started and where it's going. Metallography 8, 91-103 (1975) 